\title{
Nocardia Species: Host-Parasite Relationships
}

\author{
BLAINE L. BEAMAN* AND LOVELLE BEAMAN \\ Department of Medical Microbiology and Immunology, University of California \\ School of Medicine, Davis, California 95616
}

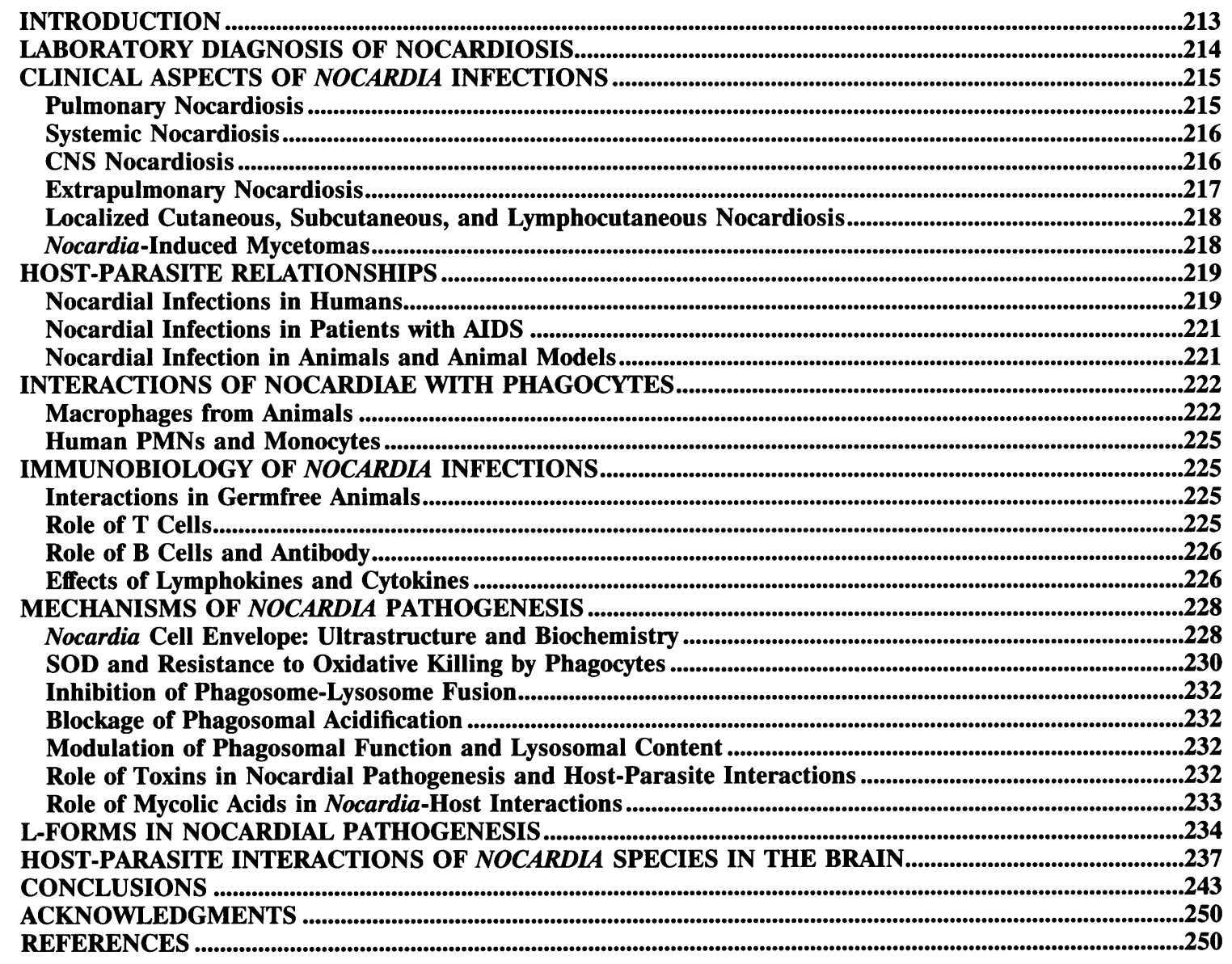

\section{INTRODUCTION}

In 1888, on Guadeloupe Island, Edmond Nocard isolated an aerobic filamentous organism from lesions in cattle suffering from farcy (490). In 1889, Trevisan created the genus Nocardia to accommodate Nocard's isolate and named it Nocardia farcinica (420, 673). One year later, in 1890, Eppinger isolated a similar aerobic, branching filamentous organism from a human with a fatal brain abscess and called this organism Cladothrix asteroides (230); however, in 1896 it was renamed Nocardia asteroides (119). Because of confusion regarding the identity of Nocard's original isolate combined with evidence that Mycobacterium causes bovine farcy, the identification of $N$. farcinica was placed in doubt (278). As a result, $N$. farcinica was officially removed as the type species and $N$. asteroides was designated as the new type species for the genus Nocardia

* Corresponding author. Mailing address: Department of Medical Microbiology and Immunology, 3146 Building MS-1A, School of Medicine, University of California, Davis, CA 95616. Phone: (916) 752-9663. Fax: (916) 752-8692.
(278). From the very beginning, there has been uncertainty over the taxonomic position of nocardioforms, i.e., bacteria that resemble Nocardia organisms. The specific taxonomy of isolates of this heterogenous group of organisms is still in flux and controversial $(275,278,403,404,420,584,676,699)$.

During the ensuing 100 years, it has been shown that $N$. asteroides is a heterogeneous taxon $(275,403,404,420)$. It is not within the scope of this review to address this complex subject, yet it is important to note that $N$. asteroides, as currently defined, probably consists of several subtypes and/or species. These include $N$. asteroides sensu stricto, $N$. farcinica, $N$. nova , and several distinct serotypes and biotypes (278, 403, $404,698,699,727)$. Regardless of their designation, all of these varieties of the $N$. asteroides taxon have been isolated from humans and animals with serious (often fatal) infections (93, $584,698,699)$. The other pathogenic Nocardia species appear to be taxonomically more homogeneous and include $N$. brasiliensis, N. otitidiscaviarum ( $N$. caviae), and N. transvalensis (275, 420). There is even one Nocardia species that infects plants: $N$. vaccinii, which causes galls on blueberry plants (420). 


\section{LABORATORY DIAGNOSIS OF NOCARDIOSIS}

Several investigators point out that the nocardiae are difficult to recognize and identify in the diagnostic laboratory (74, $104,185,486,583)$. There is sometimes a delay in growth of identifiable colonies on culture media following primary isolation from clinical samples. Furthermore, their relatively slow growth often results in the cultures being discarded before the nocardiae can be visualized. Additional complications in recognition result from the variable colony morphology of nocardiae on different types of media and with different clinical isolates $(74,104,185,403,486,583)$.

Once the nocardiae become apparent, they must be differentiated from a variety of other gram-positive bacteria which they can resemble. These include other actinomycetes such as Streptomyces spp., Actinomyces spp., Actinomadura spp., Rhodococcus spp., Gordona spp., and Tsukamurella spp., as well as Mycobacterium spp. and Corynebacterium spp. (275, $420)$. Historically, the nocardiae were recognized and differentiated on the basis of cellular morphology, combined with a small number of physiologic tests $(185,278,420)$. Although this approach is still useful in the diagnostic laboratory, it is inadequate.

The genus Nocardia consists of gram-positive, variably acidfast, strictly aerobic bacteria that form filamentous, branched cells which fragment into pleomorphic, rod-shaped, or coccoid elements $(275,420)$. The extent of the filamentation, lateral branching, and uniformity of the fragmentation process is variable and often depends on the conditions of culture (275, 420). Microscopic examination of colonies of nocardiae grown on solid media reveals that filamentous cells protrude into the air away from the surface (aerial hyphae). The extent of aerial filamentation and fragmentation may vary from sparse to abundant $(275,420)$. Colonies with abundant aerial growth have a "cotton ball" appearance that may resemble many Streptomyces spp. or, superficially, even some fungi $(275,420)$. Most Nocardia spp. produce carotenoid-like pigments that result in colonies with various shades of yellow, orange, pink, or red. Some strains produce a melanin-like, water-soluble pigment that turns the medium brown. The intensity of all of these pigments depends on the specific culture conditions used to grow the nocardiae $(53,275,420)$.

The nocardiae are catalase-positive chemoorganotrophs with an oxidative-type metabolism (275). The chemical composition of the cell envelope is most useful in differentiating genera that may resemble the nocardiae $(151,275,420)$. The cell wall is chemotype IV (420) containing meso-diaminopimelic acid (meso-DAP), arabinose, galactose, and $N$-glycolylmuramic acid. Mycolic acids are linked to the peptidoglycan by way of an arabinogalactan polymer. The mycolic acids have a carbon chain length that varies from $\mathrm{C}_{44}$ to $\mathrm{C}_{64}$ with zero to four double bonds $(76,87,151,275,334,728)$. The characteristic fatty acids released from the mycolic acids by pyrolysis-gas chromatography vary in size from $C_{12}$ to $C_{18}$. These fatty acids may either be saturated or contain one double bond $(76,87$, $151,275,334,728)$. Another characteristic fatty acid which is recognized in the cell envelope is 10 -methylstearic acid (tuberculostearic acid) $(275,420)$. The major menaquinone in nocardiae is tetrahydrogenated with eight isoprene units. The guanine-plus-cytosine composition of the DNA varies from 64 to $72 \mathrm{~mol} \%(275,420)$.

An additional criterion that may permit rapid differentiation of Nocardia spp. from most other actinomycetes depends on resistance to lysozyme $(185,275,420)$. With the exception of $N$. amarae, all Nocardia spp. grow in a nutrient broth supple- mented with lysozyme, whereas most Rhodococcus, Actinomadura, and Streptomyces spp. do not $(185,275)$.

Originally, Gordon and colleagues $(275,278,420)$ differentiated the Nocardia species on the basis of relatively simple physiological tests that still have merit. With these tests, $N$. asteroides, $N$. brasiliensis, and $N$. otitidiscaviarum form clear species separation $(278,420)$. However, as noted above, many investigators point out that the $N$. asteroides taxon is heterogeneous, whereas $N$. brasiliensis and $N$. otitidiscaviarum form more homogeneous clusters $(275,403,404,420,698,699,727)$. Therefore, numerous attempts have been made to delineate homogeneous subgroupings within the $N$. asteroides complex in order to permit more precise identification of certain clinical isolates $(151,275,403,404,420,584,676,698,699,727)$. No single study or approach has been successful; however, by combining information obtained from different laboratories via a combination of methods (i.e., chemotaxonomy, antibiotogram analysis, numerical taxonomy, DNA homology studies, and serological studies), specific subgroupings of the $N$. asteroides complex have been proposed $(74,151,275,403,404,420$, $584,677,698,699,727)$. Two of these subgroups have received species recognition as $N$. farcinica $(275,420)$ and $N$. nova $(275$, $420)$. It is important to note that by the Gordon series of tests (involving 40 different physiological properties), $N$. asteroides sensu stricto cannot be differentiated from $N$. farcinica and $N$. nova (420). In general, the $N$. farcinica type strain, ATCC 3318, is differentiated from $N$. asteroides (type strain ATCC 19247) by the ability of $N$. farcinica to grow on and produce acid from rhamnose; to grow on 2,3-butylene glycol (1\%, vol/vol), 1,2propylene glycol $(1 \%$, vol/vol $)$, and at $45^{\circ} \mathrm{C}$; and to utilize acetamide as a carbon and nitrogen source, as well as by its resistance to the antibiotics tobramycin and cefamandole (275, $420,699)$. On the other hand, $N$. nova is differentiated from both $N$. asteroides and $N$. farcinica by having larger mycolic acids $\left(C_{52}\right.$ to $\left.C_{64}\right)$, 2-week arylsulfatase activity, $\alpha$ - and $\beta$ esterase activity, lack of acid phosphatase activity, the inability to use monoethanolamine as a carbon and nitrogen source, and resistance to the antibiotics cefamandole and erythromy$\operatorname{cin}(151,275,698,727)$.

Confirmed diagnosis of nocardiosis currently requires that the organism be isolated from the patient. Specific identification of the isolate is then made on the basis of the criteria described above. A single Nocardia colony isolated from a patient who presents with appropriate clinical signs should not be ignored as insignificant, because pathogenic Nocardia species are not seen frequently as either laboratory contaminants or part of the normal flora (53). However, the same organism must be repeatedly isolated from the patient before it can be concluded that the patient has nocardiosis. Nevertheless, a single colony of $N$. asteroides isolated from the cerebrospinal fluid (CSF) of a patient showing central nervous system (CNS) symptoms probably should be viewed as significant, whereas a single colony isolated from a sputum sample may not have the same significance (53).

During the past 100 years, numerous investigators have tried to develop reliable and useful serodiagnostic tests that permit accurate and rapid diagnosis of nocardial infections in humans and other animals $(123,275,403,404)$. It is beyond the scope of this review to either describe or discuss all of these studies. Currently, there is no single serodiagnostic test that is routinely used to identify patients with nocardial infections. The major problems with developing serodiagnostic methods stem from the fact that the host infected with nocardiae usually develops a minimal antibody response (i.e., samples have low antibody titers) that is nonspecific (i.e., most nocardial antigens that the host recognizes share numerous epitopes with a variety of 
antigens from other actinomycetes, as well as Mycobacterium spp., Rhodococcus spp., and Corynebacterium spp.). This problem is complicated further by the heterogeneity of the nocardiae $(123,275,403,404)$. Nevertheless, Sugar et al. (647) and Boiron and Stynen (123) found that a 55/54-kDa protein secreted into the culture medium during nocardial growth could be used as a specific and reliable diagnostic antigen in most cases of human nocardiosis. The presence of antibodies to this $55 / 54 \mathrm{kDa}$ antigen probably represents the best single marker for active infection by Nocardia spp. (123, 647). However, Kjelstrom and Beaman demonstrated that not all clinical isolates of Nocardia spp. induced an antibody response to the $55 / 54-\mathrm{kDa}$ antigen in experimental animals (384). Furthermore, Kjelstrom found that several humans with nocardiosis confirmed by culture did not have a demonstrable response against the $55 / 54-\mathrm{kDa}$ antigen in a Western immunoblot assay (383). However, most of these individuals had antibody to other secreted nocardial antigens (i.e., 90-, 62-, 36-, and $31-\mathrm{kDa}$ antigens) that appeared to have diagnostic value (383). Therefore, Kjelstrom concluded that no single diagnostic antigen was sufficient to recognize all nocardial infections (383). As a consequence, Kjelstrom and Beaman developed a panel of tests for recognition of nocardial infections based on reactivity to a variety of antigens by using enzyme-linked immunosorbent assay of cytoplasmic, culture filtrate, and cord factor antigens; immunofluorescence assay against whole cells of $N$. asteroides; and Western blot analysis of secreted protein antigens of $N$. asteroides GUH-2 (384). In a murine model, this approach could accurately differentiate nocardial infections from other actinomycete infections including those caused by Mycobacterium spp. (384). Furthermore, animals with subclinical infections with live organisms could be differentiated from those immunized with killed cells. When this diagnostic panel was applied to human sera, there was excellent sensitivity and specificity for culture-proven cases of clinical disease caused by nocardiae (383). To determine the incidence of infection by nocardiae, healthy volunteers were screened by using this diagnostic panel, and $25 \%$ of these healthy individuals (71 of 284) had a subclinical exposure to Nocardia spp. based on seropositivity as compared with patients with culture-proven infection (383). In addition, twice as many males as females were serologically positive for nocardial infection (383). This diagnostic panel used antigens prepared from $N$. asteroides GUH-2. Of all individuals tested, $10.4 \%$ (36 of 345) reacted to all nocardial antigens in the panel (383). These data suggest that at least one-third of all seropositive individuals (108 of 345 people tested were seropositive) evaluated in this study had either a clinical or subclinical infection with an organism closely related antigenically to $N$. asteroides GUH-2 (383).

\section{CLINICAL ASPECTS OF NOCARDIA INFECTIONS}

In humans, at least six basic forms of disease may be recognized following Nocardia infection: (i) pulmonary nocardiosis $(2,7,32,38,134,190,237,287,350,356,393)$; (ii) systemic nocardiosis (involving two or more body sites) $(15,22$, $36,51,165,166,202,220,319,330,357$ ); (iii) CNS nocardiosis (43, 44, 50, 52, 133, 138, 142, 153, 184, 194, 198, 219, 309, 310), (iv) extrapulmonary nocardiosis $(3,23,48,137,147,180,216$, 234, 259, 317); (v) cutaneous, subcutaneous, and lymphocutaneous (sporotrichoid) nocardiosis $(12,47,101,123,269,293$, $303,311,315,352,353)$; and (vi) actinomycetoma $(13,14,160$, $167,286,305,321,429,442,447,489)$. In animals, other forms of disease such as bovine mastitis occur, but these will not be discussed here $(93,150)$.

\section{Pulmonary Nocardiosis}

Nocardia cells are found within the environment in soil and water and on vegetable matter $(584,718)$. These organisms may become airborne, especially on dust particles. As a consequence, pulmonary infection probably results from either inhalation or aspiration of nocardiae into the lungs $(70,78$, $583,584)$. In addition, the nocardiae can be introduced into the tissues by trauma or into the bloodstream by accidental inoculation (690). Furthermore, there is evidence suggesting that pulmonary nocardiosis occasionally spreads from the oral cavity (666) or gastrointestinal tract $(70,146,147,182,236$, 313,573 ) following ingestion of contaminated foods.

The first case of primary pulmonary nocardiosis occurring in a patient in the United States was described in 1898 by Flexner (247). Since this first report, several hundred cases of primary pulmonary nocardiosis occurring in both healthy and immunocompromised individuals have been described in the literature. The pathologic feature of pulmonary nocardiosis is usually a suppurative response, but a granulomatous response or a mixture of these resulting in radiographic presentations that are pleomorphic and not specific may occur $(38,237,393,395$, $506,734)$. The manifestation within the lungs may vary from a mild, diffuse infiltration to a lobar or multilobar consolidation (Fig. 1A). There may be solitary masses, reticulonodular infiltrates, large irregular nodules (frequently with cavitation), interstitial infiltrates, and pleural effusions $(38,237,393,395$, $411,478,506,527,734)$. The lesions produced in the lungs may be necrotizing abscesses that usually are not encapsulated, or they may be sharply circumscribed $(273,393)$. Granulomas which have undergone central necrosis may occur; however, these granulomatous lesions usually contain a mixed cellular response with polymorphonuclear leukocytes (PMNs), macrophages, and lymphocytes and usually without the epithelioid cells that can be seen in lesions induced by Mycobacterium tuberculosis. Multinucleate giant cells are occasionally observed within nocardia-induced granulomas (186, 198, 247, 623 ). Indolent, progressive fibrosis may occur if the patient does not receive adequate therapy. There are reports of Nocardia spp. colonizing airway passages without inducing disease; however, on the basis of studies with animal models, these should probably be interpreted as representing subclinical infections rather than simple colonization $(37,59-61,64$, $67,69-71,74,82,89,122,203,253,254,388,566,734)$. It would be important to determine whether these individuals develop circulating antibodies consistent with nocardial infection.

As indicated above, there are no specific clinical signs diagnostic for pulmonary nocardiosis, and the clinical presentation of disease may run the full spectrum of either acute or chronic pulmonary infection. There may be pneumonia, abscess formation, or both. A granulomatous response similar to tuberculosis also has been recognized $(38,237,704)$, and calcified lesions reminiscent of Histoplasma infection are occasionally found. Thus, pulmonary infections caused by Nocardia spp. are often misdiagnosed as pyogenic infections, mycoplasmal infections, viral infections, tuberculosis, actinomycosis, mycoses of various etiologies, benign tumors, and/or various forms of cancer. In many of these instances, the correct diagnosis can be established only by both visualization of nocardiae within the tissue and isolation of the organism in pure culture from the affected areas, often at autopsy $(18,38$, $186,198,203,237,247,253,254,393,395,478,486,506,527$, $623,703,734)$. 

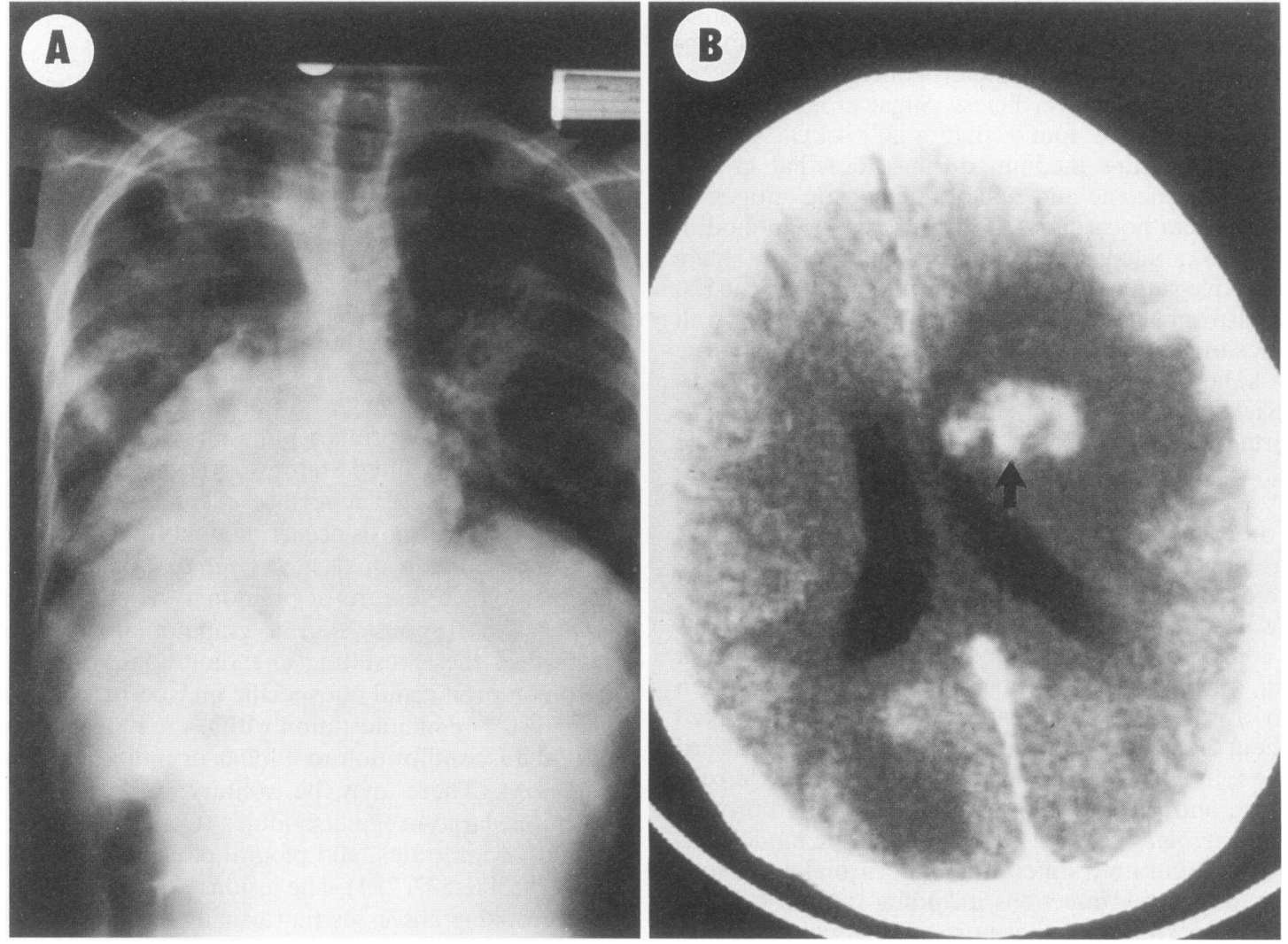

FIG. 1. Nocardial infections in humans. (A) Chest X-ray of a male patient with AIDS and progressive pulmonary nocardiosis. N. asteroides was isolated from the lungs. (B) Computed tomogram of the head of a male patient with Hodgkin's disease and systemic cerebral nocardiosis. $N$. brasiliensis was isolated from this patient. Photographs from both patients were kindly provided by Mark Abbruzzese, Georgetown University Hospital, Washington, D.C.

\section{Systemic Nocardiosis}

Nocardial lesions in the lungs or elsewhere in the body frequently erode into blood vessels. Once blood borne, the organisms can invade other anatomic locations. This process can also occur following traumatic inoculation from a contaminated source (e.g., a thorn [303, 311, 702], wood splinter [180], traumatic accident [352, 378], bullet wound [283, 463, 468], insect bite [156, 277], or animal bite [429]). Thus, when lesions are found at two or more locations within the body, the infection is defined as systemic or disseminated nocardiosis. Any anatomic location can be involved, but the most common sites that become infected during dissemination include the CNS, cutaneous and subcutaneous tissues, eyes (especially the retina), kidneys, joints, bone, and heart $(22,26,36,51,105$, $107,122,135,144,149,156,159,176,191,218,220,251,253$, $254,260,263,304,352,375,391,392,423,454,459,466,478$, $479,503,520,522,525,538,540,566,569,585,589,601,631$, 708, 719, 731, 734).

The hallmark of nocardial lesions is abscess formation, and PMNs represent the predominant infiltrating type of host cell during the early stages of infection. Thus, in systemic nocardiosis, the nocardiae behave as pyogenic bacteria $(1,36,51,528$, $583,585)$. However, as with pulmonary infections, the host cell response becomes mixed, with lymphocytes and macrophages becoming conspicuous as the infection advances into a more chronic phase. Pure granulomas, as seen with $M$. tuberculosis, can be found in infections with some Nocardia strains; however, this type of host response is not common $(186,198,247$,
$623,734)$. The abscesses enlarge by direct extension of the nocardial filaments through the tissue. Unlike pulmonary infections, disseminated or systemic nocardiosis tends to become relentlessly progressive, and self-limited or subclinical disease is not recognized frequently $(22,26,32,51,105,107$, $122,135,144,149,156,159,176,181,218,220,221,251,254$, $260,263,304,352,375,391,392,423,454,459,466,478,479$, $503,520,522,525,538,540,566,569,585,589,601,631,708$, $719,731,734)$.

\section{CNS Nocardiosis}

In an analysis of 1,050 cases selected randomly from the literature (Table 1), $238(22.67 \%)$ of these involved infections of the CNS (not all CNS infections reported in the literature were selected for this analysis). Furthermore, $44 \%$ of patients with systemic nocardiosis in this study had CNS infections, with the lungs representing the most common primary location (Table 1). In addition, $91(38.2 \%)$ of the infections described in the literature involved the CNS without evidence of infection elsewhere in the body; thus, they were regarded as primary infections of the CNS (Table 1). Of these CNS infections, $42 \%$ (100 of 238) occurred in previously healthy individuals with no identifiable predisposing factor $(1,4,5,8,19,22,26,31,32,34$, $36-40,43,44,50,51,102,106,109,112,121,132,133,135,138$, $144,152,153,159,165,166,178,179,181,192,196,198,201$, $203,215,228,231,233,238,239,253,255,264,267,271,276$, $288,292,294,298,299,301,304,308,310,314,320,323,327$, $330,341,342,344,357,361,364,365,367,369,370,373,374$, 
TABLE 1. Distribution of Nocardia spp. by the type of disease ${ }^{a}$

\begin{tabular}{|c|c|c|c|c|c|c|c|c|}
\hline \multirow{3}{*}{ Species } & \multicolumn{8}{|c|}{ No. of cases } \\
\hline & \multirow{2}{*}{$\begin{array}{l}\text { Pulmonary } \\
\text { (only) }\end{array}$} & \multirow{2}{*}{$\begin{array}{l}\text { Systemic }+ \\
\text { CNS }^{b}\end{array}$} & \multirow{2}{*}{$\mathrm{CNS}^{c}$ only } & \multirow{2}{*}{$\begin{array}{c}\text { Cutaneous }+ \\
\text { lymphocutaneous }\end{array}$} & \multicolumn{3}{|c|}{ Single site (extrapulmonary) } & \multirow{2}{*}{ Total } \\
\hline & & & & & Eyes & Bone & Other & \\
\hline$N$. asteroides & 356 & $265(113)$ & 73 & 34 & 27 & 17 & 59 & 831 \\
\hline$N$. brasiliensis & 8 & $20(5)$ & 3 & 43 & 0 & 2 & 7 & 83 \\
\hline$N$. farcinica & 6 & $0(0)$ & 4 & 1 & 0 & 0 & 2 & 13 \\
\hline N. otitidiscaviarum & 4 & $8(5)$ & 1 & 3 & 1 & 3 & 2 & 22 \\
\hline$N$. transvalensis & 1 & $2(2)$ & 0 & 0 & 0 & 0 & 0 & 3 \\
\hline Nocardia spp. & 37 & $39(22)$ & 10 & 1 & 1 & 4 & 6 & 98 \\
\hline Total & 412 & 334 & 91 & 82 & 29 & 26 & 76 & 1,050 \\
\hline
\end{tabular}

${ }^{a}$ Data are derived from references $1-9,15,18,19,21-23,25-27,31-40,43,44,47-52,99-110,112,114,121,124,125,127,132-135,137-140,142-147,149,152-157$, $159,161-166,168-171,175-183,186-188,190-198,201-204,206,207,213-220,222,224,225,228,231-239,241,247-255,257-262,264,266-272,276,277,280,284$, $285,287-304,307-311,313-320,322-324,326-329,331,337,340-344,347,348,350-354,356,357,359-367,369,370,372-374,377-380,385,386,389,392-397,400-402$, $408-410,413-419,421-425,427,428,430,432-438,440,443-446,448-451,453-456,459-463,466-468,470-475,477-486,488,492,493,495,496,503,505,506,510-512$, $514-527,531-535,537-547,549,551,553-571,573,574,576,578,580,582,586-598,601,602,605,607-609,611,616-623,625,626,628,631,634-646,648,649,653-655$, $657,658,660,662-664,666,667,672,674,675,677-684,687,690-694,696-707,709-717,719-723,725,726,730-736$.

${ }^{b}$ Systemic infections are those at two or more sites; numbers in parentheses indicate patients with CNS infection also.

c Total CNS cases, 238.

$378,380,386,394,396,397,414,418,419,422,428,430,433$, $434,437,440,448,456,459,461,466,468,477,480,482,484$, $492,495,503,505,510,512,515,517,520,522,523,525,534$, $537,538,545,551,553,555,560,562,564,576,582,588,592$, $602,605,607,609,621,622,625,631,635,636,639,641,648$, $653,655,657,658,662,679,681,684,687,693,700,705,707$, $709,712,715,723,725,726,731,734)$. On the basis of these observations combined with data from models involving experimental animals, Nocardia spp. should be regarded as primary pathogens of the CNS, especially the brain $(69-71,74,88,97$, $388,498,499$ ).

Infections of the brain by Nocardia spp. are often insidious in onset and difficult to diagnose and treat successfully (70). Nocardia spp. can invade the brain silently and persist as an inapparent infection $(357,528,562,582)$. Thus, the signs and symptoms expressed following brain infection are variable, and there may not be any outward neurologic manifestations (357, $528,562,582)$. The lesions in the brain may be recognized as either granulomata with giant cells $(228,712)$ or, more frequently, abscesses in any location within the brain (Fig. 1B). Diffuse cerebral infiltration with no focal lesions may also be present (181). Frequently, nocardial lesions are localized in the parietal, frontal, and occipital cerebral cortex $(132,228,503$, $562,658,715)$, basal ganglia $(437,683)$, midbrain $(682)$, and brain stem (pons) $(109,138,309,484,505)$. Furthermore, there may be meningitis with or without involvement of other portions of the brain $(138,142,228,267,378,430,517,625)$. Occasionally, the spinal cord represents the only location for CNS invasion by Nocardia spp. (27, 232, 482, 609, 710, 720).

The clinical presentation of CNS infection by Nocardia spp. may be acute with rapid progression, but most frequently the disease progresses gradually, resulting in a broad range of neurologic deficits extending over a period of from several months to several years (70). Unlike pulmonary or systemic nocardiosis, there may be no fever or shift in the blood cell differential to signal a bacterial infection. For example, in a study of seven liver transplant patients with nocardiosis, Forbes et al. (251) stated that "The presence of fever or leukocytosis is not inevitable. Only three of our patients had both fever and leukocytosis; and one, with disseminated disease, had neither." The patient with disseminated disease described by Forbes et al. (251) had nocardiae in the brain. Bauman et al. (50) described a nonimmunocompromised patient with a brain lesion caused by nocardiae: "Because of the absence of clinical signs of infection and the age of the patient, a presumptive diagnosis of the brain tumor was made, and therapy was instituted with dexamethasone." Since the lesion was accessible to surgery, a biopsy was performed, and Nocardia spp. were isolated from the lesion (50). The investigators reported that "No malignancy was present. The patient had normal immune response as determined by an anergy screen. No underlying illnesses predisposing to infection with Nocardia spp. were present, and the patient was afebrile throughout the course of observation" (50). Similarly, Beaman (70) described a nonimmunocompromised woman in her mid-thirties who gradually developed progressive neurologic signs over a period of 3 years. Eventually, she developed hemiparesis and had difficulty in walking. A computed tomogram showed a mass in the right upper cerebral hemisphere. Because she was afebrile and there was no evidence of an infectious disease process (all blood tests were normal), the diagnosis of brain tumor was made (70). Since the lesion was accessible, it was removed surgically. The pathologists demonstrated that the mass was not a brain tumor but, instead, a lesion from which $N$. asteroides was isolated (70). In our analysis of 238 published cases of CNS infections (described below) caused by nocardiae, we found that CNS infections tend to be more rapidly progressive in compromised hosts than in normal individuals with no underlying predisposing factor, in whom infections of the brain are indeed insidious and slowly progressive. Recently, Beaman analyzed and reviewed 150 cases involving brain infections caused by Nocardia spp. in humans (70).

\section{Extrapulmonary Nocardiosis}

Since nocardiae were originally thought to infect primarily the lungs, infections in regions of the body without identifiable pulmonary involvement were placed into the broad category of extrapulmonary nocardiosis $(64,74,78,110,122,263,583$, 585). In general, this category may be best considered separately from cutaneous, lymphocutaneous, and mycetomatous infections $(64,74,78,122,263,583,585)$. Although any anatomic site can become a focus for primary extrapulmonary nocardial infection $(3,46,49,125,147,182,236,252,259,360$, $409,450,460,481,519,526,533,573,616,643,646,655,667$, $711,732)$, the brain, bone, eyes, heart, joints, and kidneys are 
the most frequently affected sites reported in the literature (78, $122,263,586)$. As indicated above, the predilection of Nocardia spp. for the brain is striking, and it is suggested here that these infections be considered in a separate category from other types of extrapulmonary infections $(69,70)$. Thus, most cases of extrapulmonary nocardiosis outside the CNS would include primary infections of the bone $(27,198,216,264,289$, $417,453,475,524,565,730)$, eyes $(48,103,137,140,180,224$, 268, 290, 307, 316, 317, 328, 359, 377, 462, 463, 488, 543, 586, $634)$, heart $(169,234,324,369,425,493,535,654)$, joints $(23$, $177,187,474,546,672,717)$, and kidneys $(513,538,541,558$, 573 ), with a marked propensity for the eyes, especially the retina; however, retinal involvement is recognized frequently as a consequence of dissemination rather than as a primary focus $(144,149,171,206,241,337,386,416,427,444,511,539$, $560,607)$. On the other hand, corneal and other ocular lesions often result from traumatic inoculation $(48,103,137,140,180$, $224,268,290,307,316,317,328,343,359,377,462,463,488$, $543,586,634)$. Also, nocardial infections of the joints, causing an arthritis, are becoming more frequently recognized $(23,177$, $187,474,546,672,717)$. Furthermore, there are several reports of primary pericarditis and endocarditis $(169,234,324,369$, $425,493,535,585,654)$.

\section{Localized Cutaneous, Subcutaneous, and Lymphocutaneous Nocardiosis}

Primary cutaneous and subcutaneous nocardiosis $(12,99$, $100,124,156,269,291,293,296,315,352,353,410,423,542$, $547,580)$ usually occurs following traumatic introduction of Nocardia spp. into the skin by a thorn $(303,311,591,721,722)$, splinter (180), puncture wound (717), insect bite (156) (i.e., tick [423] or mosquito [277]), animal scratch (i.e., cat [418, 570] or rabbit [311]), or dog bite (429). Since the nocardiae are ubiquitous in the soil, it is likely that cutaneous inoculation into humans is relatively common. Once the organism breaches the integrity of the skin, it can begin to grow. This localized growth may progress sufficiently to induce an inflammatory response leading to the accumulation of PMNs, which results in either a cellulitis or pyoderma $(353,580)$. Often the infection becomes circumscribed to form an abscess. In some instances this infectious process is progressive, but most frequently it appears to be self-limited. Cutaneous and subcutaneous infections that manifest as cellulitis, pustules, pyoderma, or localized abscesses have the same appearance as diseases caused by other pyogenic bacteria such as Staphylococcus and Streptococcus spp., except that nocardial infections tend to be more indolent; hence, clinical misdiagnosis of these cutaneous infections caused by Nocardia spp. occurs (353). All of the pathogenic Nocardia species may cause cutaneous or subcutaneous lesions; however, $N$. brasiliensis is the most frequently recognized cause of progressive disease, whereas $N$. asteroides may be a frequent cause of the more self-limited forms of infection $(12,16,99,100,124,156,269,291,293,296,315,352$, $353,410,423,542,547,580)$.

The organism may spread from the primary site of inoculation through the lymphatics to the regional lymph nodes, resulting in lymphocutaneous nocardiosis $(47,101,225,311$, $471-473,570,591,606,674,721,722,736)$. Since this form of nocardiosis frequently results from a thorn puncture, and since it presents a clinical course that may be indistinguishable from sporotrichosis caused by the fungus Sporothrix schenckii, it is often referred to as sporotrichoid nocardiosis $(47,101,303$, $311,315,471,473,591,721,736)$. Most cases of lymphocutaneous nocardiosis reported in the literature are caused by $N$. brasiliensis; however, there are a few reports of this syndrome being caused by $N$. asteroides and $N$. otitidiscaviarum $(47,101$, $225,311,471-473,570,591,606,721,722,736)$.

The incidence of cutaneous, subcutaneous, and lymphocutaneous nocardiosis was thought to be relatively uncommon. However, several investigators have pointed out that this form of nocardiosis is probably much more common than is generally appreciated $(353,580)$. This is because the disease may mimic other, more common, pyogenic infections caused by such organisms as Staphylococcus aureus $(353,580)$. Also, the somewhat self-limited lesions are usually not cultured, and Gram stains are usually not made. Therefore the true etiology is most often never determined except in cases that do not respond to therapy or worsen over time $(353,580)$. Furthermore, nocardial infections in general are underdiagnosed because of the relatively slow growth of the organism during primary isolation from clinical material combined with the often reported failure to recover the organism, even when a Gram stain demonstrates its presence. These factors may explain why only a relatively small number of cases of primary cutaneous, subcutaneous, and lymphocutaneous nocardiosis is reported in the literature (Table 1).

\section{Nocardia-Induced Mycetomas}

A mycetoma is a chronic disease caused by a variety of fungi and actinomycetes (305). The disease process usually begins at the site of a localized injury such as a puncture wound caused by a thorn or a splinter. Therefore, mycetomas are more frequently seen on the feet, legs, arms, or hands, but they can develop at any location of the body such as the back, shoulders, and head (Fig. 2). The mycetoma most often starts as a painless nodule developing at the site of the injury days to months after the injury. This nodule increases in size and may eventually become purulent and necrotic. Pus may discharge through sinus tracts that develop. During the progressive development of the lesions, chronic granulomatous inflammation with concomitant swelling and enlargement of the surrounding areas occurs with the formation of additional, multiple secondary nodules and draining sinus tracts that exude serous fluid which may contain pus cells $(583,599,600)$. The exudate from these sinus tracts usually contains granules that have a characteristic size, shape, and color. The granules represent small colonies of the infecting agent surrounded by masses of inflammatory cells $(439,599,600)$. Usually the mycetoma remains localized but enlarges by extension of the organisms through the tissues. With time, the infection involves both the muscle and bone, wherein a destructive osteomyelitis occurs. Once established, these lesions become relentlessly progressive over a period of years and frequently do not respond to chemotherapy $(583,599,600)$.

Mycetomas can be divided into two basic categories that depend on the type of microorganism causing the disease. Mycetomas caused by fungi are called eumycetomas, whereas those caused by the actinomycetes are actinomycetomas ( 305 , $599,600,604,659,669)$. At least half of the mycetomas reported in the world literature are caused by actinomycetes, and the majority of these are caused by Nocardia spp. Members of the genus Actinomadura are the most frequently reported causes of actinomycetoma in certain geographic locations $(599,600)$, whereas other actinomycetes such as Streptomyces spp. may cause mycetomas in other geographic areas $(305,599,600,604,659,669)$. Nocardia brasiliensis is the most frequently recognized cause of Nocardia-induced mycetomas; however, it must be emphasized that $N$. asteroides, $N$. otitidiscaviarum, and $N$. transvalensis can also cause mycetomas 


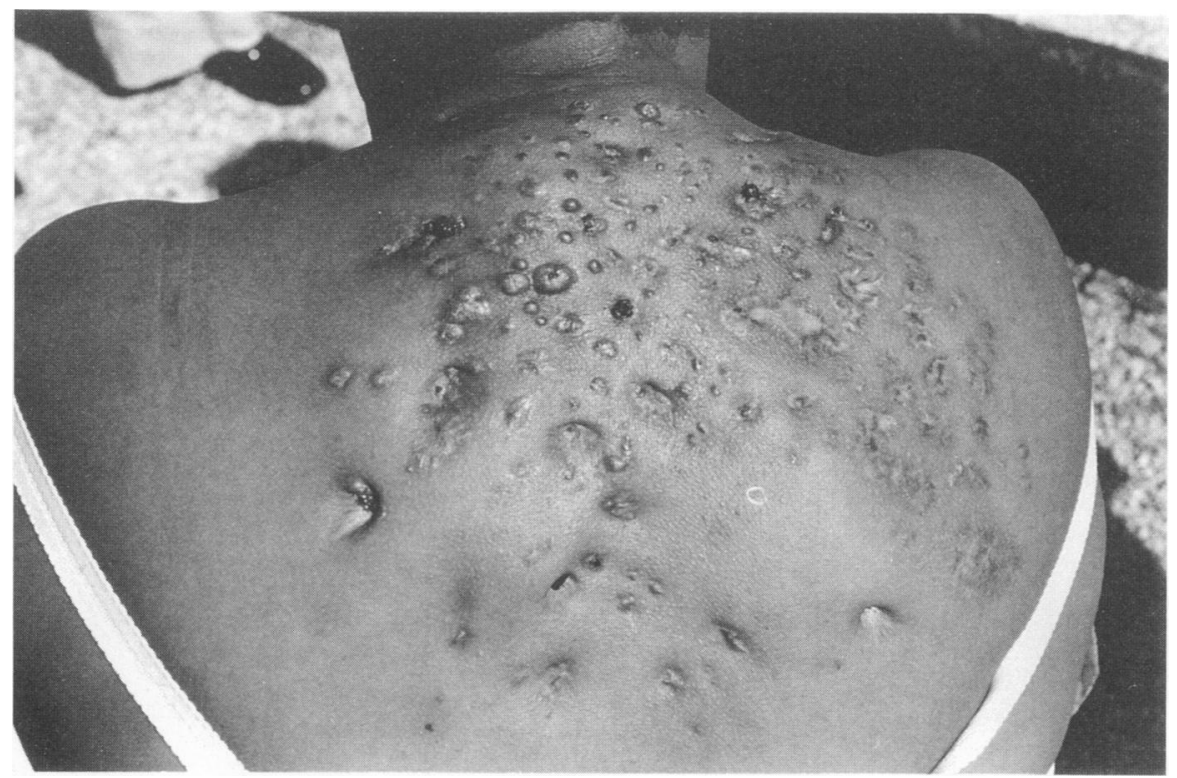

FIG. 2. Nocardial mycetoma of the back of a previously healthy woman several years after trauma that resulted from carrying bundles of wood on her shoulders and back. Both N. brasiliensis and N. asteroides were isolated from biopsy specimens of these lesions. Photograph by B. L. Beaman, and case presentation by José Serrano, University of the Andes, Merida, Venezuela.

$(9,13,14,167,273,282,283,286,305,321,429,439,447,449$, $577,579,581,599,600,604,659,668,669,714)$.

\section{HOST-PARASITE RELATIONSHIPS}

\section{Nocardial Infections in Humans}

There are no studies that address adequately either the epidemiology or the incidence of nocardial infections in human and animal populations. Since no agency or organization monitors diseases caused by Nocardia spp., the incidence of infections by these bacteria remains unknown. However, by analyzing the literature, an image of the impact of nocardial infections on human and animal health is emerging.

In 1976, Beaman et al. (78) attempted to determine the incidence of nocardial disease in humans in the United States by surveying members of the Infectious Disease Society of America and comparing the data with records of nocardial isolates referred to the Centers for Disease Control in Atlanta, Ga., during the same period. Before this project began, there was an indication in the literature that nocardial infections were quite rare but increasing, and therefore only a few cases were expected. Surprisingly, the data suggested that at least 500 to 1,000 cases of nocardial disease were recognized each year in the United States. Since it is well documented that recognition of nocardial disease is difficult and frequently unsuccessful, it is probable that the 500 to 1,000 cases reported in this study were a great underestimate. Furthermore, the survey itself had design limitations that resulted in a probable underestimate of cases (78). Since this survey, several additional analyses have been presented in the literature that indicate that the incidence of nocardial diseases has been underestimated and is increasing $(122,263,585)$. Therefore, human disease caused by Nocardia spp. in the United States, and elsewhere in the world, is substantially more common than suggested by the estimates published previously $(78,122,263$, 585). Therefore, nocardial infections in humans are not rare and, indeed, may be relatively common.
For a comparative analysis, we randomly selected 1,050 case presentations of nocardial infections in humans described in the literature (see the references in Table 1). Since significantly more than 1,050 cases have been published, this study does not include every reported case. Furthermore, cases describing nocardia-induced mycetomas were excluded from this analysis because these will be considered separately. In addition, reviews that presented large series of cases with no individual data were not included $(78,122,263,585)$. We chose 500 cases published since 1980 (recent) to compare with 500 cases published between 1950 and 1979 (past) (see the references in Table 1). In addition, we selected 50 cases described before the current antibiotic era (before 1950) to serve as a base in order to analyze historical trends in nocardial infections $(39,102$, $103,112,140,152,155,207,213,230,231,236,247,270,272$, $291,295,308,342,367,379,436,531,619,679,706)$. Unfortunately, the same amount of detailed information about each patient is not provided by the authors in every publication. Nevertheless, adequate data are presented in the publications selected to permit a comparative analysis.

Of the 1,000 cases published since 1950 that were selected for further analysis, 384 occurred in patients with no identifiable underlying illness or predisposing factors and therefore represented primary infections in otherwise healthy people (Table 2). In 23 of the 1,000 cases, inadequate information was provided to permit an evaluation of predisposing factors. In the remaining 643 cases, specific underlying conditions appeared to predispose the individuals to disease caused by Nocardia spp. There has been an increased recognition of Nocardia spp. in compromised patients since 1980 compared with the period between 1950 to 1979 . For example, since 1980, at least $28.4 \%$ of infections were in healthy individuals, whereas prior to $1980,48.4 \%$ of the cases were reported in normal, noncompromised patients. The 643 cases that represent "opportunistic nocardial disease" can be divided into at least 30 different categories of specific predisposing conditions, 18 of which are listed in Table 2. Organ transplantation and AIDS represent the most significantly increased factors recog- 
TABLE 2. Factors that predisposed individuals to infection with Nocardia spp. ${ }^{a}$

\begin{tabular}{|c|c|c|c|}
\hline \multirow[b]{2}{*}{ Factor } & \multicolumn{3}{|c|}{ No. of cases diagnosed in: } \\
\hline & $1950-1979$ & 1980-1991 & $\begin{array}{l}1950-1991 \\
\text { (total) }\end{array}$ \\
\hline None & 242 & 142 & 384 \\
\hline AIDS & 0 & 49 & 49 \\
\hline Alcohol abuse & 13 & 9 & 22 \\
\hline Alveolar proteinosis & 17 & 6 & 23 \\
\hline Arthritis (steroids) & 2 & 5 & 1 \\
\hline Asthma & 6 & 4 & 10 \\
\hline Cancers (miscellaneous) & 17 & 16 & 33 \\
\hline Chronic lung disease (emphysema) & 6 & 9 & 15 \\
\hline Chronic granulomatous disease & 4 & 9 & 13 \\
\hline Diabetes & 5 & 12 & 17 \\
\hline Heart transplant & 7 & 40 & 47 \\
\hline Hodgkin's disease & 23 & 13 & 36 \\
\hline Leukemia & 20 & 10 & 30 \\
\hline Liver transplant & 0 & 12 & 12 \\
\hline Lymphoma and lymphosarcoma & 15 & 17 & 32 \\
\hline Renal transplant & 30 & 51 & 81 \\
\hline Sarcoidosis & 4 & 4 & 8 \\
\hline Systemic lupus erythematosus & 12 & 13 & 25 \\
\hline Tuberculosis (culture proven) & 29 & 7 & 36 \\
\hline $\begin{array}{l}\text { Miscellaneous (variety of single } \\
\text { factors) }\end{array}$ & 41 & 56 & 97 \\
\hline Unknown & 7 & 16 & 23 \\
\hline Total & 500 & 500 & 1,000 \\
\hline
\end{tabular}

a Data derived from the references listed in Table 1, footnote $a$. These data refer to 1,000 cases identified since 1950 .

nized since 1980 compared with factors reported before 1980 . The ratios of infection in most other categories appeared to remain unchanged for the two periods being analyzed. Of course, AIDS was not recognized until after 1980, and this population represents about $10 \%$ of the total cases of nocardiosis published since 1980 . Overall, there appears to be an increase in cases reported since 1980, which supports the view of many investigators that the incidence of disease due to Nocardia spp. is on the rise $(122,263,585)$. The most frequent predisposition for nocardial infection is organ transplantation, since the number of infected patients who received a renal transplant (81 patients), a heart transplant (47 patients), or a liver transplant (12 patients) made up 140 of the 643 studied (21.8\%). The next largest group represented individuals with various forms of malignancy such as lymphoma and lymphosarcoma (32 patients), Hodgkin's disease (36 patients), leukemia (30 patients), and miscellaneous cancers (33 patients), for a total of $131(20.4 \%)$. Tuberculosis has been cited frequently as a predisposing factor (Table 2). However, in most instances, nocardiosis and tuberculosis were coexistent, and only the cases of tuberculosis that were identified by isolation of $M$. tuberculosis are included in this table. Therefore, tuberculosis per se should not be considered a predisposing factor for nocardiosis, because in most cases it is not clear which disease occurred first or that one predisposed the individual to the other. Furthermore, it is well documented that mycobacterial and nocardial infections often occur together in the same patient, and this dual relationship has even been reported to occur naturally in animals $(78,150,617)$.

Several investigators have indicated that nocardial infections are more frequently recognized in males than in females (78, $122,263,585)$. A review of 1,050 cases supports this interpretation since overall $70.8 \%$ of the infections were reported in

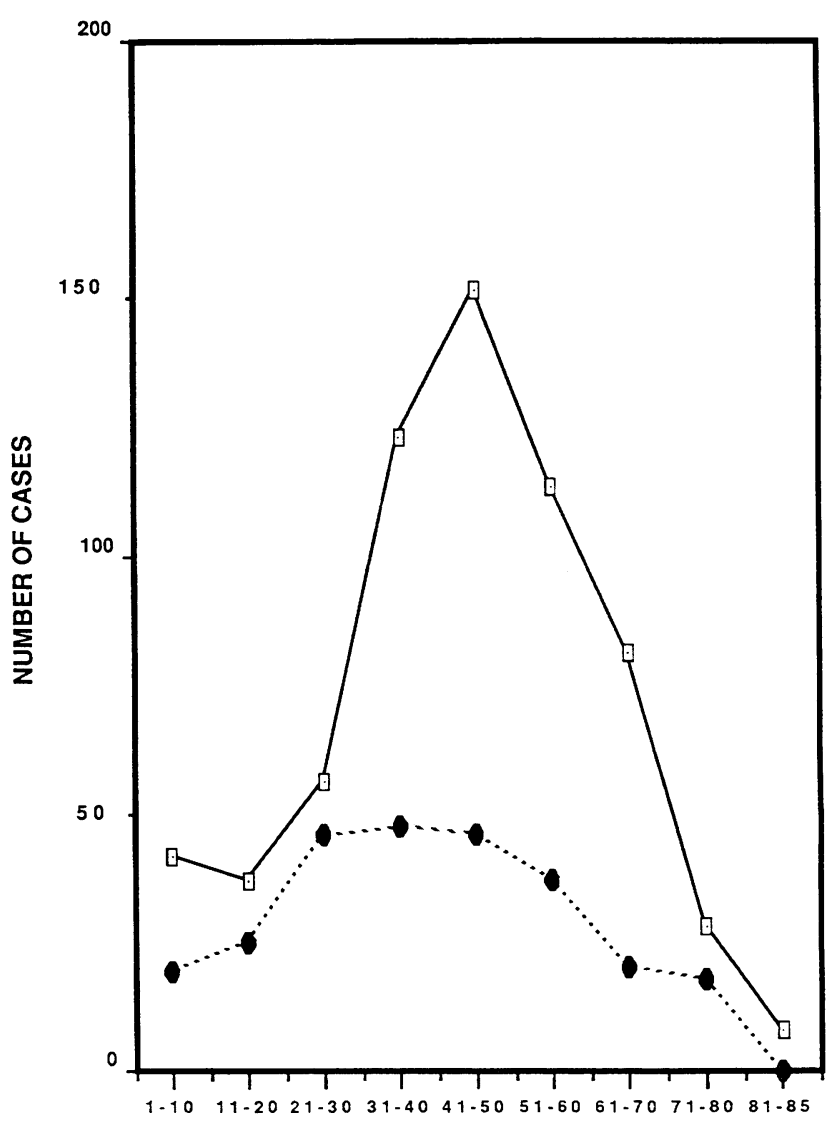

AGE RANGE (YEARS)

FIG. 3. Distribution by age and sex of 1,000 cases of nocardial infections in humans reported in the literature since 1950 (the data are from the references listed in Table 1). Symbols: $\square$, male; $\boldsymbol{0}$, female.

males whereas only $29.2 \%$ were in females (2.4:1). Furthermore, the ratios of male to female infections were not significantly different among the 500 cases reported before 1980 compared with the 500 cases after 1980 . Analysis of the ages of patients with nocardiosis as a function of sex, however, shows that age influenced significantly the male dominance of the reported cases (Fig. 3). Thus, there was little difference in the male-to-female ratio of patients in their twenties, whereas there was almost a 4:1 ratio in individuals in their forties (Fig. $3)$. As noted overall, the distribution of patients reported before 1980 was essentially the same as those after 1980 except in one group. Patients with AIDS had a very different ageversus-sex distribution (see the section below).

Of the 1,000 individuals infected with Nocardia spp., death was reported in 349 , resulting in an overall mortality of at least $34.9 \%$ (see the references in Table 1). However, the outcome of the infection was not indicated in 64 cases. Of the 50 patients selected before 1950,35 died, resulting in a $70 \%$ mortality, but 221 of the $500(44.2 \%)$ reported between 1950 and 1979 died, and only 128 of $500(25.6 \%)$ patients reported since 1980 died. Even though the mortality rate in nocardiosis remains exceptionally high, there has been a significant improvement in successful therapy reported since 1980 (see the references in Table 1). It is beyond the scope of this review to discuss therapy; therefore recent reviews on this topic should be consulted $(74,585,699)$. Of the 349 patients with nocardi- 
osis who died, the sex was indicated for $300 ; 85$ of the 300 $(28.3 \%)$ were female whereas $215(71.7 \%)$ were male (maleto-female ratio, $2.5: 1$ ). Thus, the sex of the patient appeared to have no significant effect on the clinical outcome. However, the degree of severity of the immunocompromise had a significant effect on the survival of the patient. Of the 384 patients with no identifiable predisposing factor (primary infection), only 76 died $(19.8 \%)$. In contrast, 273 of $643(42.4 \%)$ of the individuals with an underlying disorder did not survive. The mortality was significantly greater (more than $50 \%$ ) in persons who had either systemic or CNS nocardiosis, whereas localized pulmonary or extrapulmonary (excluding CNS) infections appeared to respond better to therapy (with mortality being less than $20 \%$ ) (see the references in Table 1).

\section{Nocardial Infections in Patients with AIDS}

Nocardia spp. are becoming more frequently recognized as serious but potentially treatable pathogens in patients with AIDS (Table 2). From the literature, there appears to be a difference in the perception among clinicians concerning the incidence of nocardial infections in AIDS patients $(174,330$, $373,393)$. However, the suggestion by some clinicians that nocardiosis is a rare complication in AIDS patients is not supported by either the literature or our own experience $(4,7$, $40,122,124,125,148,174,184,214,217,252,263,324,330$, $346,351,373,374,390,393,400,435,438,449,453,493,513$, $559,585,593,602,610,664,680,708)$. Our impression is that there may be differences in geographic location related to the incidence of nocardiosis in patients with AIDS. Thus, the relative incidence may be higher in the southern and rural regions of the United States than in metropolitan areas of the east and west such as in New York and San Francisco. Unfortunately, there are too few published data to address these impressions adequately. Nevertheless, approximately 50 confirmed cases have been described in the literature in the United States, and many more cases have been noted in publications concerning nocardiosis in AIDS patients in Australia, England, France, Germany, Japan, Spain, and Uganda $(4,7,40,122,124,125,148,174,184,214,217,252,263,324$, $330,346,351,373,374,390,393,400,435,438,449,453,493$, $513,559,585,593,602,610,664,680,708)$. Furthermore, we are aware of numerous unpublished cases of nocardiosis in AIDS patients from many different regions of the United States (Fig. 1A). Obviously, there is no mechanism whereby the incidence of nocardiosis in AIDS patients can be calculated accurately. Scott and Kuhlman (593) performed percutaneous transthoracic needle biopsy on 13 AIDS patients with undiagnosed focal pulmonary lesions; in 2 of these patients (15\%) the lesions turned out to be caused by $N$. asteroides. De la $\mathrm{Hoz}$ Caballer et al. (214) reported on seven AIDS patients who had an adverse reaction to therapy with sulfonamides. Interestingly, one (14\%) of these had disseminated infection caused by $N$. asteroides. Kim et al. (373) reported that from 1980 through 1989, 2,000 patients with AIDS were seen at one New York City hospital and that only 6 of these had nocardiosis, resulting in an incidence of $0.3 \%$. On the other hand, Kramer and Uttamchandani (393) reported 21 cases of pulmonary nocardiosis in AIDS patients seen at the University of Miami between 1983 and 1989. In addition, they referred to cases of extrapulmonary nocardiosis in some AIDS patients seen at this facility but did not provide the numbers of patients seen (393). Burton et al. (148) reported on a retrospective analysis of specimens from 93 consecutive cervical lymph node biopsies done by them between 1985 and 1989. Of these patients, 20 were HIV positive and 10 of them were diagnosed as having
AIDS (148). Of the 20 HIV-positive individuals, 10 had tender and enlarging cervical lymph nodes. A Mycobacterium sp. was recognized in lymph nodes from eight of these patients whereas a Nocardia sp. was found in nodes from two patients (20\%). Thus, all of the HIV-positive individuals in this study who had tender, enlarging cervical lymph nodes were infected with either Mycobacterium spp. (80\%) or Nocardia spp. $(20 \%)$ (148).

A review of the literature resulted in at least 71 published cases of nocardiosis in AIDS patients between 1984 and 1992; a majority of these were reported since $1990(4,7,40,122,124$, $125,148,174,184,214,217,252,263,324,330,346,351,373$, $374,390,393,400,435,438,449,453,493,513,559,585,593$, $602,611,664,680,708)$. The site of the disease caused by Nocardia spp. was provided for 60 of 71 cases (84.5\%). Not surprisingly, the lung was the only focus for the disease in 31 of $60(51.7 \%)$ patients. The CNS (brain) was involved in 7 of 60 $(11.7 \%)$ patients. Other important sites included the heart (both pericarditis and endocarditis; four cases), lymph nodes (three cases), kidneys (two cases), esophagus (two cases), paraspinal abscess, peritoneal abscess (two cases), bone marrow, skin, pharyngeal abscess, and inner ear. Some cases (4 of 60 patients) were reported only as systemic disease. Since it is well established both experimentally and clinically that Nocardia spp. have a propensity for the retina during dissemination, it is surprising that no instances of retinitis were reported among the 60 cases. This may be because retinitis in AIDS patients is most frequently ascribed to cytomegalovirus. Males with nocardiosis outnumbered females by 42 to 9 (4.7:1). The clinical outcome was given for 35 patients, of whom 20 died $(57 \%)$. In many of the patients, Nocardia spp. were not the only organisms found; interestingly, one of the most frequently observed second pathogens was $M$. tuberculosis, which was also identified in at least 5 of the $71(7.0 \%)$ patients $(4,7,40,122$, $124,125,148,174,184,214,217,252,263,324,330,346,351$, $373,374,390,393,400,435,438,449,453,493,513,559,585$, $593,602,610,664,680,708)$.

\section{Nocardial Infection in Animals and Animal Models}

The pathogenic Nocardia species not only cause disease in humans but also cause similar diseases in a large variety of animals (93). Since the range of naturally acquired infections in animals has been reviewed previously (93), we will focus on trends related to host-parasite interactions, with a particular emphasis on experimental animal models. Nevertheless, it should be noted that naturally acquired infections have been reported in cattle $(17,150,221,240,504,529,575)$; goats $(42$, $509,603)$; pigs (387); sheep (603); horses $(111,458,529)$; dogs $(41,131,141,281,381,407)$; cats $(20,205,504)$; primates $(11$, 126, 349, 368, 426, 457, 572); armadillos (265); antelopes and gazelles $(28,376)$; deer $(223)$; foxes $(431)$; mongooses $(431)$; dolphins, porpoises, whales, and seals $(345,504,529,530,656)$; birds $(189,338,339,612)$; fish $(158,172,173,312,382,398,399$, $405,627,724)$; crustaceans (10); and oysters (256). N. asteroides is the most frequently recognized pathogen in these animals, but $N$. brasiliensis and $N$. otitidiscaviarum ( $N$. caviae) have also been recovered from infections in many of these animal species (93). Furthermore, $N$. seriolae and $N$. crossostreae have been isolated from infections in fish and oysters, respectively $(256,398,399,405,689)$. Pulmonary and systemic nocardioses, including infections of the brain, are the most frequently recognized; however, cutaneous and mycetomatous lesions also occur. In dairy animals, especially cows, mastitis is a distinct clinical manifestation of major importance $(17,150$, $221,240,504,529,575)$. Large numbers of outbreaks of 
nocardial mastitis have been reported in the world literature, and in states such as California, $N$. asteroides and $N$. otitidiscaviarum currently represent a significant cause of mastitis in dairies, involving hundreds of cows throughout the state (53, 150).

Several experimental animal models have been investigated since the discovery of Nocardia spp. in the 1880s. In developing a valid animal model, it is important that the critical features to be studied in the experimental infection parallel or mimic the naturally acquired process. In 1891, Eppinger was the first to use animal models to study the pathogenicity of $N$. asteroides (231). His experiments with rabbits and guinea pigs fulfilled Koch's postulates for establishing the role of $N$. asteroides as the etiology of an infectious disease. He injected an isolate from the brain of a patient (the first isolate from a human [230]) into guinea pigs and rabbits and found that it caused a typical "pseudotuberculosis" similar to the infection in the human. These experiments clearly established the etiology of the human disease and demonstrated the pathogenicity of this organism for guinea pigs and rabbits. Initial experiments with mice suggested that these animals were resistant to infection by Nocardia spp. (231). Since Rabe discovered in 1888 that Nocardia spp. caused natural infections in healthy dogs, one of the first animal model systems developed was in the dog (436). In 1902, MacCallum studied healthy dogs following intravenous (i.v.) inoculation with $N$. asteroides. He demonstrated that these animals were quite susceptible to metastatic lesions in various organs and died as the result of their disseminated disease (436). In 1936, Balozet and Pernot demonstrated that $N$. asteroides caused brain infection in an 18-month-old dog (41). Naturally acquired nocardial infection in dogs with no predisposing underlying illness may be relatively common, and the young German shepherd appears to be one of the most susceptible to nocardial infection $(53,93,131,141,281,381$, 407). Therefore, dogs represent a good animal model for studying naturally acquired nocardial infection because they manifest all of the same clinical features of pulmonary and systemic disease that are recognized in humans $(93,131,141$, 281, 381, 407, 436). However, since 1902 there has been only sporadic use of the dog as an animal model to study nocardial pathogenicity. This is probably due to the relative cost and inconvenience of working with large numbers of these animals as well as the development of better models that are more easily studied (93). In addition to mice, rabbits, guinea pigs, and dogs, a variety of other animals have been used experimentally to study nocardiosis $(93,144,231,274,436,452,624$, $684,686)$. These include primates (442), fish $(172,173)$, chickens (502), cattle (575), and oysters (256).

The nocardiae have been difficult organisms to work with in the laboratory, partially because of the misconception that they were fungi and not bacteria. Only during the last 20 to 25 years has reliable and reproducible information about mechanisms of pathogenesis and host immunity to nocardial infections been forthcoming $(56,60,64,67,74,93)$. One of the major problems that had to be solved was the development of a defined experimental animal model system that would allow careful and systematic investigation. The early studies were not carefully controlled, and the experiments were rather crude, which reflected the difficulties and misconceptions in handling the nocardiae. As a consequence, the initial attempts to induce disease in mice and guinea pigs resulted in conflicting and contradictory results $(56,93)$. Therefore, as late as the $1960 \mathrm{~s}$, knowledge of whether pathogenic strains of nocardiae could even infect guinea pigs or mice was controversial and not clearly resolved. This was because several groups of investigators administered Nocardia spp. to rabbits, guinea pigs, and mice by every conceivable route of exposure, using nonstandardized and variable methods for preparing the inocula. Often the inocula were combined with artificial adjuvants, such as mineral oil or hog gastric mucin, which rendered the results of these experiments on host responses to Nocardia spp. difficult to interpret. As the result of these studies, virtually every conceivable experimental outcome was obtained, which added to the confusion $(54,56,60,64,67,74,93,107,273,452,624$, $685)$.

Beaman and colleagues selected for analysis more than 60 isolates of Nocardia spp. including strains from the American Type Culture Collection and organisms freshly recovered from human and animal infections (53). The growth characteristics of these isolates were determined, and standardized methods that permitted the preparation of homogeneous cell suspensions of the organisms at specific stages of growth were developed $(54,55,58,60,64,67,68,75,76,84,86,87)$. The relative virulence of each nocardial strain at each stage of growth was quantitated on the basis of $50 \%$ lethal dose $\left(\mathrm{LD}_{50}\right)$ determinations in mice $(59,84-86,89,93,695)$. By using these methods, three strains of $N$. asteroides that represented a spectrum of virulence were selected as models for further study of the mechanisms of pathogenesis and host-parasite interactions. Thus, cells of $N$. asteroides ATCC 10905 were shown to be least virulent for mice, cells of $N$. asteroides ATCC 14759 were of intermediate virulence, and cells of $N$. asteroides GUH-2 (an isolate from a human with a fatal infection) were most virulent during all stages of growth $(59,84-86,89,93)$.

Filice and co-workers studied pneumonia induced in mice by the virulent strain $N$. asteroides GUH-2 and described a early neutrophil response followed by a subsequent mononuclear cell response (246). Blockage of the early neutrophil response in infected mice resulted in more nocardial growth than in controls (246). A decrease in monocytes induced by silica resulted in more severe pneumonia (536), indicating both neutrophils and monocytes are necessary in pulmonary defense against $N$. asteroides GUH-2.

\section{INTERACTIONS OF NOCARDIAE WITH PHAGOCYTES}

\section{Macrophages from Animals}

Macrophages can eliminate most bacteria from host tissues by nonselective phagocytosis of invading organisms or by specific mechanisms under control of humoral and cell-mediated immune processes. The fate of the phagocytized bacteria depends on several factors including the metabolic state of the phagocyte and the presence of specific virulence factors produced by the bacteria which enable them to survive the oxygen-dependent or oxygen-independent microbicidal products of the phagocyte (94).

In one of the first studies on specific host cell interactions with nocardiae (129), it was shown that $N$. asteroides was readily phagocytized in vitro by cultured macrophages (Fig. 4). Microscopic studies with the less virulent $N$. asteroides ATCC 10905 suggested that the organism was slowly degraded by macrophages; however, viable plate counts showed a decrease in numbers during the first 12 days followed by significant increases after 16 days. Electron microscopy revealed the presence of wall-less, spheroplast-like organisms with many properties of bacterial L-forms within the macrophages (129). This indicated that a few of the organisms were capable of surviving within macrophages in an altered cellular state (refer to the section on L-forms in pathogenesis below).

Splino et al. $(632,633)$ demonstrated that guinea pig peritoneal and alveolar macrophages phagocytized $N$. asteroides 


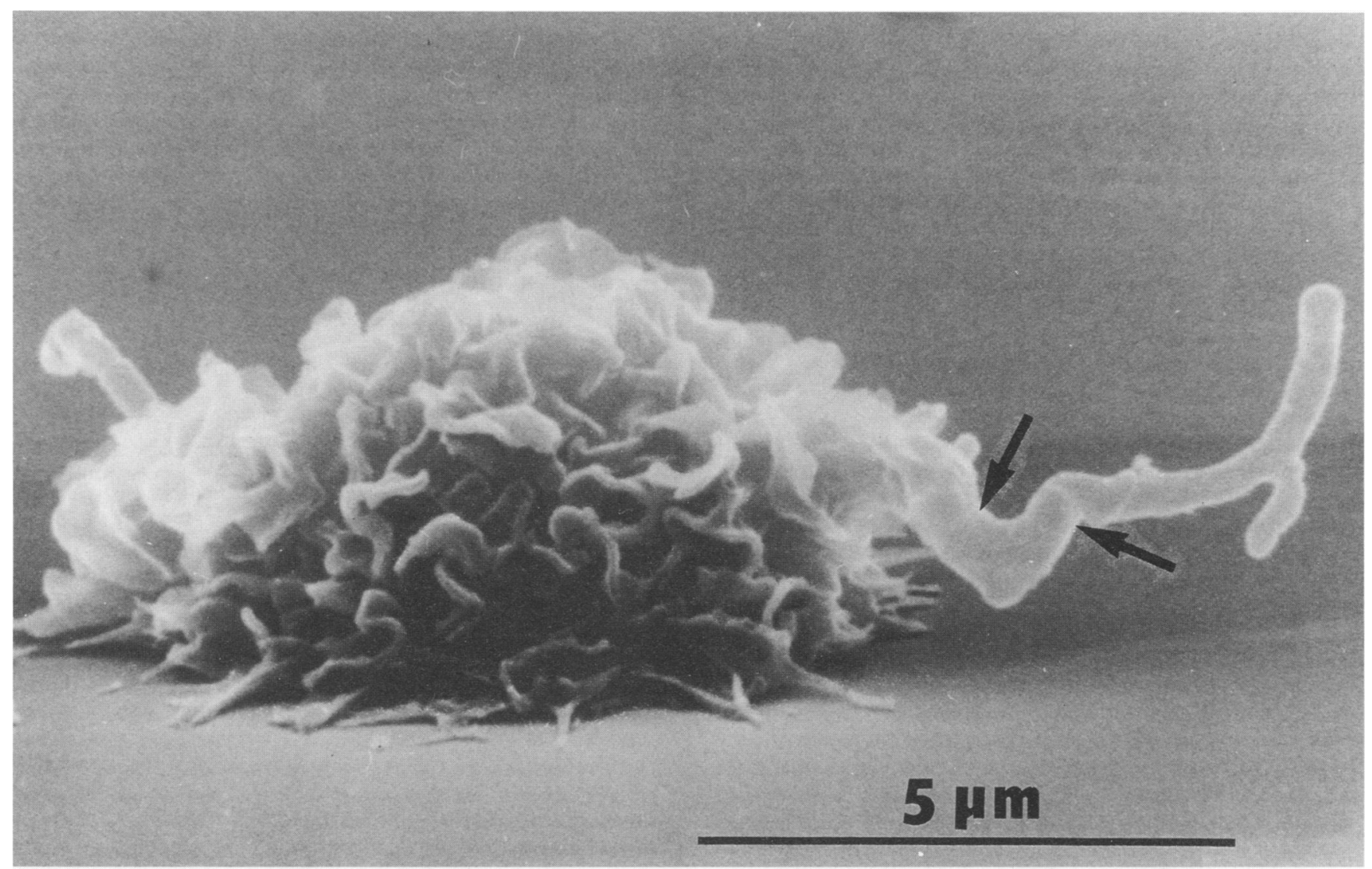

FIG. 4. Scanning electron micrograph of a rabbit alveolar macrophage in the process of phagocytizing N. asteroides ATCC $147591 \mathrm{~h}$ postinfection. The arrows indicate where the nocardial cell is being engulfed by the macrophage. Reprinted from reference 57 with permission of the publisher.

Weipheld but that within $8 \mathrm{~h}$ of culture, nocardial filaments grew through the phagocytic cell membrane. Furthermore, this strain appeared to be cytotoxic for phagocytic cells (632).

Beaman and Smathers (92) found that the less virulent $N$. asteroides ATCC 10905 was rapidly phagocytized and destroyed by rabbit alveolar macrophages, except for a few cells that persisted within the macrophages in a gram-negative form. In a manner similar to that reported for murine peritoneal macrophages (129), L-forms of $N$. asteroides were isolated from rabbit alveolar macrophages 9 days after inoculation. L-forms were not isolated from the medium (92). In contrast, cells of a more virulent strain, $N$. asteroides ATCC 14759, were not destroyed after being ingested by rabbit alveolar macrophages; instead, the CFU per macrophage increased significantly by $6 \mathrm{~h}$ postinfection and, after $24 \mathrm{~h}$, this strain grew out of the macrophages (Fig. 5) as acid-fast branching filaments (92). In addition, some of the cells of $N$. asteroides ATCC 14579 elicited a migratory response in the in vitro grown alveolar macrophages and induced these aggregated macrophages to fuse, forming multinucleate giant cells (57). These multinucleate giant cells appeared to be more destructive for the intracellular bacteria than the isolated, individual macrophages. In contrast, neither the less virulent strain ATCC 10905 nor the more virulent strain $N$. asteroides GUH-2 induced macrophage fusion to elicit this giant cell response $(57,58,92,96,129)$.

$N$. asteroides GUH-2 from all stages of growth grew intracellularly in normal rabbit alveolar macrophages; however, log-phase cells increased in numbers more rapidly than did stationary-phase cells. Macrophages obtained from the lungs of specifically immunized rabbits inhibited the growth of stationary-phase cells, but growth of log-phase organisms was only temporarily retarded (58). Specific antiserum added to the nocardial cells before incubation with immune macrophages slightly enhanced the phagocytosis and inactivation of the log-phase cells but not the stationary-phase cells (58). Logphase cells were more toxic to the macrophage monolayer than were stationary-phase cells. Macrophages from immunized animals did not by themselves appear to be sufficient to control infection by virulent strains of $N$. asteroides. Activated macrophages from mice infected with Toxoplasma gondii or injected with Corynebacterium parvum inhibited the growth of two strains of $N$. asteroides that were in the stationary phase of growth (245). In control macrophages, nocardial filaments extended from within macrophages to the outside and the bacteria were not acid fast. In activated macrophages, most of the nocardial cells remained in the coccobacillary form, indicating that bacterial growth was being inhibited, but the few bacteria that did grow were strongly acid fast, indicating that a change had occurred in the nocardial cell wall as the result of growth within these "hostile" phagocytes (245).

When in vitro maintained rabbit alveolar macrophages were infected with three strains of $N$. asteroides, it was found that GUH-2 was the most resistant, ATCC 14759 was intermediate in resistance, and ATCC 10905 had little resistance to being killed by macrophages (208). These results correlated with 

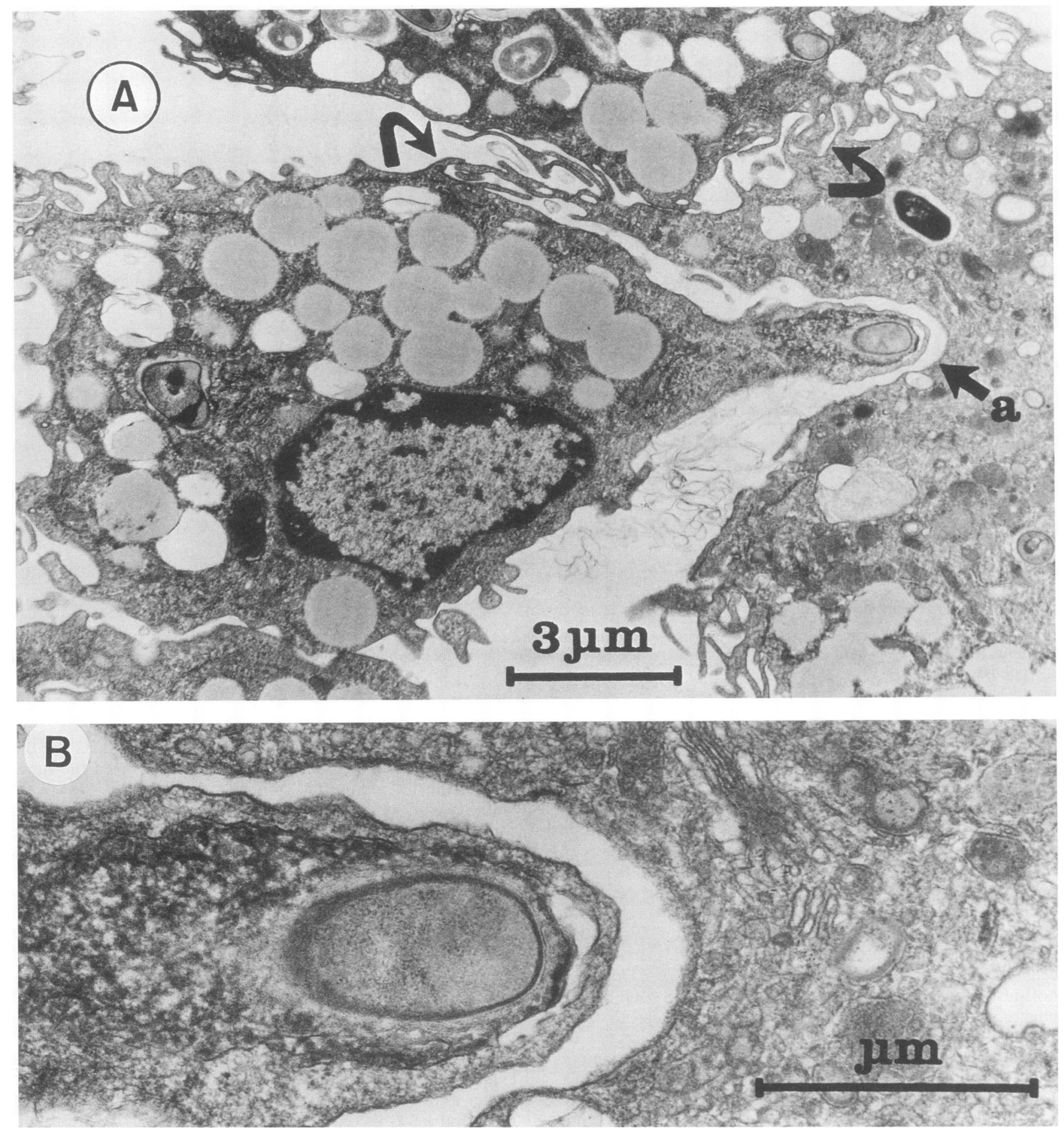

FIG. 5. Electron micrograph of cultured rabbit alveolar macrophages $24 \mathrm{~h}$ after infection with N. asteroides ATCC 14759. (A) Lowmagnification micrograph showing the nocardial cell migrating out from one macrophage and extending into an adjacent macrophage (straight arrow). Bent arrows indicate close physical contact among adjacent infected macrophages. (B) High-magnification insert from panel A (arrow a) showing that the nocardial cell appears to be surrounded by electron-dense material and is not closely associated with a phagosomal membrane. This process appears to be identical to that reported for intercellular movement of Listeria cells $(358,476,670)$. Reprinted from reference 57 with permission of the publisher. 
previous data on the relative virulence of these strains for mice $(54,80,83,84)$. Furthermore, the virulent strain, GUH-2, inhibited phagosome-lysosome fusion (Fig. 6A); the intermediately virulent strain, ATCC 14759 , only partially inhibited fusion; whereas the less virulent strain, ATCC 10905, was unable to inhibit fusion as shown by electron microscopy (208). Electron microscopy of infected macrophages demonstrated that the cells of GUH-2 were not damaged compared with cells of strain ATCC 10905, which exhibited considerable cellular destruction (208). The ability of $N$. asteroides GUH-2 to inhibit phagosome-lysosome fusion in alveolar macrophages was growth stage dependent in that log-phase cells were more effective at inhibiting fusion than were stationary-phase cells from the same culture (209). Specifically activated rabbit alveolar macrophages incubated with primed lymph node cells obtained from immunized rabbits, immune serum, and alveolar lining material were able to both decrease the number of viable organisms recovered and increase the incidence and extent of bacterial cell damage with the virulent strain GUH-2 (210) (Fig. 6B).

\section{Human PMNs and Monocytes}

PMNs and monocytes kill most microorganisms through either oxygen-independent or oxygen-dependent microbicidal mechanisms. Filice et al. (244) found that monocytes and PMNs from normal individuals killed $90 \%$ of Listeria monocytogenes and Staphylococcus aureus cells within $4 \mathrm{~h}$; however, for five strains of $N$. asteroides, the numbers of viable nocardiae after $4 \mathrm{~h}$ of incubation with PMNs and monocytes were only 10 and $21 \%$ less, respectively, than numbers of nocardial cells incubated without phagocytes. With the more virulent strain GUH-2, there was no reduction in CFU over this period with either PMNs or monocytes (244). The observation that chemiluminescence occurred when phagocytes encountered $N$. asteroides indicated that PMNs and monocytes were not able to kill $N$. asteroides even after the occurrence of an oxidative metabolic burst. However, it should be pointed out that the nocardiae induced a much less intense metabolic burst in PMNs than did Candida spp. (244). It was shown that this resistance of $N$. asteroides to the oxidative killing mechanisms of phagocytes was due in part, but not completely, to the relatively high level of catalase activity within the cells of virulent $N$. asteroides strains (243). Thus, the PMNs from humans killed $80 \%$ of the cells of less virulent $N$. asteroides ATCC 10905 but only $50 \%$ of the log-phase growth of the more virulent $N$. asteroides GUH-2 after 3 h; however, these PMNs were unable to kill early-stationary-phase cells of GUH-2 that contained 10 times more intracytoplasmic catalase than the log-phase cells of the same organism (73). After treatment of early-stationary-phase cells of $N$. asteroides GUH-2 with rabbit antibody specific for purified nocardial superoxide dismutase (SOD), the PMNs were able to kill more than $50 \%$ of the antibody-treated nocardial cells. In contrast, the PMNs were able to kill more than $90 \%$ of the cells of $L$. monocytogenes used as a control. The role of SOD in nocardial pathogenesis is discussed in more detail below. The results indicated that both nocardial SOD and catalase played a key role in the resistance of $N$. asteroides to PMNs (73). By using electron microscopy, Filice found that $N$. asteroides phagocytized by PMNs had no apparent cell damage (243). However, when fresh PMNs were continually added to in vitro preparations of PMNs infected with $N$. asteroides, there was an inhibition of filament formation from intracellular coccobacillary cells (243). Odell and Segal (497) found that at acid pH, $N$. asteroides was resistant to human neutrophil primary granule lysate obtained from either healthy controls or patients with chronic granulomatous disease. Thus, $N$. asteroides was resistant to nonoxidative killing mechanisms of PMNs as determined by CFU recovered after $60 \mathrm{~min}$ of incubation with granule lysates (497).

Studies with human monocytes maintained in vitro demonstrated that pretreatment of these phagocytes with either recombinant gamma interferon (rIFN- $\gamma$ ) or recombinant tumor necrosis factor alpha (rTNF- $\alpha)$ prior to infection with $N$. asteroides resulted in enhanced nocardial growth as measured by filament elongation. However, coincubation of rIFN- $\gamma$ or rTNF- $\alpha$ with $N$. asteroides during phagocytosis by human monocytes resulted in inhibition of nocardial growth even though the nocardiae were not killed. Therefore, the timing of the exposure of the phagocyte to either rIFN- $\gamma$ or rTNF- $\alpha$ had a significant effect on their ability to alter nocardial growth (96). It is known that monocytes exposed to factors that induce activation show changes in a number of characteristics including increased synthesis of lysosomal hydrolases. However, increased production of hydrolases such as acid phosphatase may enhance nocardial growth, since $N$. asteroides has been shown to use acid phosphatase as a carbon source and this enzyme synergistically enhanced filament elongation when glutamate was the only carbon source (98).

\section{IMMUNOBIOLOGY OF NOCARDIA INFECTIONS}

\section{Interactions in Germfree Animals}

Germfree N:NIH(S) mice were found by Beaman et al. (81) to be significantly more susceptible to dying of $N$. asteroides infection during the acute phase of infection after either intranasal or i.v. inoculation than were conventionally grown animals. Pretreatment of germfree mice with lipopolysaccharide increased host resistance to the level seen in conventionally grown animals that possessed a normal resident microflora. Infection in two organs, the lungs and the brain, was dramatically different in germfree mice from that in conventionally grown animals. The pulmonary response was significantly altered, and lipopolysaccharide treatment restored the host resistance to pulmonary infection. The rate of growth of GUH-2 in the brain of germfree N:NIH(S) mice was about 50 times greater than in normal mice. In infected germfree $\mathrm{N}: \mathrm{NIH}(\mathrm{S})$ mice pretreated with lipopolysaccharide, nocardial growth in the brain was retarded and the nocardiae were more rapidly eliminated than in conventionally grown mice (81). These data indicated that nonspecific activation of phagocytes in the brain, perhaps microglia, and activation of phagocytes in the lungs are important in nocardial clearance following infection $(69,81)$.

\section{Role of T Cells}

Nude mice (deficient in functioning $T$ cells) were found to be more susceptible to a chronic nocardial infection induced by i.v. injection with $N$. asteroides GUH-2 than were their heterozygous $(\mathrm{Nu} /+)$ littermates $(80)$. When nude mice were infected in the footpad with $N$. asteroides GUH-2, they developed a systemic infection and died within 4 weeks with little inflammation in the footpad, whereas the $\mathrm{Nu} /+$ mice developed extensive local lesions in the foot but did not die (80). Congenitally athymic mice infected intranasally or by inhalation with $N$. asteroides GUH-2 were more susceptible to nocardial infection than $\mathrm{Nu} /+$ littermates or Swiss Webster mice (82). This indicates that $\mathrm{T}$ cells are essential for an adequate host response against lethal infection with a virulent strain of $N$. asteroides. 
When $N$. caviae 112 was injected into normal and athymic mice by several different routes (89), the nude mice were more susceptible to lethal infection after intranasal administration than were their $\mathrm{Nu} /+$ littermates. However, chronic mycetomas following i.v. infection occurred more readily in immunocompetent mice, in which L-forms of $N$. caviae were observed, than in the nude mice, in which L-forms were not isolated (89). Apparently, functioning $\mathrm{T}$ cells are required for development of the granulomatous inflammatory response that results in mycetomas.

Deem et al. (211) adoptively transferred unprimed spleen cells, Nocardia-primed spleen cells, or Nocardia-primed splenic $\mathrm{T}$ cells from $\mathrm{Nu} /+$ to $\mathrm{Nu} / \mathrm{Nu}$ mice and infected the mice with $N$. asteroides GUH-2 2 days later. Adoptive transfer with either primed spleen cells or primed splenic $T$ cells enhanced the survival of the nude mice and increased their ability to eliminate $N$. asteroides from the liver, spleen, and brain. This indicates that cell-mediated immunity and $\mathrm{T}$ lymphocytes are important in host resistance to systemic nocardial infection (211).

Asplenic mice, which have a qualitative deficiency of T-cell function as well as a quantitative reduction in immunoglobulin levels in serum, were not as susceptible to lethal nocardial infection as were nude mice. However, asplenic mice could not eliminate nocardiae from infected kidneys as readily as their heterozygous littermates did (80).

The role of $\mathrm{T}$ cells in nocardial infection is thought to be primarily the activation of macrophages and stimulation of a cellular immune response. However, Deem et al. (212) showed that T lymphocytes may be involved directly in killing $N$. asteroides. They found that Nocardia-primed lymphocytes, but not normal lymphocytes (macrophage and B-cell depleted, T-cell enriched spleen cells) killed $N$. asteroides but not Rothia dentocariosa. Furthermore, there had to be a close association between the nocardial cell wall and the T-lymphocyte membrane as shown by light and electron microscopy (Fig. 7). Lysing the lymphocytes with anti-Thy-1.2 plus complement eliminated the ability to kill nocardiae (212). This may be important in host defense against the nocardiae that escape intracellular killing by activated macrophages.

\section{Role of B Cells and Antibody}

Although it is clear that $\mathrm{T}$ cells, macrophages, and cellmediated immunity are important in host resistance to Nocardia spp. $(57,58,80,82,89,210-212,245,650-652)$, there is less information on the role of B cells. Beaman and Maslan found that cyclophosphamide treatment of mice $72 \mathrm{~h}$ prior to infection dramatically increased host susceptibility to nocardial infection with strains ATCC 10905 and ATCC 14759 but less so with the virulent strain GUH-2 (83). Cyclophosphamide is a polyfunctional cytotoxic agent that can affect B-lymphocyte function. Beaman et al. (79) infected immunized and nonimmunized B-cell deficient $\mathrm{CBD} 2 / \mathrm{F}_{1}(\mathrm{CBA} / \mathrm{N} \times \mathrm{DBA} / 2)$ mice with $N$. asteroides GUH-2 by different routes of infection. The $F_{1}$ males that were unable to produce nocardia-specific antibody were not more susceptible to infection than female littermates with an intact B-cell system (79). Preimmunized male or female mice that expressed normal cell-mediated responses were equally able to clear $N$. asteroides from their adrenals, brains, kidneys, livers, lungs, and spleens. Thus, the requirement for functioning $B$ cells in host resistance to nocardial infection was not shown to be as important as the requirement for functioning $\mathrm{T}$ cells (79).

Rico et al. (552) found that transfer of nocardia-specific antibody into immunologically normal or T-cell-deficient mice (thymectomized, lethally irradiated adult mice reconstituted with T-cell-depleted bone marrow) did not protect the mice from development of mycetomas following footpad injection of $N$. brasiliensis. In fact, the passive transfer of antibody along with the injection of antibody-coated nocardiae magnified the severity of the subsequent symptoms. Lethally irradiated mice, reconstituted with spleen cells depleted of B lymphocytes that bore receptors for nocardial antigenic extract, lacked the ability to form antibodies to nocardial antigen; however, these mice had a positive delayed hypersensitivity response to nocardial extract (supernatant obtained after Ribi cell fractionator treatment of the nocardiae) and were more effective in controlling their nocardial infection than were T-cell depleted mice (552). Ortiz-Ortiz et al. concluded that cellular immunity mediated by $\mathrm{T}$ cells, not B cells and antibody, was an essential mechanism for defense against $N$. brasiliensis infection (507).

\section{Effects of Lymphokines and Cytokines}

The nocardial cell wall contains structural components that modulate lymphokines and cytokines in such a manner as to affect the host response to these organisms. Of these components, Nocardia rubra (now classified as Rhodococcus rubra) cell wall skeleton (N-CWS) has been studied extensively, and it was found to augment the production of interleukin-1 (IL-1) from peritoneal macrophages in mice (332). Prostaglandin $E_{2}$ inhibited the augmentation of IL-1 production and indomethacin increased IL-1 production by N-CWS-stimulated macrophages. N-CWS had been shown to have antitumor activity in experimental animals. After it was found that N-CWS stimulated IL-1 production, the fever occurring as a side effect of $\mathrm{N}-\mathrm{CWS}$ treatment of tumors was believed to be due to the production of IL-1 acting as an endogenous pyrogen (500). The culture supernatants of guinea pig peritoneal macrophages pretreated with N-CWS had L-929 cell-killing activity resembling that of TNF (501). Gel filtration of the culture supernatants on Sephadex G-200 showed that the fractions with lymphocyte-activating activity (IL-1) were not the same as

FIG. 6. Electron micrographs of activated alveolar macrophages from immunized rabbits infected with $N$. asteroides GUH-2. The lysosomes were labeled with horseradish peroxidase prior to incubation with the nocardiae. (A) $N$. asteroides completely inhibited phagosome-lysosome fusion in macrophages incubated in the presence of $20 \%$ normal rabbit serum. Note that there is no ultrastructural evidence of damage to the nocardiae and that there is no horseradish peroxidase within the phagosome. The asterisk shows a granular zone surrounding the nocardiae evident in the cytoplasm of the macrophage with an apparent loss of cytoplasmic and microfilament organization in the vicinity of the phagosomes. Arrows indicate that the intact phagosomal membrane is tightly adjacent to the outer layer of the nocardial cell wall. (B) Occurrence of both phagosome-lysosome fusion and nocardial cell destruction in activated macrophages incubated with $20 \%$ immune rabbit serum with complement, alveolar lining material, and specifically primed lymph node lymphocytes from rabbits immunized with formalin-killed cells of $N$. asteroides GUH-2. Arrows indicate the phagosomal membrane surrounding the ingested nocardiae. Note the electron-dense horseradish peroxidase label within phagosomes, showing that phagosome-lysosome fusion had occurred. Most of the nocardial cells show ultrastructural evidence of damage. There is no granular zone as seen in panel A, but, instead, microfilament and cytoplasmic organization appear intact. Reprinted from reference 210 with permission of the publisher. 

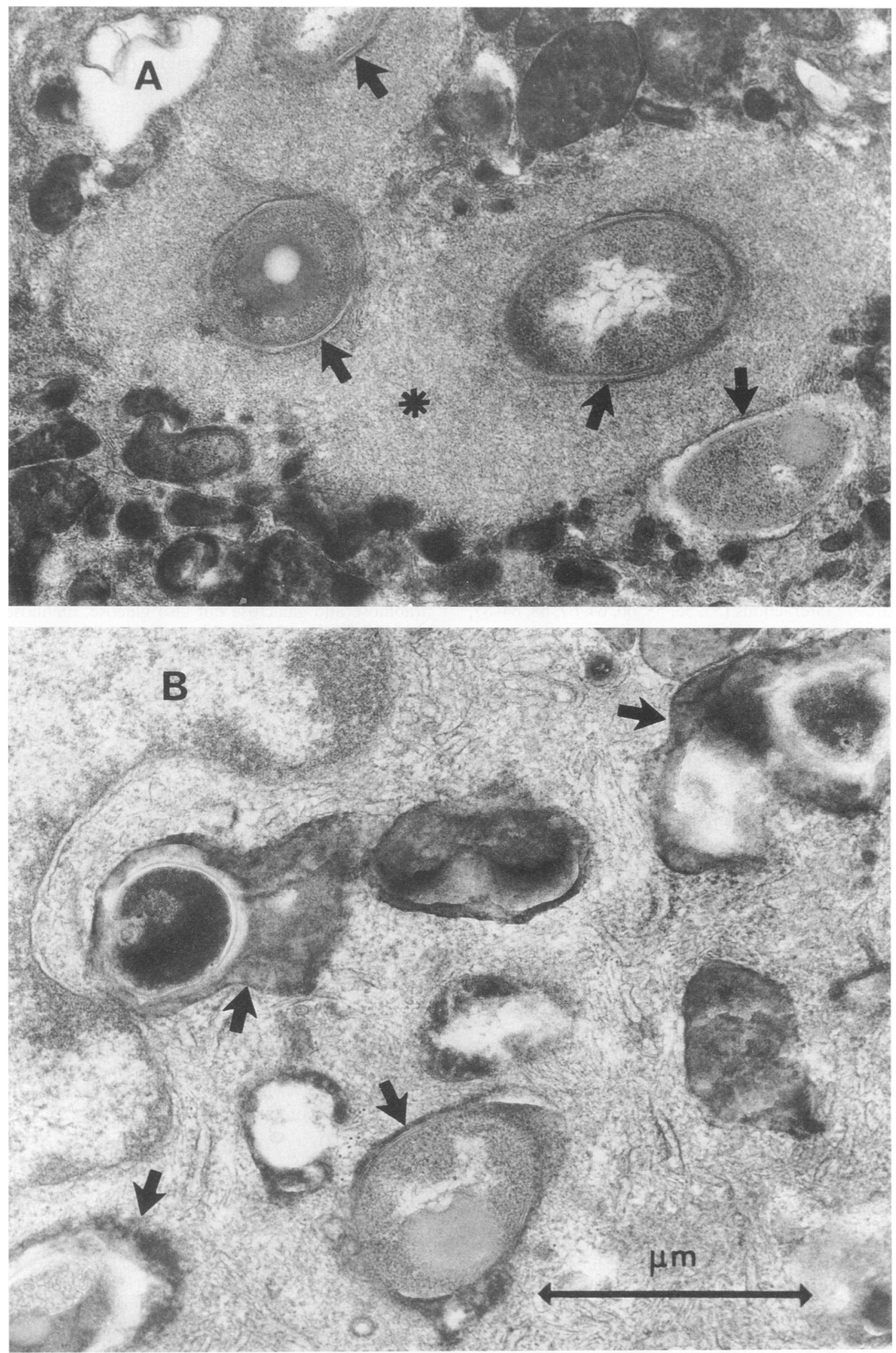
those with cytotoxic activity. N-CWS-sensitized T lymphocytes stimulated with N-CWS were found to produce colony-stimulating factor (306). Several fractions derived from Nocardia opaca (Rhodococcus opaca) have been shown to have immunomodulating properties, including the enhancement of natural killer cell activity (45). The fractions were thought to stimulate the production of IFN- $\alpha$ and IFN- $\beta$, which enhanced natural killer cell activity (45). It is not known whether N-CWS from $N$. asteroides cell wall fractions have effects similar to N-CWS of N. rubra or N. opaca (136); however, all of these organisms have similar basic cell wall components $(199,200)$.

By using the same methods described for N. opaca (136), an extract of $N$. brasiliensis was found to be mitogenic for murine $\mathrm{B}$ lymphocytes (508). In addition, TNF activity was detected in sera from mice infected with $N$. brasiliensis, and treatment of infected mice with antibody for TNF increased the number of CFU recovered from spleens and livers (614). This suggests a role for TNF in resistance to $N$. brasiliensis infection (613).

\section{MECHANISMS OF NOCARDIA PATHOGENESIS}

\section{Nocardia Cell Envelope: Ultrastructure and Biochemistry}

The cell envelope of Nocardia spp. is a dynamically changing and complex structure that undergoes both ultrastructural and chemical modification during growth (Fig. 8). These changes in structure result in alterations of cell surface characteristics, of cell-cell interactions, and of specific growth patterns, which, as a consequence, have significant effects on nocardial virulence and host-parasite interactions $(55,56,58,60,64,67,68,84-87$, 91, 695).

By growing standardized cultures of Nocardia spp. in broth followed by differential centrifugation, homogeneous preparations consisting of suspensions of single cells at specific phases of growth can be obtained $(55,84)$. Cells of different strains of $N$. asteroides at specific growth phases have been studied by using these methods of preparation. It was shown that cells of $N$. asteroides at each phase of growth differed from each other in their virulence for mice, toxicity to host cells, host-parasite interactions both in vivo and in vitro, and ultrastructure and chemical composition of the cell envelope $(58,60,67,76$, $84-87,93,209)$. Thus, the coccoid cells characteristic for the stationary phase of growth were consistently less virulent and less toxic than were the filamentous, logarithmically growing cells from the same organism $(58,84,93)$. Furthermore, some strains of $N$. asteroides were significantly less virulent at all stages of growth than other isolates of $N$. asteroides (93). On the basis of these observations, strains of $N$. asteroides that differed in their virulence were used to study further the relationships of cell wall composition to pathogenicity.

The peptidoglycan layer of the cell wall of Nocardia spp. is structurally similar to that found in Mycobacterium and Rhodococcus spp. (29). The basal glycan consists of $\beta-N$-acetylglucosaminyl-1,4- $N$-glycolylmuramic acid with L-alanine linked to the carboxyl group of $N$-glycolylmuramic acid (30). The amino acid side chains consist of diamidated L-alanine-D- $\alpha$-glutamine-meso-DAP tripeptides and L-alanine-D- $\alpha$-glutaminemeso-DAP-D-alanine tetrapeptides $(29,688)$. These tetrapeptides are cross-linked by direct linkage between the D-alanine of one polymer to the meso-DAP of the adjacent polymer or by linkages between adjacent meso-DAP residues $(199,200,464$, 688). In most strains of $N$. asteroides, the peptidoglycan represents only 20 to $25 \%$ of the total cell wall mass $(76,86)$; however, at certain stages of growth (stationary phase) in some Nocardia strains, it may make up as much as $45 \%$ of the cell wall (55). As in mycobacterial cell walls, the peptidoglycan is then attached by way of a phosphodiester linkage to the arabinose portion of an arabinogalactan polymer. Some of the arabinose residues of this arabinogalactan are esterified to a mycolic acid molecule, thus forming a large peptidoglycanarabinogalactan-mycolate complex $(55,76,86,200,464,688)$. Portions of this structure (especially the arabinogalactan) are immunogenic and possess epitopes that are shared with Mycobacterium, Rhodococcus, and Corynebacterium spp. (199, 200).

The cell envelope of Nocardia spp. does not contain teichoic acid, but it does have a large number of other substances either loosely or covalently associated with the peptidoglycan-arabinogalactan-mycolic acid complex. Between 15 and $25 \%$ of the cell wall consists of nonpeptidoglycan amino acids that represent peptides or proteins either alone or linked to lipid to form lipoproteins, peptidolipids, or glycolipoproteins $(55,76,86,87$, 469). The cell walls of most nocardiae contain not only arabinose and galactose but also glucose, mannose, and inositol $(55,76,86,87,371)$. Most strains of $N$. asteroides contain trehalose which is usually linked to two molecules of mycolic acid in the $6,6^{\prime}$ positions $(24,86,87,333-336,412,469,614)$. This trehalose-6,6'-dimycolate (cord factor) has specific biologic activity; it is toxic, it inhibits calcium-dependent membrane fusion, it inhibits phagosome-lysosome fusion in macrophages, and it appears to be associated with nocardial virulence $(336,615,629,630,661,729)$. Furthermore, there are specific additional fatty acids and mycolic acids firmly linked to the cell wall. Among these is a significant amount of 10 -methyl stearic acid (tuberculostearic acid) that is uniquely found in the envelope of Mycobacterium, Nocardia, and Rhodococcus spp. and a few additional but closely related actinomycetes (24, 469). The cell envelope of nocardiae also contains an ironbinding secondary hydroxymate (nocobactin), long-chain ketones (nocardones), and a variety of unidentified substances $(464,469,548)$. Clearly, the cell envelope of Nocardia spp. is chemically complex and its structure and composition are not yet completely defined.

Electron microscopy combined with biochemical analysis reveals that the nocardial cell wall is a multilayered structure, with all of its constituents being altered during its growth cycle (thus there are growth stage-dependent alterations in structure and chemical composition [Fig. 8] [55, 84, 86, 91]). Polysac-

FIG. 7. Electron micrographs of Nocardia-primed T lymphocytes from BALB/c mice immunized with $N$. asteroides GUH-2. These T cells were purified from spleens of immunized animals by first removing B lymphocytes by the panning technique with rabbit anti-mouse kappa light-chain antibody and then removing macrophages with carbonyl iron powder and bar magnets. This T-cell-enriched population was purified further by an indirect panning technique with monoclonal antibody against Thy-1.2. The $\mathrm{T}$ lymphocytes were characterized by the detection of specific cell surface markers combined with their inactivity in natural killer cell assays. They were incubated with cells of $N$. asteroides GUH-2 for 6 h. (A and B) Close association between the nocardial cell and the cytoplasmic membrane of the $\mathrm{T}$ cell (curved arrows). There is electron-microscopic evidence of damage to the nocardial cells (straight arrows in panel B). Viability assays demonstrated that the nocardial cells were killed by these lymphocytes. This direct lymphocyte-mediated killing occurred in the absence of antibody and complement. Furthermore, the nocardial killing was abrogated by treating the lymphocytes with monoclonal anti-Thy-1.2 plus complement. Bar, $1.0 \mu \mathrm{m}$. Reprinted from reference 212 with permission of the publisher. 

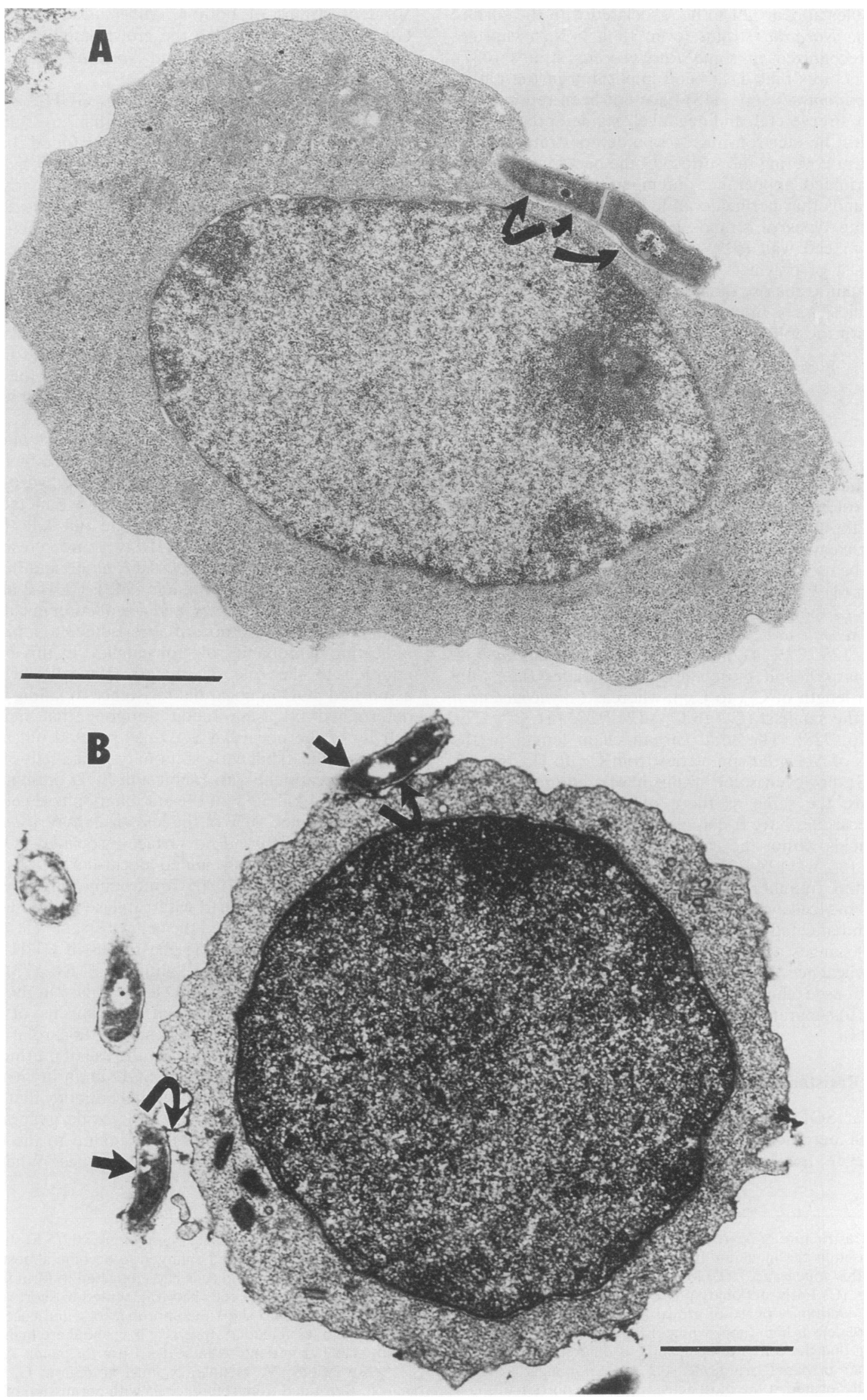
charide capsules appear not to be associated with the surface of pathogenic Nocardia strains, even though such capsules have been recognized in some Rhodococcus strains (487). Pilus-like structures that have been implicated in the pathogenesis of Actinomyces spp. (113) have not been reported for Nocardia spp. Freeze-etch and negatively stained preparations visualized with the electron microscope demonstrate that the outermost layer covering the surface of the bacterial cell has a folded or wrinkled appearance interspersed with numerous rope-like strands that permeate all levels of the cell wall (55, 91). The same types of strands have been reported in the Mycobacterium cell wall (91), and it is believed that these "ropes" consist of polymers of mycolic acids and that they probably contain trehalose dimycolates (279).

Mycolic acids are $\alpha$-branched, $\beta$-hydroxylated, long-chain fatty acids with the following general formula $(128,334,728)$ :

$$
\begin{array}{rl}
\beta \text { chain } & \\
\mathrm{R}-\mathrm{HO} & \mathrm{C}-\mathrm{H}-\mathrm{C}-\mathrm{COOH}
\end{array}
$$

Methyl ester derivatives of this molecule undergo pyrolytic cleavage at the central bond at $300^{\circ} \mathrm{C}(128,334,728)$. A fatty acid methyl ester results from the $\alpha$ chain, and an aldehyde results from the $\beta$ chain $(24,275,412,420)$. The products of this pyrolytic cleavage are characteristic for a specific mycolic acid and can be used to differentiate the genera of bacteria that possess them $(412,420)$. Mycolic acids are uniquely found in the cell walls of the genera Mycobacterium, Nocardia, Rhodococcus, Corynebacterium, Caseobacter, Gordona, and Tsukamurella $(24,128,275,412,420,728)$. Mycobacterium spp. contain the largest and most complex mycolates (i.e., total carbon chain length of $\mathrm{C}_{60}$ to $\mathrm{C}_{90}$ ), whereas Corynebacterium spp. possess the smallest $\left(C_{22}\right.$ to $\left.C_{36}\right)(24,128,151,275,279$, $333,420,676,728)$. The total carbon chain length of the mycolic acids of Nocardia spp. varies from $\mathrm{C}_{44}$ to $\mathrm{C}_{60}(86,87$, $128,334,728$ ); however, some strains have additional mycolic acids that are the same as those of Corynebacterium spp. (87). The nocardiae have a complex mixture of various sizes of mycolic acids within the same cell at any point in their growth cycle $(86,87,128,334,728)$. Both the size and degree of unsaturation (number of double bonds) of the mycolic acids within the cell wall of $N$. asteroides are growth stage dependent and affected by the temperature of growth $(86,87$, 671). These changes appear to correspond to differences in toxicity and virulence $(86,87,336)$. Furthermore, some investigators have used these variations in size and degree of unsaturation to separate the nocardiae into taxonomic groupings $(151,728)$.

\section{SOD and Resistance to Oxidative Killing by Phagocytes}

Intracellular SOD serves a protective role against oxygen toxicity in all aerobic organisms by scavenging superoxide $\left(\mathrm{O}_{2}{ }^{-}\right)$; however, few bacteria secrete SOD during growth.
Virulent strains of both $M$. tuberculosis and $N$. asteroides GUH-2 secrete SOD into the growth medium, whereas nonpathogenic Mycobacterium and Nocardia strains do not (90, 406).

The log-phase cells of $N$. asteroides GUH-2 are as much as 1,000 times more virulent for mice than are stationary-phase cells from the same culture (84). It was found that the rate of secretion of SOD into the culture medium by GUH-2 was significantly higher on a per-cell basis during early growth than during the stationary phase. Furthermore, the SOD secreted by Nocardia spp. was unique in that it contained three metals ( $\mathrm{Fe}, \mathrm{Mn}$, and $\mathrm{Zn}$ ) in equimolar ratios, but its amino acid composition appeared to be more closely related to that of the Mn-containing enzymes of Mycobacterium spp. (90). Beaman et al. (90) found that this SOD had a molecular weight of approximately 100,000 and that it was composed of four equal subunits (molecular weight, 25,000) that were not covalently joined. Immunofluorescent staining specific for $N$. asteroides SOD indicated that the enzyme was associated with the outer cell wall of GUH-2 (90).

The interaction of phagocytes with most microorganisms results in an oxidative burst as demonstrated by the release of oxygen metabolites such as superoxide and hydrogen peroxide. $N$. asteroides GUH-2 induced an oxidative metabolic burst in PMNs; however, the leukocytes did not kill the nocardiae (244). It was shown that GUH-2 was more resistant than $S$. aureus to the lethal effects of $\mathrm{H}_{2} \mathrm{O}_{2}$ alone and in combination with lactoperoxidase and iodide (242). GUH-2 also had more catalase than did $S$. aureus, and a reduction in catalase activity by inhibitors reduced nocardial resistance to leukocyte killing, indicating a probable role for catalase in this effect (73). In addition to the role of catalase, the role of the surfaceassociated SOD in nocardial resistance to killing by PMNs was determined by using rabbit antibody that neutralized the activity of the nocardial SOD. As pointed out above, PMNs were not able to kill early-stationary-phase cells of GUH-2, but after pretreatment with rabbit anti-SOD antibody the PMNs were able to kill $50 \%$ of the stationary-phase cells within $3 \mathrm{~h}$. The PMNs killed $80 \%$ of the less virulent $N$. asteroides ATCC 10905 cells, which had no surface-associated SOD (73). Furthermore, exogenously added nocardial SOD partially protected strain ATCC 10905 from being killed by PMNs, and nocardial SOD combined with catalase had an additive effect that completely protected the cells of strain ATCC 10905 (73). Addition of catalase to log-phase cells of GUH-2 resulted in complete protection from killing by PMNs (73). These data indicated a role for both SOD and catalase in the resistance of nocardiae to the microbicidal mechanisms of PMNs (73). Further proof of the importance of nocardial cell surfaceassociated SOD was obtained by the use of murine monoclonal antibodies specific for GUH-2 SOD in an in vivo model (95). An anti-nocardial SOD monoclonal antibody that inhibited the activity of nocardial SOD on superoxide generation in vitro was prepared (95). This antibody bound to the bacterial cell surface as shown by immunofluorescence. When mice were

FIG. 8. Ultrastructure of $N$. asteroides ATCC 14759 during its growth cycle in BHI broth. (A) Mid-lag phase of growth (5 h) showing that the coccoid cells used as the inoculum had increased in size and the outer layers of the cell envelope had enlarged to become almost capsular (not every cell had this appearance). (B) Mid-log phase of growth $(16 \mathrm{~h}$ ) showing that $100 \%$ of the coccoid cells had elongated to form filaments, some with branching. (C) Early stationary phase of growth $(55 \mathrm{~h})$ showing that most of the filamentous cells had fragmented to short rods or coccoid cells. (D) Late stationary phase of growth $(168 \mathrm{~h})$ showing that the cells had fragmented into short pleomorphic rods and cocci. The percent viability of these cells is high (approximately $100 \%$ of the cells will grow if transferred to fresh media). Inserts a, $b$, c, and $d$ are high-magnification inserts showing that the cell envelope profile is different at each stage of growth. The bar in panel A indicates $1 \mu \mathrm{m}$ for panels A, B, C, and D, whereas the bar in panel b indicates $0.2 \mu \mathrm{m}$ for panels a, b, c, and d. Abbreviations: V, vacuole; N, nuclear region; G, granular zone characteristically located at the most actively growing portion of the nocardial cell. Reprinted from reference 55 with permission of the publisher. 


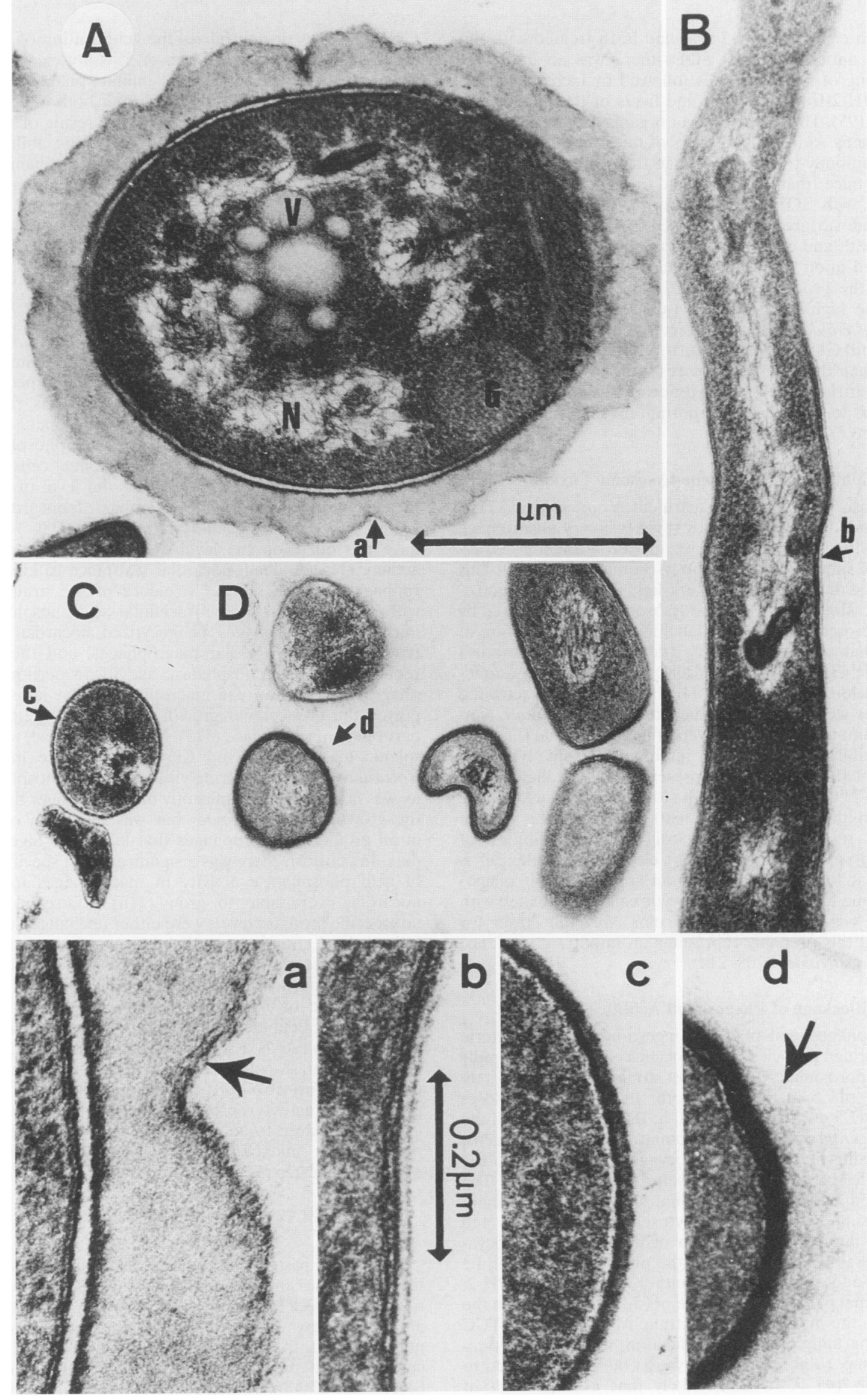


injected with cells of GUH-2 that had been treated with this monoclonal antibody against SOD, there was an initial enhanced killing of nocardial cells followed by increased clearance of GUH-2 from the lungs and livers of the mice over a 48 -h period (95). Thus, at $48 \mathrm{~h}$ fewer organisms were recovered from the brains, kidneys, and livers of mice that had received anti-SOD antibody-treated nocardiae than from these organs of control mice that had received antinocardial antibody nonreactive with SOD (95). Therefore, in this system, the secreted and surface-associated SOD of GUH-2 probably interacted with and catalyzed the dismutation of the superoxide produced upon contact with phagocytes. This interaction resulted in the production of $\mathrm{H}_{2} \mathrm{O}_{2}$, which was then broken down by the high levels of catalase present in the cells of virulent $N$. asteroides strains. The fact that the controls, GUH-2 in saline and GUH-2 treated with antibody to cell surface antigens other than SOD, were resistant to killing in mice indicated that the SOD protected nocardiae in vivo, and thus SOD appears to represent an important mechanism for nocardial virulence $(73,95)$.

\section{Inhibition of Phagosome-Lysosome Fusion}

Phagocytosis of cells of the avirulent $N$. asteroides ATCC 10905 was found to be followed by rapid fusion of macrophage lysosomes with phagosomes; however, the virulent $N$. asteroides GUH-2 inhibited phagosome-lysosome fusion (208). This effect was first demonstrated by dark-field fluorescence microscopy with acridine orange-labeled lysosomes and confirmed by electron microscopy (Fig. 6) by labeling primary (detection of acid phosphatase) or secondary (detection of horseradish peroxidase-labeled) lysosomes (208). Increased phagosomelysosome fusion occurred with GUH-2 only when activated macrophages were infected in the presence of immune lymphocytes, immune serum, and alveolar lining material (Fig. 6B) (210). The ability of GUH-2 to inhibit phagosome-lysosome fusion may be due in part to the presence of $\alpha, \alpha$-trehalose- $6,6-$ dimycolate (TDM) in the cell wall (for further discussion, see elsewhere in this review) $(629,630)$. However, the precise mechanisms responsible for nocardia-induced inhibition of phagosome-lysosome fusion are not clear. Nevertheless, it is apparent that the ability of Nocardia spp. to inhibit phagosome-lysosome fusion within phagocytic cells is associated with the relative virulence of the particular Nocardia strain for animals, and this probably represents an important virulence factor for $N$. asteroides (208-210).

\section{Blockage of Phagosomal Acidification}

The intraphagosomal $\mathrm{pH}$ after ingestion of most bacteria and other foreign particles by phagocytic cells becomes rapidly lowered to approximately $\mathrm{pH} 5$. Most strains of $N$. asteroides do not grow at pH 5 in buffered broth. In fact, GUH-2 loses viability at $\mathrm{pH} 5$ over a period of $50 \mathrm{~h}$. Black et al. studied the effect of Nocardia spp. on phagosomal pH in murine macrophages by using fluorescein isothiocyanate conjugated to the surface of the bacteria as a pH-sensitive probe (117). The fluorescent emission within individual phagosomes was quantitated by using a computerized cytospectrophotometer, and because the fluorescence spectrum of fluorescein isothiocyanate changes as a function of $\mathrm{pH}$, the phagosomal $\mathrm{pH}$ can be calculated. Following ingestion of either live or dead GUH-2, the phagosomal $\mathrm{pH}$ remained above $\mathrm{pH} 7$ for $2 \mathrm{~h}$ (117). On the other hand, the nonpathogenic strain $N$. asteroides ATCC 19247 only partially blocked acidification, whereas with Saccharomyces spp. (a nonpathogenic yeast) the $\mathrm{pH}$ decreased to approximately $\mathrm{pH}$ 5. It seems likely that a component of
GUH-2 blocks or neutralizes the acidification of phagosomes in murine macrophages. However, it is not clear whether this substance is the same one that inhibits phagosome-lysosome fusion, because acidification may occur both independently of phagosome-lysosome fusion and as a result of phagosomelysosome fusion (117). In any event, this ability to block acidification is probably an important mechanism for the intracellular survival of $N$. asteroides in macrophages.

\section{Modulation of Phagosomal Function and Lysosomal Content}

Black et al. $(115,116)$ found that the growth of virulent strains of $N$. asteroides within macrophages affected the levels of lysosomal enzyme activity. The activity of acid phosphatase in individual macrophages was quantitated by means of a computer-assisted cytospectrophotometry system, and then the same samples were counterstained with the Gram stain. With the assistance of this computer-operated cytospectrophotometer, the number of ingested nocardiae was recorded for individual macrophages in which acid phosphatase levels had previously been measured $(115,116)$. Acid phosphatase activity was decreased in alveolar and peritoneal cells after infection with $N$. asteroides GUH-2, and the level of activity was inversely proportional to the number of nocardial cells ingested. Killed nocardiae and $N$. asteroides ATCC 10905 did not have this effect on the level of lysosomal acid phosphatase activity (115). Indeed, nocardial resistance to killing by macrophages and the relative virulence of the strain correlated with its ability to reduce intracellular acid phosphatase levels. Peritoneal macrophages phagocytized nocardial cells more readily than did alveolar macrophages, and there was less reduction of acid phosphatase activity in peritoneal macrophages than in alveolar macrophages. The latter cells supported the intracellular growth of nocardiae better than did peritoneal macrophages (115). When peritoneal, alveolar, and splenic macrophages and Kupffer cells were infected with Nocardia strains of differing virulence, acid phosphatase activity was not changed significantly in macrophages that inhibited the growth of $N$. asteroides but was increased or enhanced in all groups of macrophages that killed the ingested nocardiae. In contrast, there was a significant and specific reduction of acid phosphatase activity in macrophages in which the nocardiae were able to grow (116). Lysozyme levels and nonspecific protease levels were either unchanged or increased following infection by nocardial cells even in macrophages that had lost most of their acid phosphatase activity (118). This indicated that acid phosphatase was not lost because of degranulation or lysosomal membrane leakage. To explain these results, Beaman et al. found that strain GUH-2 utilized acid phosphatase as a sole carbon source (98). Furthermore, acid phosphatase combined with glutamate enhanced nocardial growth in vitro (98). Therefore, the decrease in acid phosphatase activity observed in macrophages infected with GUH-2 appeared to be due to the ability of this organism to preferentially metabolize acid phosphatase during growth within phagocytes $(72,98)$.

\section{Role of Toxins in Nocardial Pathogenesis and Host-Parasite Interactions}

During the past 100 years, there have been sporadic reports that nocardiae injected into experimental animals induced toxic responses. However, until recently, attempts to isolate and identify exotoxins from pathogenic Nocardia strains were not successful. In 1990, Mikami and colleagues reported that certain strains of $N$. otitidiscaviarum secreted a potent toxin $(465,494)$. This toxin, named HS-6, was shown chemically to 
be a 16-member macrocyclic compound with a molecular formula of $\mathrm{C}_{43} \mathrm{H}_{68} \mathrm{O}_{12}$ (molecular weight, 776) (465). The $\mathrm{LD}_{50}$ of HS-6 toxin for mice was $1.25 \mathrm{mg} / \mathrm{kg}$, and the $50 \%$ effective dose $\left(E D_{50}\right)$ for L1210 cultured cells was $0.3 \mathrm{ng} / \mathrm{ml}$ (465). Furthermore, HS-6 caused significant damage to the pancreas, liver, stomach, small intestine, heart, thymus, and kidneys in ICR mice $(465,494)$. Electron microscopy revealed that HS-6 induced autophagic vacuoles in the rough endoplasmic reticulum in pancreatic acinar cells, in hepatocytes in the liver, in Paneth's cells in the intestine, in smooth muscle, and in cells in urinary tubules (665). These cellular changes occurred within $20 \mathrm{~min}$, and both the size and numbers of the autophagic vacuoles expanded over a $24-\mathrm{h}$ period. In addition, an intraperitoneal injection of HS-6 induced a granulomatous response in the pancreas, liver, and regional lymph nodes in the animals (665). Even though this toxin caused considerable damage to host tissues, Terao et al. (665) suggested that it might not play an important role in nocardial pathogenesis. They noted that cells of the toxin-producing strain of $N$. otitidiscaviarum injected into mice did not induce the same autophagocytic cellular responses and that the experimental infection caused by the live nocardiae was different from damage caused by the toxin (665). Nevertheless, it seems likely that the HS-6 toxin may have significant effects on host cells during invasion by toxin-producing strains of $N$. otitidiscaviarum.

Another group of toxins produced by some strains of nocardiae may be hemolysins. Although many clinical isolates of Nocardia spp. do not appear hemolytic on blood agar, some strains of $N$. asteroides, $N$. brasiliensis, and $N$. otitidiscaviarum exhibit various degrees of either alpha or beta hemolysis against erythrocytes (RBCs) from a variety of animals (53, 229, 624). Smith and Hayward (624) suggested that beta-hemolytic strains of $N$. otitidiscaviarum were more pathogenic for mice than were nonhemolytic strains of $N$. asteroides. In their study, five of seven strains of $N$. otitidiscaviarum were beta hemolytic on ox and rabbit blood but not on horse blood, and these isolates were most pathogenic for mice. None of the four strains of $N$. asteroides showed hemolytic activity against any of the types of RBC tested (624). In a more recent study, Emerueva described a beta hemolysin isolated from $N$. asteroides 55 (229). This beta hemolysin was localized within the bacterial cell, and it was purified from crude cell wall preparations, suggesting that it was cell wall associated (229), which was in contrast to the hemolysin secreted into the growth medium by $N$. otitidiscaviarum $(229,624)$. The hemolysin isolated from the cell wall fraction of $N$. asteroides 55 was a protein that had hemolytic activity against the RBCs of sheep, humans, and cows but it was inactive against the RBCs from rabbits, rats, dogs, mice, chickens, guinea pigs, horses, or pigs (229). Thus, the hemolytic activity of the N. asteroides hemolysin had a different specificity for RBCs than did the activity of the hemolysin secreted by $N$. otitidiscaviarum $(229,624)$.

Analysis and characterization of the $N$. asteroides hemolysin showed that it was toxic for mice, resulting in the death of the animals $24 \mathrm{~h}$ after intraperitoneal injection (229). Furthermore, it appeared to have increased hemolytic activity when isolated from coccoid, stationary-phase cells compared with the filamentous cells. Thus, the specific activity of the hemolysin appeared to be growth stage dependent (229). In addition, the activity of this hemolytic protein toxin was relatively $\mathrm{pH}$ stable (optimal activity at $\mathrm{pH} 7$ ), sensitive to temperature (optimal activity at $37^{\circ} \mathrm{C}$ ), sensitive to catabolite repression, affected by the levels of $\mathrm{Ca}^{2+}$ and $\mathrm{Na}^{+}$ions in the media, and immunogenic in rabbits (229). However, its role, if any, in nocardial pathogenesis is not known.

\section{Role of Mycolic Acids in Nocardia-Host Interactions}

A group of biologically active and toxic glycolipids have been identified on the surface of bacterial cells of Corynebacterium, Mycobacterium, Nocardia, and Rhodococcus spp. (24, 86, 120, $226,227,279,333,335,336,491,614,615,630,729)$. Most of these are composed of large hydroxylated fatty acids (mycolic acids as described above) esterified to the disaccharide trehalose to form a trehalose glycolipid (279). The most extensively studied of these glycolipids is TDM. Because it was thought that there was a relationship among mycobacterial virulence, serpentine cord formation of virulent cells of $M$. tuberculosis, and the presence of TDM, this glycolipid was named cord factor $(120,491)$.

Cord factors have been shown to exhibit a myriad of biological activities both in vitro and in vivo (279). Microgram amounts of cord factor emulsified in mineral oil are lethal for mice $(279,336,615,617)$. Furthermore, cord factors alter leukocyte migration, have antitumor activity, serve as immunomodulators, are toxic to mitochondria, and induce foreign body granulomas (i.e., are granulomogenic) $(279,355)$. Also, particles coated with cord factors may interact with the coagulation system in a manner that permits them to become systemically disseminated (550). It is not within the scope of this review to discuss the extensive literature concerning cord factors; therefore, for more information, please refer to the recent review by Goren (279).

There have been relatively few studies on the biological activities of cord factors isolated from Nocardia spp. (sensu stricto), and most of the research on these compounds involved substances isolated from either Mycobacterium spp. or the rapidly growing, soft colony nocardiae (Rhodococcus spp.) (24, $86,120,226,227,279,333,335,336,491,614,615,630,729)$. Tamplin and McClung (661) reported that there appeared to be a relationship between the cellular content of TDM in $N$. asteroides and virulence. Strains that contained larger amounts of TDM were more virulent for mice than were those that had little or no TDM (661). Silva et al. (615) demonstrated that cord factor purified from $N$. asteroides, suspended in mineral oil, and injected intraperitoneally in mice caused a lethal, wasting form of disease. In addition, cord factor induced hypertriglyceridemia and depressed glucose levels in plasma in these animals (615). Silva et al., like most other investigators studying the toxicity of cord factors, used TDM emulsified in mineral oil (615). Although it is clear that TDM is lethal for mice when prepared in this manner, the role of the mineral oil emulsion in augmentation of the host response to TDM is not understood, since $N$. asteroides TDM incorporated into liposomes composed of phospholipids does not induce the same lethal response (53). Furthermore, cord factors injected into mice in a pure form in aqueous suspension do not appear to be toxic but, instead, activate effector cells of the immune system (279). The biological effects of TDM and its toxicity in mineral oil depend on the concentration of TDM emulsified in the oil (i.e., larger amounts of TDM in mineral oil are less toxic than smaller amounts) as well as the manner in which the cord factor is administered. Thus, a single large injection is not as toxic as a series of small injections, and a single injection of TDM in mineral oil is more toxic if either preceded or followed by an injection of mineral oil without TDM (279). Furthermore, it should be noted that TDM in mineral oil is lethal only for certain strains of mice and that most other animal species appear to be more resistant to the toxicity of cord factor (279).

Even though some of the toxicity ascribed to TDM may be an artifact of the method of administration, it is not inert 
biologically (279). Cord factors from $N$. asteroides were shown to be membrane interactive and were inserted easily into phospholipid bilayer vesicles (630). TDMs from $N$. asteroides GUH-2 altered the biophysical properties of phospholipid vesicles (liposomes) and strongly inhibited calcium-induced membrane fusion (630). Furthermore, liposomes containing this glycolipid inhibited phagosome-lysosome fusion of particles phagocytized by human monocytes in vitro (629). Spargo demonstrated that cord factors appeared to be responsible for the inhibition of phagosome-lysosome fusion reported in virulent strains of $N$. asteroides (629). Thus, these cord factors are abundant in the virulent $N$. asteroides GUH-2, which inhibits phagosome-lysosome fusion, whereas they are undetectable in the avirulent $N$. asteroides ATCC 10905, which does not inhibit phagosome-lysosome fusion $(336,629)$. Extraction of cord factor from the cells of $N$. asteroides GUH-2 with ethanol-ether abrogated their ability to inhibit phagosome-lysosome fusion in human monocytes and murine macrophages in vitro $(53,336$, 629).

A variety of other compounds linked to mycolic acids are localized in the nocardial cell envelope $(24,29,55,86,226,277$, $333,469)$. Little is known concerning the toxicity or biological activity of these compounds. It was shown that the relative composition of mycolic acids in the cell walls of $N$. asteroides changes during the growth phases of the organism when it is cultured in brain heart infusion (BHI) broth $(76,86,87)$. There are concomitant changes in the virulence and toxicity of the organism when tested both in vitro and in vivo $(58,67,76,84$, $86,87,209)$. With the model strain, $N$. asteroides GUH-2, log-phase cells are enriched for polyunsaturated, even-carbonchain-length mycolates that are predominantly $\mathrm{C}_{52}, \mathrm{C}_{54}, \mathrm{C}_{56}$ $(86,87)$. These cells are more virulent for mice, rabbits, rats, and monkeys when injected i.v. than are stationary-phase cells from the same culture $(53,84,86,93,144)$. Log-phase cells of GUH-2 are also more toxic for a variety of cells maintained in vitro than are the stationary-phase cells $(58,97)$. The mycolic acids in the cell walls of stationary-phase coccobacillary cells of $N$. asteroides GUH-2 are predominantly saturated and monoand diunsaturated $\mathrm{C}_{50}$ and $\mathrm{C}_{52}$ compounds $(86,87)$. In addition, significant amounts of odd-carbon-chain-length mycolic acids (e.g., $\mathrm{C}_{49}, \mathrm{C}_{51}, \mathrm{C}_{53}$ ) are absent in log-phase cell walls (86, 87). Obviously, the mycolic acid-containing glycolipids in the cell envelope must reflect these relative changes in composition during nocardial growth. A mutant of $N$. asteroides GUH-2 that had a different colony morphology was selected and shown to be less virulent at all stages of growth in mice than the parental strain was (695). An extensive analysis of this mutant revealed that it differed from the parental strain by possessing significantly reduced amounts of one type of mycolic acid in the cell wall $\left(\mathrm{C}_{54: 3}\right)$ while having increased levels of odd-carbon-chain-length mycolates (i.e., increased $\mathrm{C}_{49}, \mathrm{C}_{51}$, $\mathrm{C}_{53}$, and $\mathrm{C}_{55}$ ) (86). Most dramatically, this mutant had completely lost the ability to invade and grow within the murine brain (86). These results suggest that the structure of the mycolic acids in the cell envelope plays an important role in both virulence and the interactions of $N$. asteroides in the brain (86).

\section{L-FORMS IN NOCARDIAL PATHOGENESIS}

L-forms are microbial variants that lack a structurally intact cell wall. As a consequence, they grow and replicate as nonrigid cells, and on a semisolid medium they produce characteristic colonies that have a "fried-egg" appearance (441). Typically, L-forms are gram negative and osmotically fragile; however, variants that appear to be osmotically stable have been described (441). In general, L-forms are divided into two categories: (i) stable forms, which do not revert readily to the parental form, and (ii) unstable forms, which revert to the parental form once the inducing condition is removed (441). Some L-forms may produce colony variants that do not have the typical fried-egg morphology on semisolid media. It should be noted that the isolation and growth of most types of bacterial L-forms require specially prepared culture media that may be different for each strain of bacterium. Furthermore, the cellular morphology of L-forms may become very complex depending on the amount or type of cell wall constituents that are present (Fig. 9). Thus, type A L-forms have no apparent cell wall when visualized by electron microscopy (Fig. 9A), and these cellular forms appear as protoplasts (441). In contrast, type B L-forms have a cell wall that is incomplete or fails to impart structural rigidity to the cells, and the cellular forms that result may be highly pleomorphic with a dominance of involution forms (Fig. 9B) (441). Not all bacteria grow as L-forms, and there is considerable variability in the ability to induce and isolate L-forms (441).

The in vitro induction of $\mathrm{L}$-forms from a variety of nocardiae was analyzed $(65,130)$. Some strains of $N$. asteroides and $N$. otitidiscaviarum, but not $N$. brasiliensis, were converted readily into protoplasts or spheroplasts by growth in media that contained glycine and lysozyme or D-cycloserine. These cells could then be grown on appropriate media to produce L-forms (130). However, the nocardial species differed greatly in their ability to produce spheroplasts that would subsequently grow as L-forms (130). Of the Nocardia species studied, all strains of $N$. otitidiscaviarum were readily converted to L-forms, but $N$. brasiliensis strains could not be converted to L-forms in vitro (130).

The interactions of several strains of $N$. asteroides with macrophages maintained in vitro have been described $(57,58$, 92, 129). N. asteroides ATCC 10905 differed significantly from either strain ATCC 14759 or GUH-2 when incubated with peritoneal macrophages obtained from mice (129). Following infection of peritoneal macrophages with strain ATCC 10905, viable plate counts on brain-heart infusion (BHI) agar showed that there was greater than $99 \%$ reduction in viable intracellular nocardiae after 8 days of incubation. However, at 16 days after infection there was a dramatic increase in the ability to

FIG. 9. Electron micrographs of L-forms of $N$. asteroides ATCC 10905 grown on BYE-L agar for 1 week. (A) Type A L-form showing that this protoplast-like cell has no ultrastructural evidence of residual cell wall (arrow). N, nuclear region; V, vacuole; CM, cytoplasmic membrane. (B) Type B L-form showing clearly that the outer portion of the cell wall is irregularly distributed around the cell whereas there appears to be an absence of peptidoglycan structure; thus, the cell is abnormally large and pleomorphic (compare with Fig. 8A, showing a lag-phase cell of $N$. asteroides ATCC 14759). LV, Lipid vacuole; GZ, granular zone characteristically localized at the growing tip of the nocardial cell; N, nuclear region; OL, outer layer of the cell envelope. (C) Normal cell grown for 1 week on BHI agar. Note the presence of an intact cell wall. Compare panels A, B, and C, which are at the same magnification. (D) Phase-contrast micrograph of an L-form colony incubated for 1 month on BYE-L agar at $37^{\circ} \mathrm{C}$ in $5 \% \mathrm{CO}_{2}$. This isolate was obtained from murine peritoneal macrophages that had been infected with normal cells of strain ATCC 109053 weeks earlier; panels A and B are thin sections of similar L-forms isolated at the same time from previously infected peritoneal macrophages but incubated for only 1 week. LB, large body. Reprinted from reference 56 with permission of the publisher. 


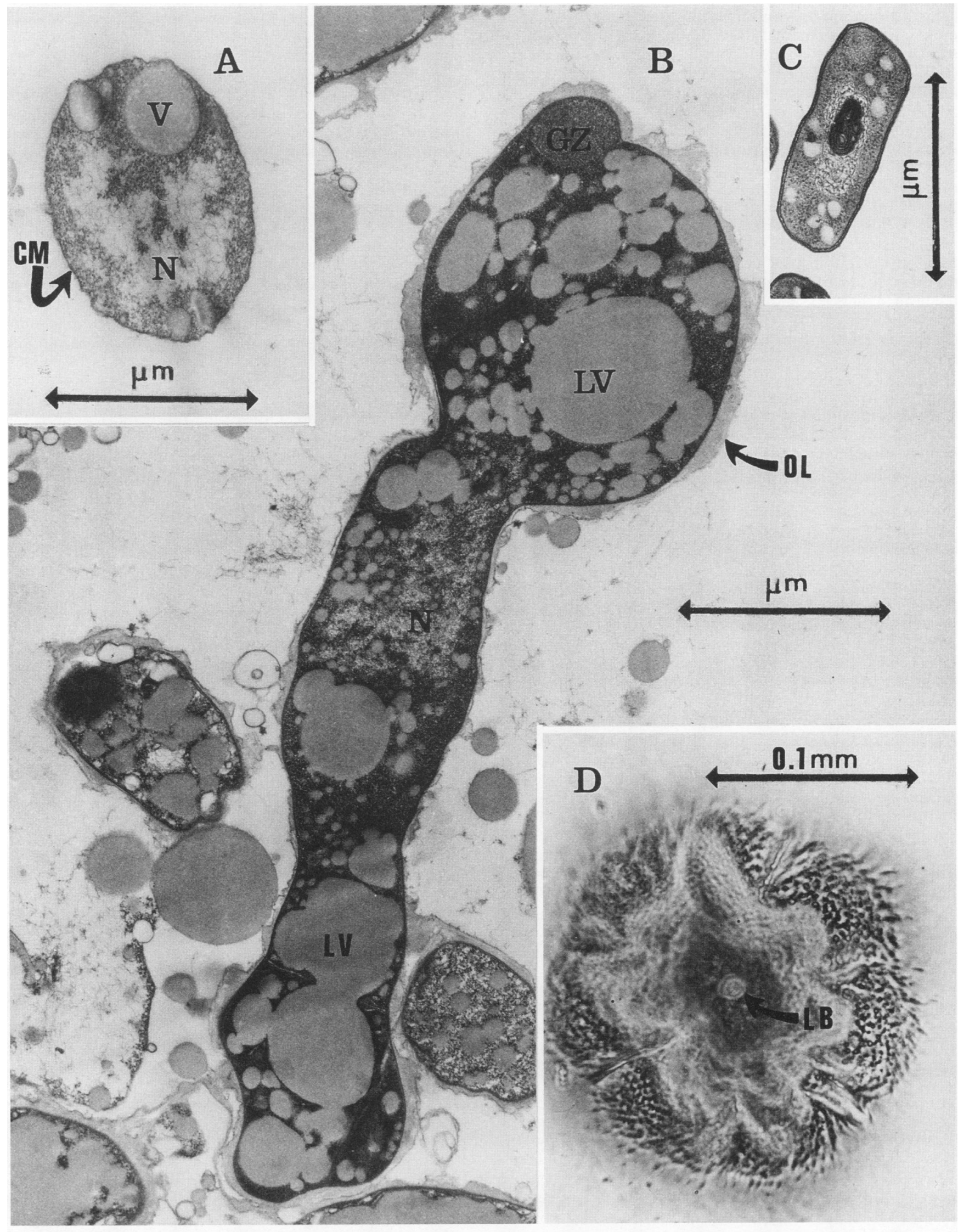


once again isolate nocardiae from the macrophage cultures (129). During this process, light microscopy of Gram-stained preparations revealed that there was a loss of gram positivity, so that after 8 days no gram-positive bacteria could be found (129). Even after 16 days, when viable cells could be recovered on BHI agar, there were no gram-positive bacterial cells apparent in these cultured macrophage monolayers (129). Immunofluorescence microscopy with antibody from rabbits immunized against crude cytoplasmic membrane preparations of ATCC 10905 demonstrated that there were immunofluorescence-positive intracellular bacteria in the macrophages at all times (129). Furthermore, electron microscopy failed to show intact bacteria in the macrophages 8 days after infection, but, instead, numerous spheroplast-like organisms were observed from days 8 through 27 (129). When these monolayers of macrophages were plated on $\mathrm{BHI}$ supplemented with $20 \%$ fetal calf serum, $5 \% \mathrm{NaCl}$, and $0.7 \%$ agar, only L-forms of $N$. asteroides were recovered. These data establish that macrophages have the ability to induce and maintain L-forms of certain strains of $N$. asteroides (129).

Since L-forms of $N$. asteroides can be induced in vitro either by growth in glycine plus lysozyme (129) or by macrophages (130), it is important to determine whether they occur in the intact host. It is well established that visualization of nocardiae in humans and animals with progressive disease and isolation of nocardiae from these hosts may not be successful (61-63, 66). The literature is replete with examples that describe chronic, progressive nocardial infections that developed after a prolonged latency in which Nocardia cells could not be recognized. Furthermore, there are several reports that describe recurrences of Nocardia spp. after repeated, prolonged, and apparently successful chemotherapy $(61-63,66)$. This inability to either visualize nocardiae in infected tissues or isolate them from these tissues does not establish L-forms as being responsible. However, these observations are consistent with the concept that cell-wall-deficient forms of Nocardia spp. play a significant role in both pathogenesis and latency of disease as well as the recurrence of infections after apparently successful chemotherapy $(61-63,66)$.

L-forms of $N$. asteroides have been isolated from the CSF of humans with CNS nocardiosis (62). One specific case was described wherein the patient (a man in his forties) developed pulmonary nocardiosis secondary to the use of steroids to control polymyositis. The pulmonary infection initially responded to chemotherapy; however, after several months of therapy there was a relapse which indicated an infection of the brain. A computed tomogram revealed a small diffuse cerebral lesion; however, a repeat scan obtained days later failed to show a brain lesion even though the patient expressed signs of an infection of the brain. Attempts to culture nocardiae from the CSF on standard microbiological media failed repeatedly. Ultimately, the CSF from this patient was inoculated onto Barile-Yarguchi-Evaland (BYE) agar to look for L-forms. Within 2 weeks, $10^{4}$ L-forms per ml of CSF were recovered on BYE agar. Four additional samples of CSF were obtained several weeks apart and plated on BYE agar. In every instance, approximately $10^{4} \mathrm{~L}$-form colonies per ml of CSF were recovered. The true identity of these L-forms was established when they reverted to typical cells of $N$. asteroides following agar block transfers to fresh media. The L-form revertant strain of $N$. asteroides appeared to be the same as the original pulmonary isolates except that they had very different antibiotic susceptibility patterns. The L-form revertant had acquired multiple drug resistance that the original lung isolate did not have (62). There have been additional reports of the isolation of L-forms of Nocardia species from the CSF of patients with chronic infections of the CNS (62). In addition to the human cases, L-forms of $N$. asteroides were isolated from a naturally acquired infection in a dog with both steroid- and antibioticunresponsive polyarthritis (141). The authors concluded that these L-forms played a direct role in the etiology of the polyarthritis in this dog (141). These reports show that L-forms of Nocardia spp. can be recovered from clinical material obtained from humans and other animals. Furthermore, these observations suggest strongly that L-forms play an active role in the disease process (62). The role of nocardial L-forms in the pathogenesis of disease has been established by using experimental murine models $(59,61,89)$. Uesaka et al. (685) studied lesions induced in mice several days after intraperitoneal injection with several different Nocardia spp. They often found that organisms could be isolated from tissues in which they could not be visualized microscopically and suggested that gram-negative variants of Nocardia spp. were present (685). Gonzalez-Ochoa (274) studied the virulence of several strains of $N$. asteroides by inoculation of the nocardiae into the footpads of mice. He noted that in some instances animals developed large lesions over a period of 1 week followed by a spontaneous healing process, so that at 2 to 3 weeks the lesions were gone and no organisms could be found. However, the same mice would later develop signs of inflammation in the footpad, and after 2 months they had well-established mycetomas (274).

Beaman et al. $(54,59,65,77,85,89)$ studied the morphological, structural, and tinctorial properties of a variety of Nocardia spp. following inoculation into mice. Most Nocardia strains are not acid-alcohol fast when grown in BHI broth; however, many of them become strongly acid fast when grown in vivo (77). Furthermore, this acid fastness, unlike with Mycobacterium spp., can be extracted with pyridine (77). Most Nocardia strains stain uniformly with the Gram stain when cultured on BHI but become gram variable and highly beaded in the host. In fact, cells of $N$. asteroides ATCC 10905 become gram negative, club shaped, and involuted in granules that give rise to mycetomas during experimental infection of mice (56, 63,83 ). Histochemical analysis demonstrated other alterations in both nocardial cell structure and host response during infection. For example, periodic acid-Schiff reactivity is positive for $N$. asteroides ATCC 10905 in tissues but negative when this organism is grown in BHI. Similarly, acid hematin staining for phospholipids is positive with cells of $N$. asteroides Mahvi growing in vivo but negative with cells grown in BHI. These reactions appear to be correlated with the relative degrees of virulence for mice and indicate that the structure of the cell envelope is altered during growth in the host $(56,62,63,66,68$, 83). Thus, the less virulent strains typically undergo the greatest alterations when grown in vivo, whereas the most virulent strains appear to be affected least. Furthermore, L-forms are more readily induced and maintained in vitro with the less virulent strains of $N$. asteroides $(56,62,63,66,68$, 83).

L-forms of both $N$. asteroides GUH-5 and $N$. otitidiscaviarum CDC 112 were induced in the spleens of mice following intraperitoneal injection of log-phase cells (61). In addition, L-forms of $N$. otitidiscaviarum CDC 112 were induced in the lungs of mice following intranasal administration (59). Furthermore, it was shown that these L-forms played an active role in producing a fatal pneumonitis in the mice because at the peak of this pulmonary response, bacteria with cell walls could not be visualized or recovered from the lungs whereas large numbers of L-forms of $N$. otitidiscaviarum CDC 112 were isolated from these dying animals (59).

Following an i.v. injection of $N$. otitidiscaviarum CDC 112 
into normal, athymic, and asplenic mice, L-forms were induced and maintained within immunologically intact hosts. L-forms were not recovered from the immunodeficient animals (89). Furthermore, these nocardial L-forms were involved in the pathogenesis of disease as well as in bacterial persistence. Two colony types of L-forms were recognized in these infections. L-forms that gave rise to a typical colony morphology were isolated from the brain, kidneys, spinal cord, and mycetomatous lesions 1 year after infection, whereas L-form variant colonies that were quite different in appearance were recovered from the bone marrow, eyes, and spinal cord (89). With $N$. otitidiscaviarum CDC 112, it appeared that the cell-walldeficient form of the organism played a major role in the development of the bacterial granule that is characteristic in mycetomatous lesions. Frequently, the mice that survived the acute phase of the infection developed progressive neurologic signs, including uncontrolled vertical bobbing of the head (category II sign [70]). It was found that $78.6 \%$ of these mice had only L-forms in their brain and that normal organisms could not be isolated from the brain of these animals. These results suggest that the persistence of the wall-deficient form of the nocardiae in the brain may be related to the development and persistence of the neurologic signs $(69,70,89)$.

When injected into mice, L-forms of Nocardia spp. that had been induced in vitro caused disease $(62,63)$. $N$. otitidiscaviarum CDC 112 and $N$. asteroides GUH-2 were induced to grow as L-forms in vitro $(62,63,65)$ and then injected either i.v. or intraperitoneally into mice $(60,62)$. The animals were monitored for 1 year to assess the persistence of $\mathrm{L}$-forms, the latency of disease, the induction of a pathologic response, the reversion of the $\mathrm{L}$-forms to the normal walled cell type, and the induction of progressive disease (62). L-forms from both Nocardia strains, when injected intraperitoneally, induced a pathologic response in the mice, and the L-forms from $N$. otitidiscaviarum CDC 112 persisted within the host for 1 year, inducing typical mycetomatous lesions (62). Furthermore, Lforms injected i.v. could be recovered from the mice, especially the kidneys, for extended periods even though the tissue appeared normal and there was no detectable pathologic response in the kidneys (62). In some instances, only L-forms were recovered from the mycetomatous lesions 1 year after the initial injection of L-forms of $N$. otitidiscaviarum CDC 112 induced in vitro. These cell-wall-deficient bacteria were isolated from the lesions, grown in vitro, and then inoculated into other mice. These mice developed mycetomatous lesions 6 months after infection, and only L-forms were visualized or isolated from these lesions (Fig. 10). These experiments demonstrated that L-forms of $N$. otitidiscaviarum were pathogenic and that Koch's postulates were fulfilled $(62,63,66)$.

\section{HOST-PARASITE INTERACTIONS OF NOCARDIA SPECIES IN THE BRAIN}

Analysis of 1,050 randomly selected cases of human nocardiosis (excluding mycetomas) published in the world literature revealed that $238(22.7 \%)$ of these involved the CNS (most of these infections were limited to the brain). In a 1974 survey of infectious disease experts, Beaman et al. (78) obtained information on 253 clinical isolates of Nocardia spp. in the United States during a 2-year period. It was reported that 39 of these isolates $(15.4 \%)$ were from CNS infections (78). More recently, Georghiou and Blacklock (263) reviewed 70 clinically significant Nocardia isolates collected between 1983 and 1988 at the Queensland State Health Laboratory. Of these, 38 $(54.3 \%)$ were limited to infections of the skin or soft tissues (263). The remaining 32 isolates were from either pulmonary or systemic nocardiosis, and 8 of these isolates $(25 \%)$ infected the CNS (263). Schaal and Lee reported on 131 clinical isolates of Nocardia spp. that they collected at both the Institute of Hygiene, University of Cologne, Cologne, Germany, and the Institute for Medical Microbiology and Immunology, University of Bonn, Bonn, Germany (585). Of these isolates, 19 $(14.5 \%)$ involved either the brain or the meninges, whereas only $47(35.9 \%)$ caused infections in the lungs, pleura, or chest wall (585). Boiron et al. (122) reviewed nocardial infections reported to the National Reference Center, Institut Pasteur, Paris, France, between 1987 and 1990. A total of 63 clinical isolates were identified, but for only 48 was there adequate clinical history as to the site of infection. The CNS was involved in $10.4 \%$ of these cases (122). Data from these studies indicate that between 10 and $25 \%$ of all nocardial infections (excluding mycetomas) recognized in humans involve the CNS $(78,122,263,585)$.

Murine models that permit analysis of the mechanisms involved in nocardial invasion of the brain have been established $(69-71,74,88,97,388,498,499)$. Thus, it was shown that i.v. inoculation of mice (tail vein) with a suspension of virulent nocardiae resulted in deposition of cells in the brain followed by a rapid growth of these bacteria $(388,498,499)$. Whether nocardiae bound specifically to cells in the brain or simply become trapped within blood vessels has been the focus of several investigations (69-71, 74, 88, 97, 388, 498, 499).

It was shown that the stage of growth greatly affected the number of nocardiae that were in the brain at $1 \mathrm{~h}$ after i.v. inoculation $(388,498,499)$. Thus, when $10^{6} \mathrm{CFU}$ of log-phase cells of $N$. asteroides GUH-2 were injected i.v. into mice, approximately $10^{3}$ CFU remained in the brain after $1 \mathrm{~h}$, whereas when $10^{6} \mathrm{CFU}$ of stationary-phase cells from the same culture were injected i.v., only 10 to $12 \mathrm{CFU}$ remained in the brain after the same period $(68,86)$. In both instances, the total inoculum could be recovered from the mouse, indicating that neither log-phase nor stationary-phase cells of GUH-2 were being killed or eliminated by the host within this period; instead, the nocardiae were distributed differently within the murine body $(68,86)$. Since log-phase cells are long and filamentous whereas stationary-phase cells are short and coccobacillary, it was thought that the size and shape of the cell might be responsible for this altered distribution. Therefore, an unrelated nonpathogenic actinomycete (cells of Streptomyces ramosus having the same size and shape during log and stationary phases of growth as $N$. asteroides GUH-2) was injected i.v. into mice and the numbers of bacteria deposited in the brain were enumerated. It was observed that there were twice as many filamentous log-phase Streptomyces cells in the brain compared with the number of stationary-phase coccobacillary cells (53). Light microscopy of Gram-stained coronal sections of the brain revealed that the Streptomyces cells were trapped in the small capillaries and that their association with brain cells appeared different from that of $N$. asteroides GUH-2. These observations suggested that the size and shape of the organism may have a slight effect (i.e., twofold) on nonspecific deposition of the organisms in the brain. However, the 100-fold increase in binding in the brain observed with log-phase cells of GUH-2 compared with stationary-phase cells indicated the probable presence of a specific ligand on the surface of the filamentous $N$. asteroides cell (53) that permitted it to attach to receptors on endothelial cells in the brain.

The distribution of the attachment of $N$. asteroides GUH-2 within specific regions of the brain was determined by the use of microdissection (498). BALB/c mice were injected through the tail vein with suspensions of different concentrations of 


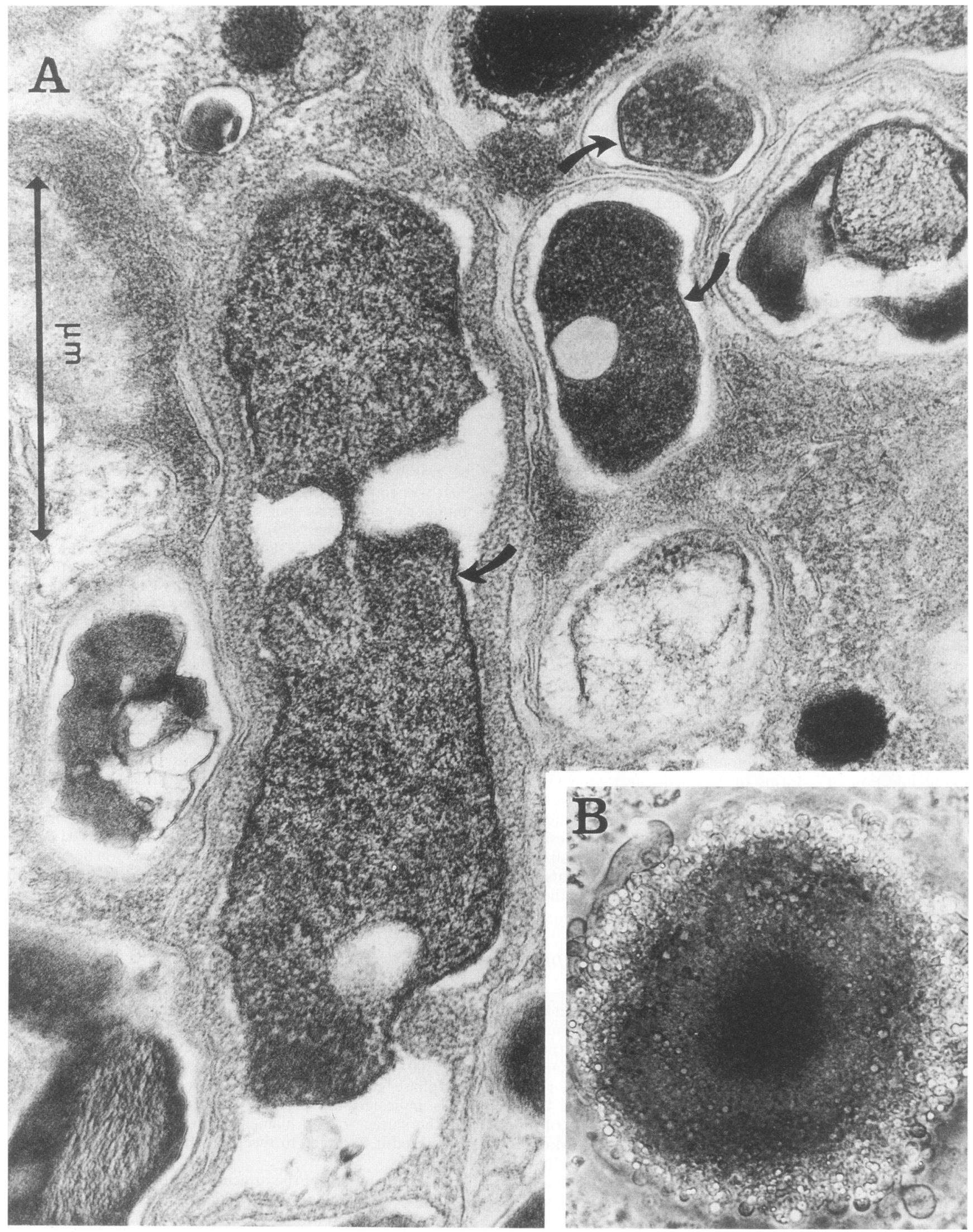


log-phase cells of GUH-2. After $3 \mathrm{~h}$, the brains were removed, eight different regions were dissected and homogenized, and viable counts were determined (498). These studies showed that nocardiae adhered within all major regions of the brain and that the distribution of adherence was independent of the amount of the inoculum. Two mutants of $N$. asteroides GUH-2 were selected on the basis of their ability to induce different neurologic responses following i.v. injection into mice (498, 499). Each of these mutants possessed significantly altered binding characteristics in the brain compared with the parental GUH-2 strain. The results of these studies indicated that $N$. asteroides GUH-2 used specific receptors to facilitate attachment in the brain $(498,499)$.

The attachment of nocardiae to endothelial cells within capillaries and arterioles in the murine brain was determined by electron microscopy following intra-arterial perfusion with log-phase cells of $N$. asteroides GUH-2 (88). Within $15 \mathrm{~min}$ of exposure, nocardiae attached to the surface of the endothelial cell membrane, and this attachment occurred mostly by way of the tip of the growing nocardial filament (Fig. 11). Furthermore, the outermost layer of the nocardial cell wall had electron-dense areas that bound firmly to the cytoplasmic membrane of the host cell (Fig. 11). This attachment appeared to be specific for regions of the pons, substantia nigra, thalamus, hypothalamus, and cerebral cortex (88). At the sites of apical attachment between the nocardiae and the endothelial cell, there was induction of a cup-like indentation followed by rapid penetration of the endothelial surface so that the bacteria were internalized within minutes. Scanning electron microscopy revealed that the nocardiae actively penetrated the endothelial surfaces of capillaries and arterioles (Fig. 12). Penetration of the endothelium by the nocardiae was prevented by heating the organisms at $60^{\circ} \mathrm{C}$ for $2 \mathrm{~h}$. However, these heat-killed cells still attached to the endothelial surface but with a decreased frequency (88). These observations indicate that nocardiae have both an adhesion factor for attachment and an invasion factor for penetration $(88,498$, 499).

The site-specific growth of $N$. asteroides GUH-2, as well as two mutants that differed in their ability to grow in the brain, in eight different regions of the murine brain was determined following i.v. inoculation (499). It was found that strain GUH-2 grew at different rates in the specific locations within the brain. Thus, at a nonlethal dose, GUH-2 grew most rapidly in the hippocampus, cerebral cortex, and mid-brain, whereas the growth rate was significantly diminished in the cerebellum and hypothalamus (499). In contrast, mutant NG-49 (which does not induce significant neurologic signs in mice) was cleared from the substantia nigra, did not grow in the striatum, and demonstrated very limited, slow growth in all other regions of the brain compared with the parental strain $N$. asteroides GUH-2 (499). Mutant I-38 syn had a different growth pattern in the brain from that of either NG-49 or the parental strain of GUH-2. Furthermore, there appeared to be a relationship between the growth rate of these three nocardial strains within specific regions of the brain and the type of neurologic signs expressed by the mice following a sublethal infection (499).
An ultrastructural analysis of the growth of $N$. asteroides GUH-2 during invasion of the murine brain was performed (71). At $24 \mathrm{~h}$ after injection of a lethal dose of nocardiae in the tail vein, it was observed that the organisms were growing perivascularly in the pons, substantia nigra, hypothalamus, and thalamus regions of the brain (Fig. 13) (growth occurred in other areas of the brain as well, but these were not studied in detail). The nocardiae entered most types of brain cells, but there appeared to be a specific preference for growth within the soma of neurons (Fig. 14) as well as along their axonal extensions (71). The nocardiae growing within the cells of the brain were surrounded by 1 to 30 layers of membrane with the innermost membrane adherent to the bacterial cell wall (Fig. 14). Even though the nocardiae did not induce an inflammatory response during this process and there was only limited host cell damage, the bacteria were not completely inert. Some of the brain cells containing nocardiae showed evidence of degeneration, and the myelin sheaths of axons were affected the most (Fig. 15). Furthermore, demyelinization and axonal degeneration associated with the bacterial growth were apparent (Fig. 16) (71). Some of the nocardiae and surrounding tissue were phagocytized by the more compact microglia. However, $24 \mathrm{~h}$ after infection, there was no ultrastructural evidence that the microglia damaged the nocardiae during a lethal infection (71).

Following a nonlethal i.v. injection of $N$. asteroides GUH-2 into BALB/c mice, there was rapid growth of nocardiae within the brain for 24 to $48 \mathrm{~h}(388,499)$. This was followed by persistence of the organism for approximately 1 week, and then the bacteria were cleared from the brain, so that after 2 weeks nocardiae were not recovered from the brain $(388,499)$. The mechanisms whereby nocardial growth in the brain was stopped were not known. However, by studying nocardial interactions in vitro with astrocytes and microglia obtained from the brains of newborn mice, it was shown that microglia that were cultured for 14 days prevented intracellular growth of $N$. asteroides GUH-2. In contrast, astrocytes maintained in culture for the same period supported intracellular growth of the nocardiae (97). These data suggested that activation of microglia, and not astroglia, was important in controlling the growth of $N$. asteroides in the murine brain (97). Furthermore, microglia and astroglia differed in their interactions with $N$. asteroides GUH-2. By using standard in vitro separation methods, at least two types of astroglia were obtained from the brains of newborn mice. One type was characterized as being relatively large and polygonal, whereas the second type was smaller, more ramified, and spindly (97). Nocardial cells adhered poorly to the larger, polygonal astroglia but adhered readily to the smaller astroglia (Fig. 17). In addition, the nocardiae adhered more specifically to the processes radiating from these cells (Fig. 18), and the astroglial extensions often encircled the nocardial cell by a pseudopod coil (Fig. 18) (325) as if attempting to engulf the organism (97). This type of phagocytic response to nocardiae by host cells has not been observed frequently; however, it has been seen in human astrocytoma cells exposed to $N$. asteroides GUH-2 (53). Furthermore, in vivo, phagocytosis of $N$. otitidiscaviarum by pseudopod coiling has been observed with PMNs in actively

FIG. 10. L-forms of $N$. otitidiscaviarum CDC 112 in a granule in a mycetoma induced in a mouse 1 year after i.v. infection with a suspension of L-forms grown in vitro. (A) Electron micrograph of a granule showing nocardial cells without an intact cell wall (curved arrows). Normal bacteria that possessed cell walls were not observed in thin sections of tissue from the mycetoma, and only L-forms were isolated. (B) Typical L-form colony of $N$. otitidiscaviarum isolated from the same mouse as in panel A. These L-forms were then grown in vitro and injected into additional mice. At 6 months to 1 year later, most of these mice had developed progressive mycetomatous lesions from which L-forms were again isolated, thus fulfilling Koch's postulates. Reprinted from reference 62 with permission of the publisher. 

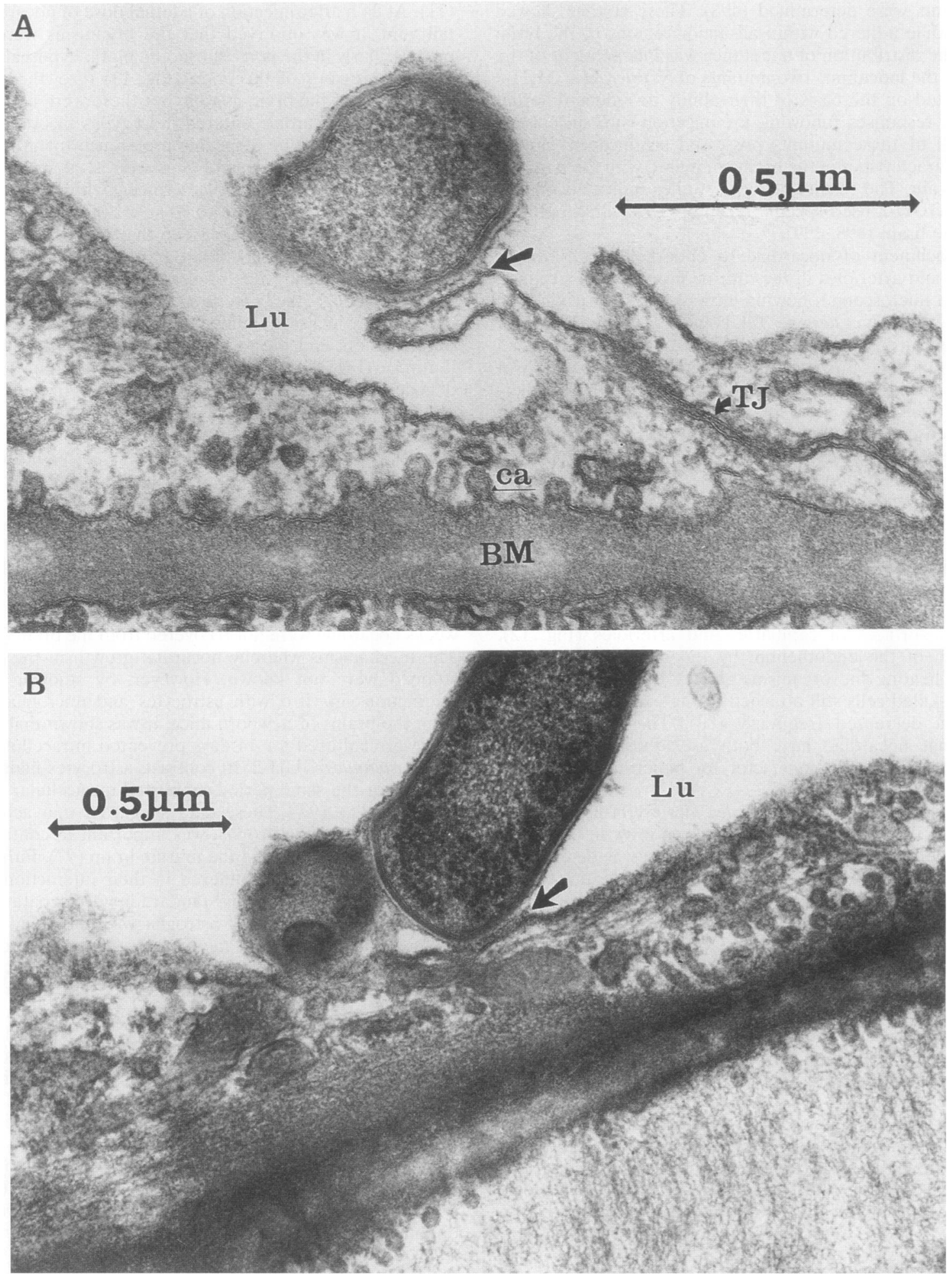

FIG. 11. Electron micrographs showing the attachment of log-phase cells of $N$. asteroides GUH-2 to the endothelial cell surface of capillaries in the murine brain. (A) The arrow points to electron-dense regions of the outer nocardial cell wall adherent to the host cell membrane at the flap region near an intercellular tight junction (TJ) in a capillary located within the pons region of the brain. (B) The arrow indicates the tight association between the outer cell surface at the tip of the nocardial cell and the cytoplasmic membrane of the endothelial cell in a capillary in the substantia nigra region of the brain. ca, caveolae; Lu, lumen of the capillary; TJ, tight junction. Reprinted from reference 88 with permission of the publisher. 

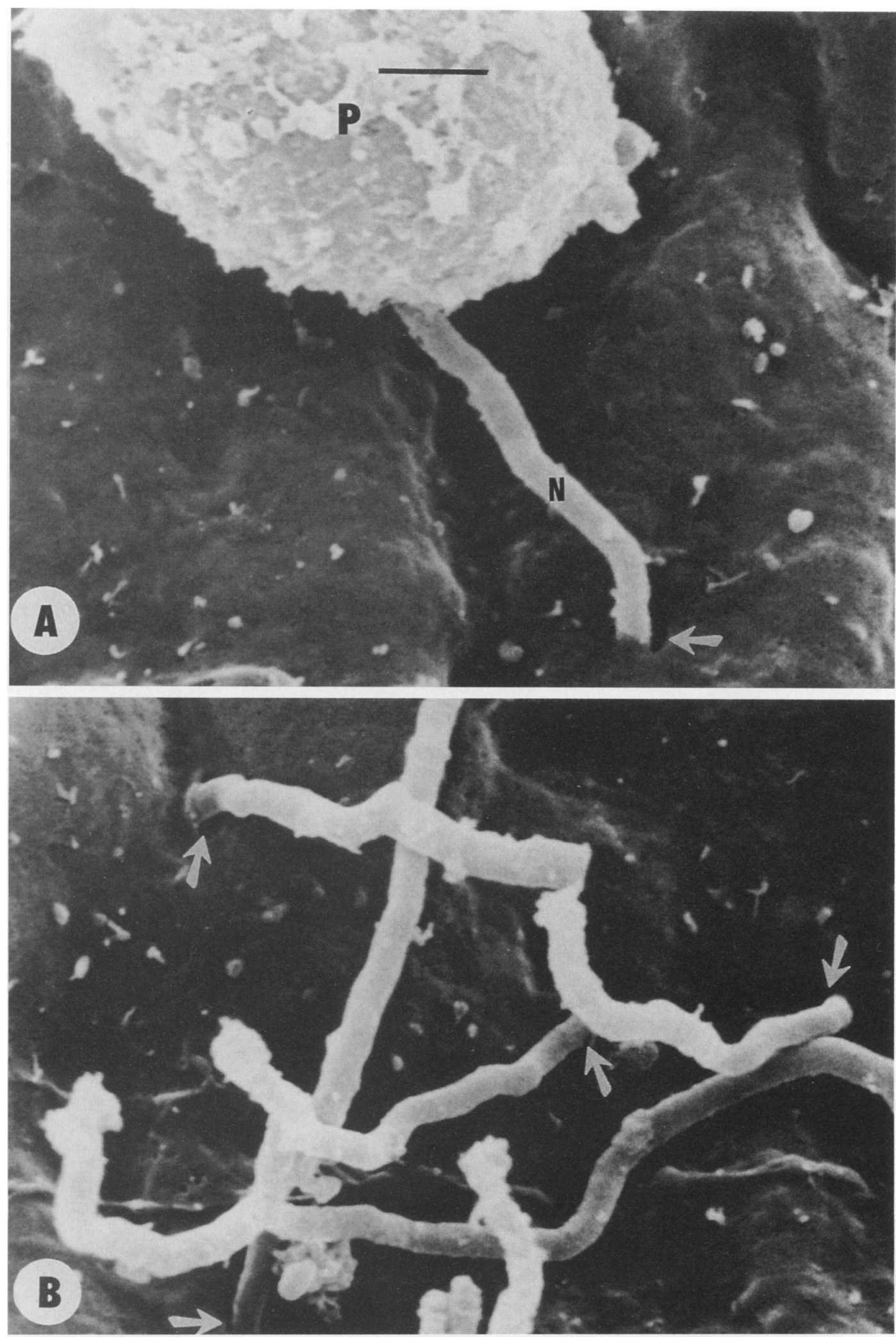

FIG. 12. Scanning electron micrographs of nocardial cells penetrating the endothelial surface of arterioles in the brain of a BALB/c mouse 15 min after intra-arterial perfusion with a suspension of log-phase cells of $N$. asteroides GUH-2 as described in reference 88. (A) A single nocardial filament $(\mathrm{N})$ is penetrating the endothelial cell surface (arrow) while, at the same time, a phagocytic cell (P) is attempting to phagocytize the other end of the nocardial filament. Bar, $1 \mu \mathrm{m}$. (B) Several nocardial filaments penetrating an arteriole (arrows) in the mid-brain region. 


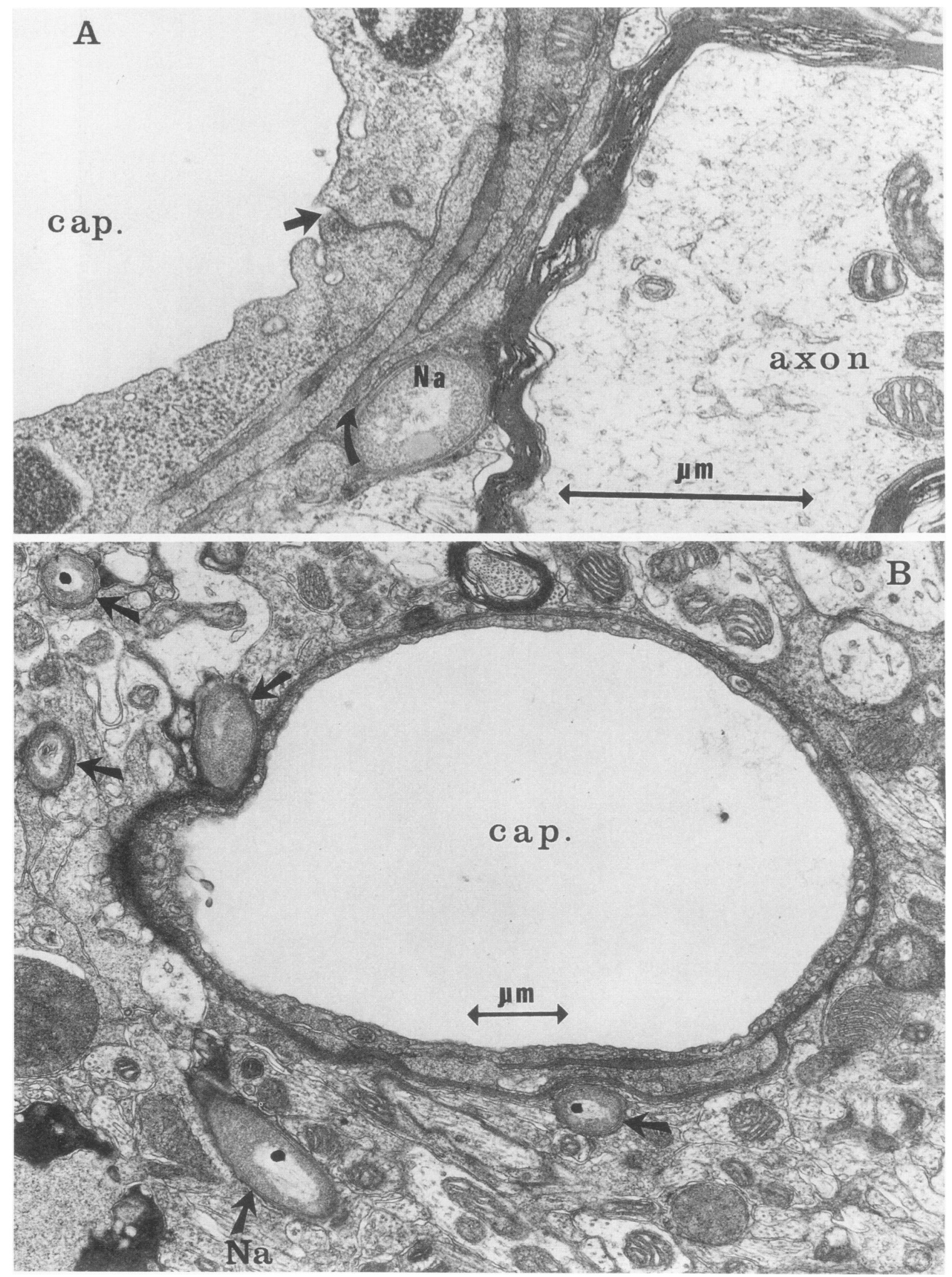


expanding lesions in athymic mice 3 months after i.v. inoculation (Fig. 19). Nocardial filaments usually attached to these astroglia by way of their apex, and they were seen to penetrate the cell surface (Fig. 18) (97). On the other hand, the interactions of $N$. asteroides GUH-2 with the microglia were similar to those reported with macrophages (97). Indeed, in side-by-side comparisons, the phagocytic uptake of nocardiae by microglia was the same as that by murine peritoneal macrophages (97).

Kohbata and Beaman (388) demonstrated that mice that received a relatively low dose of log-phase cells of $N$. asteroides GUH-2 by i.v. injection often developed specific neurologic signs 10 to 14 days after the inoculation. The behavior of animals infected with various Nocardia strains was grouped into at least 10 categories $(69,70)$. Approximately $10 \%$ of the mice infected with GUH-2 expressed an L-dopa-responsive rhythmic tremor or vertical headshake several times per second. They had a stooped posture, which was exaggerated when they were suspended by the tail; they had tremulous hesitating forward movement; they were hypoactive; and they expressed retropulsion when placed on a smooth surface (category II [70]). It was observed that mice from category II had a loss of Nissl substance and tyrosine hydroxylase immunoreactivity in the neurons of the substantia nigra region of the mid-brain (388). Furthermore, hyaline inclusion bodies that resembled Lewy bodies were found in neurons 1 month or more after infection (388). There was a degenerative loss of neurons, and these neurodegenerative changes were both permanent and progressive. Therefore, mice in category II expressed several features that were similar to those in humans with Parkinson's disease $(70,388)$. It should be emphasized that not all isolates of pathogenic Nocardia strains invaded the brain to induce a neurodegenerative response. Indeed, in an analysis of 65 Nocardia isolates injected into mice, only 27 (41.5\%) of these induced category II signs (53). Nevertheless, subclinical infection of mice with Nocardia spp. may serve as a model for studying a variety of neurodegenerative diseases including parkinsonian changes in the brain $(70,388)$. These observations raise several intriguing possibilities regarding the nature of neurodegenerative disease in humans following a silent bacterial infection of the brain. Furthermore, on the basis of these studies, combined with similar data now obtained in a primate model system (53), it is tempting to speculate that certain strains of nocardiae may be etiologically associated with some cases of neurodegenerative processes in humans.

\section{CONCLUSIONS}

Historically, nocardiae were believed to be fungi that only rarely caused disease in humans; however, it has now been established clearly that these organisms are bacteria that may be relatively common pathogens causing a variety of clinical problems in humans and most other vertebrates $(93,275,420)$. Therefore, it is now known that the nocardiae are grampositive, strictly aerobic actinomycetes that are closely related phylogenetically to the genera Corynebacterium, Mycobacterium, and Rhodococcus $(275,420)$.

$N$. asteroides, $N$. farcinica, $N$. nova, $N$. brasiliensis, and $N$. otitidiscaviarum are primary pathogens causing disease in the general population; however, these organisms are more often recognized as opportunistic pathogens in individuals with an underlying condition $(74,78)$. Diseases caused by these bacteria are worldwide in distribution and may be very difficult to diagnose; this probably leads to underestimation of their incidence $(74,78,583)$. Pulmonary infections appear to be the most commonly recognized; however, the organisms that cause these infections can become blood-borne, and then the brain becomes a primary target $(74,78,583)$. In addition, the skin, muscles, bones, and lymphatics become common sites of infection following traumatic inoculation $(74,78,583)$. It is important to note that any body site can become targeted by the nocardiae following either dissemination or direct implantation by trauma $(74,78,583)$.

The virulent strains of $N$. asteroides are facultative intracellular pathogens that can grow in a variety of cells from humans and experimental animals $(57,58,71,97,244)$. The mechanisms of pathogenesis have been studied extensively and have been shown to be multiple, complex, and not yet fully understood $(60,67,68,74)$. The virulence of $N$. asteroides appears to be associated with its stage of growth and with its ability to inhibit phagosome-lysosome fusion, neutralize phagosomal acidification, resist oxidative killing mechanisms of phagocytes, alter lysosomal enzymes within phagocytes, and invade and grow within the brains of experimental animals $(57,58,69,71$, $73,84,86,98,115-118,208-210,244)$. Some of the nocardial components that appear to be involved in these processes include secreted SOD, high levels of catalase, complex glycolipids in the cell wall (e.g., trehalose dimycolate), and hemolysins and other toxic substances secreted by the nocardiac (73, $86,87,90,95,229,465,494,624,629,630)$.

The mechanisms of host resistance to nocardiae are also complex and not understood completely $(60,69,74)$. Filice et al. suggest that PMNs play a role in retarding the growth of the nocardial cells to permit adequate time for a cell-mediated immune response to develop, since activated macrophages are better able to kill nocardiae than are PMNs in vitro (242-246). However, in vivo studies in experimental animals demonstrate that virulent strains of nocardiae are not killed within the host for at least $3 \mathrm{~h}$ following i.v. injection, since $100 \%$ of the inoculum dose can be recovered from the animals during this period $(69,79,80,86,95)$. Furthermore, during this 3 -h period, nocardiae are cleared from the blood and become localized within specific body sites such as the lungs, spleen, liver, kidneys, and brain $(69,79,80,86,95)$. Different Nocardia strains can then grow rapidly in these different locations. The animal will either die or mount an effective response several days after injection $(79,80,81,83,86,89,95)$, and the ability to mount an immune response appears to depend on functional $\mathrm{T}$ lymphocytes and cell-mediated immunity $(74,79,80$, $81,82,83,89,210-212,246)$.

FIG. 13. Perivascular growth of $N$. asteroides GUH-2 in the murine brain $24 \mathrm{~h}$ after injection into the tail vein. (A) The nocardial cell (Na) is growing between the basement membrane and an axon. The bacterial cell appears to be surrounded by the inner membrane from the basement membrane (curved arrow) and adherent to the outer layer of the myelin sheath of the large axon. The axonal body appears to have undergone some degeneration (i.e., loss of microtubular integrity and some demyelination). The intercellular tight junction forming the blood-brain barrier (arrow) appears not to be damaged. cap., capillary lumen. (B) Nocardial cells are growing around the periphery of the capillary, and some are tightly associated with the basement membrane (arrows point to several nocardial cells). Note the absence of an inflammatory response or cytopathic effect within this region of the brain. The integrity of the capillary is unaltered. Reprinted from reference 72 with permission of the publisher. 

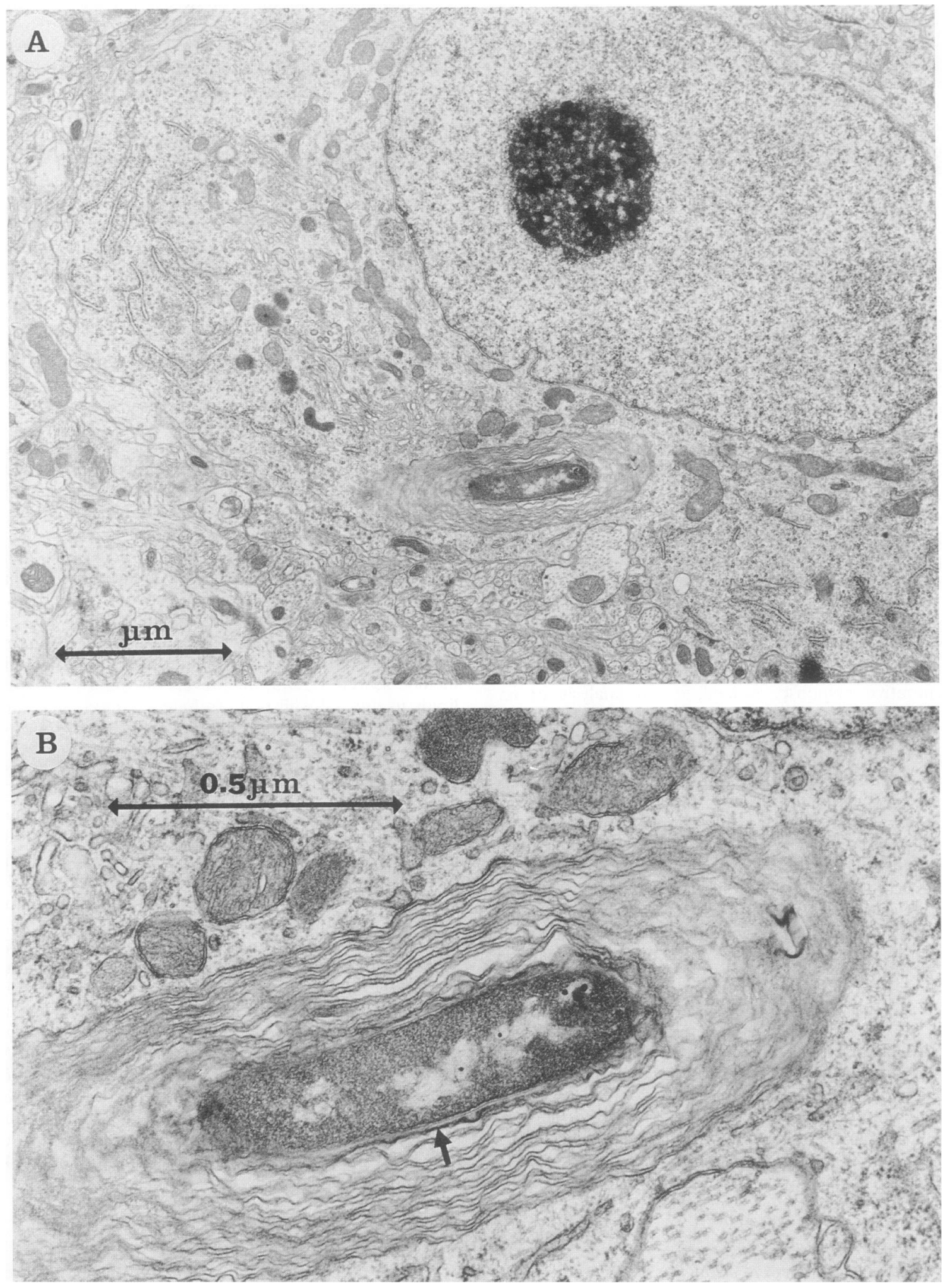

FIG. 14. Electron micrographs of $N$. asteroides GUH-2 during growth in a neuron in the brain $24 \mathrm{~h}$ after injection of the nocardiae into the tail vein of the mouse. (A) Low-magnification view of the neuron showing that the integrity of the cell is intact. There is little or no evidence of damage to the neuron caused by the intracellular growth of the Nocardia cell. (B) High-magnification insert from panel A, showing that the nocardial cell is surrounded by numerous layers of membrane and that the innermost membrane is tightly adherent to the surface of the nocardial cell wall (arrow). There is no ultrastructural evidence of damage to or alteration of the bacterium during growth in the neuron. Reprinted from reference 71 with permission of the publisher. 

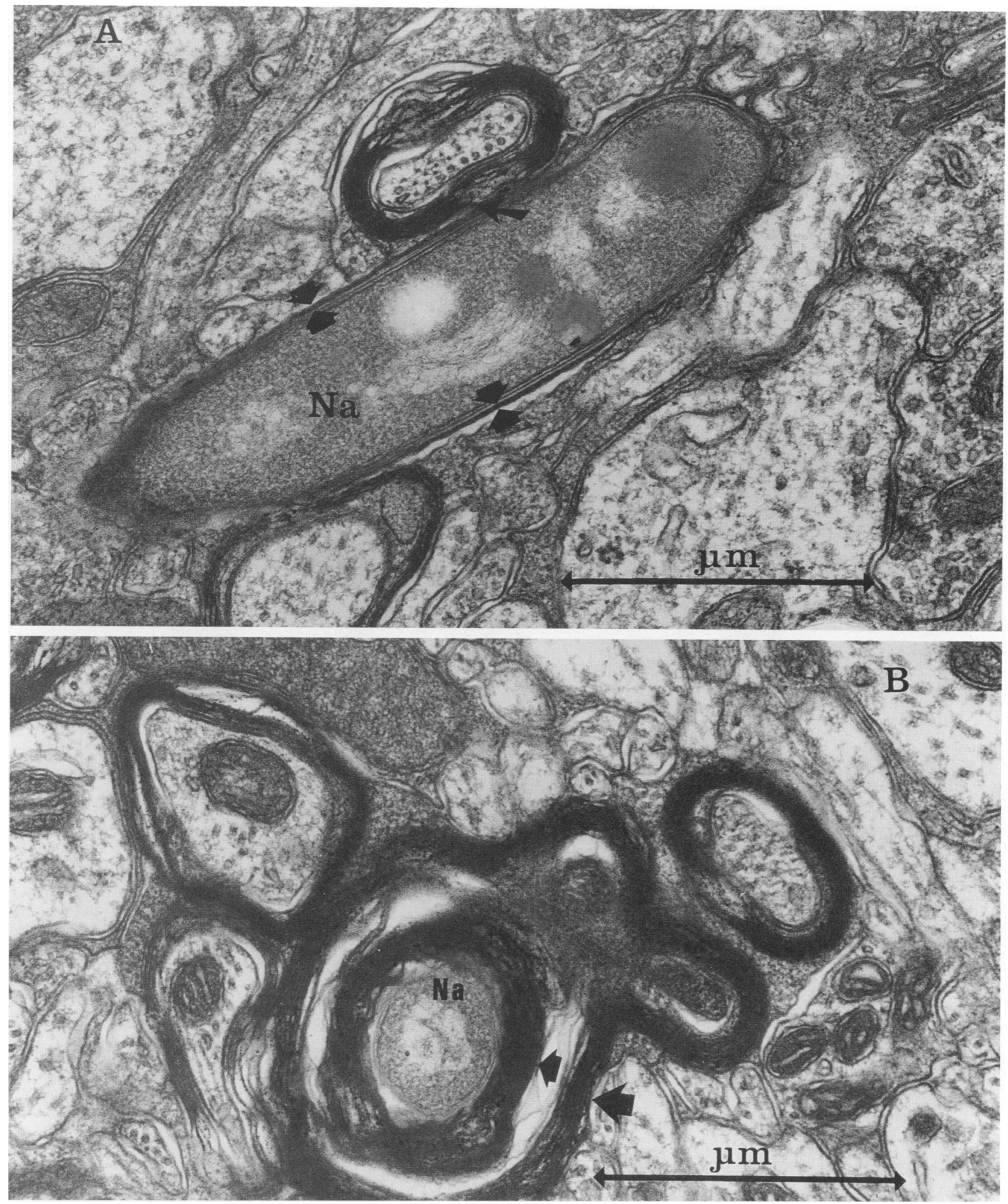

FIG. 15. Growth of N. asteroides GUH-2 in the brain $24 \mathrm{~h}$ after injection into the tail vein of a BALB/c mouse. (A) Nocardial cell (Na) growing adjacent to a myelinated axon. The thin arrow points to the outer axonal membrane, which appears to extend around the bacterium. The thick arrows indicate what appears to be the axonal membrane tightly adherent to the bacterial cell wall. (B) Nocardial cell (Na) within a myelinated axon. There is significant disruption of the myelin sheath surrounding the axon (thick arrows). Reprinted from reference 72 with permission of the publisher. 

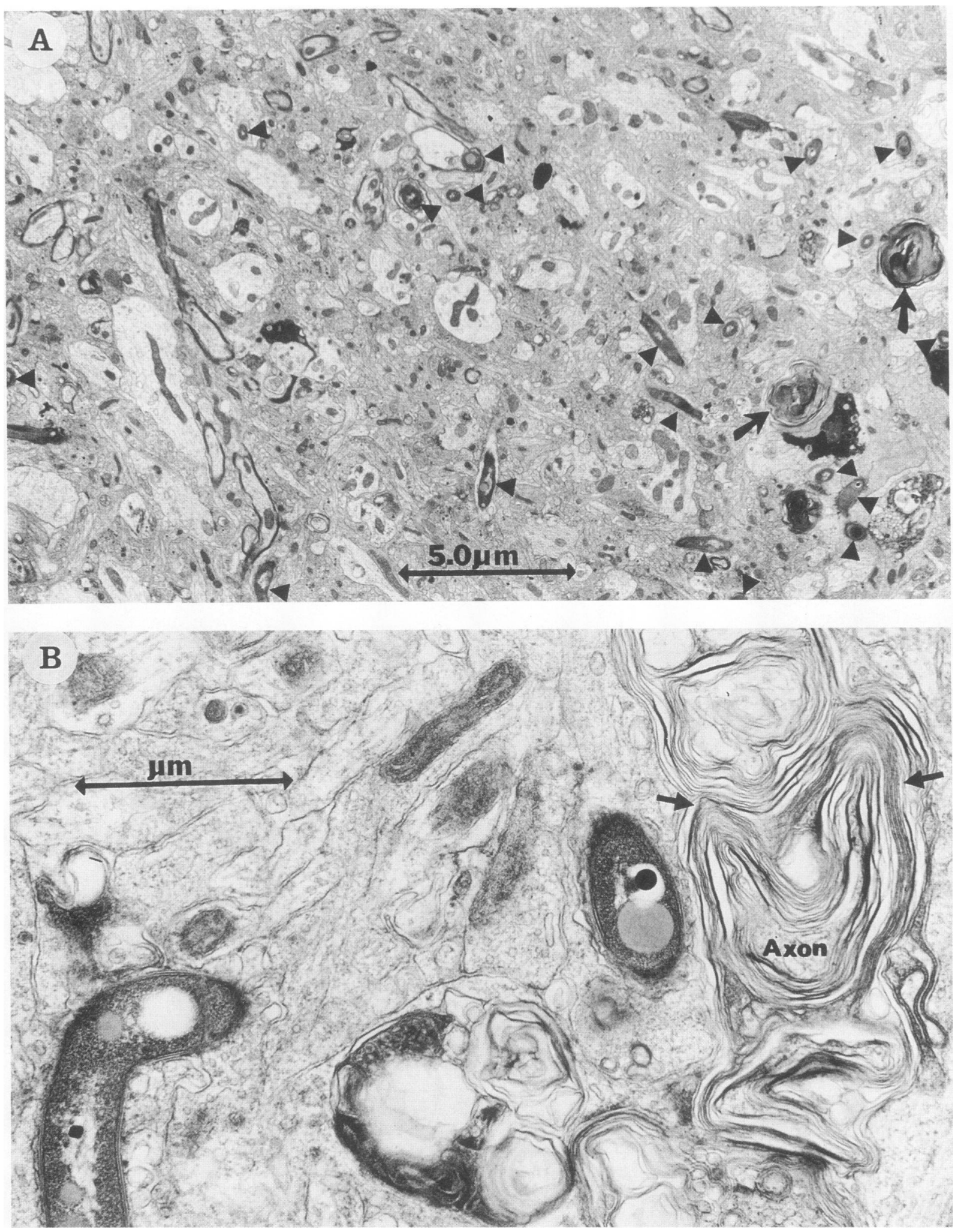

FIG. 16. Thin section of the murine brain $24 \mathrm{~h}$ after injection of $N$. asteroides GUH-2 into the tail vein. (A) Low-magnification view showing that the nocardial cells are growing freely throughout the brain tissue without inducing an inflammatory response (the triangular pointers note at least 19 bacteria in this area of the brain). The arrows indicate evidence of degeneration of myelinated axons in the vicinity of nocardial cells. (B) High-magnification view of area of the brain adjacent to that shown in panel A. Note the extensive axonal degeneration and myelin disruption (arrows) in axons in proximity to the nocardial cells. Reprinted from reference 71 with permission of the publisher. 

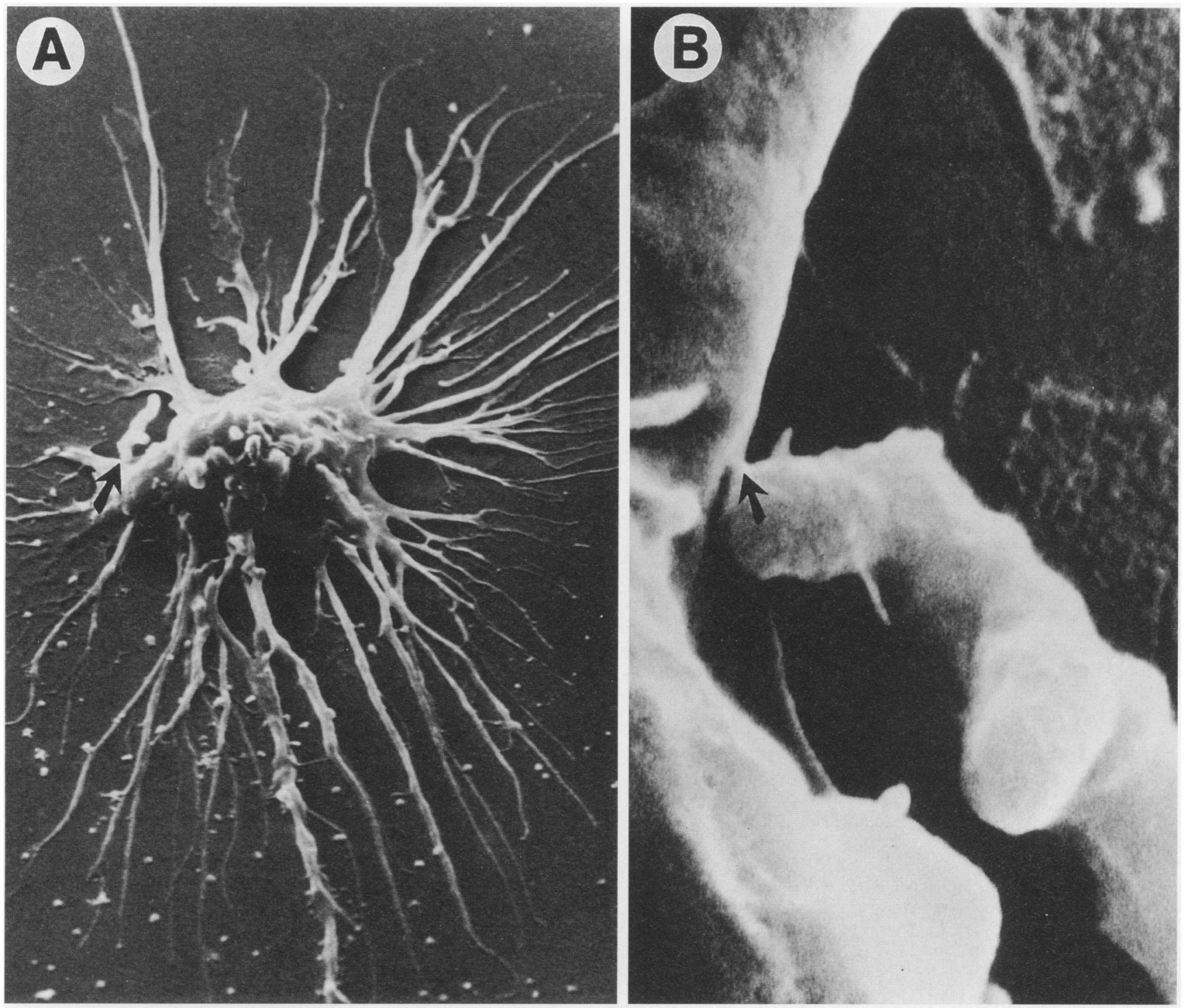

FIG. 17. Scanning electron micrographs of the interaction of nocardial cells with astroglia cultured from the brains of neonatal BALB/c mice. (A) Low-magnification view of an astroglial cell with a filamentous cell of $N$. asteroides GUH-2 adherent to the astroglial cell surface (arrow). (B) High-magnification view of panel A showing the attachment of the tip of the nocardial filament to the surface of the astroglial cell (arrow). Reprinted from reference 97 with permission of the publisher.

It is clear that L-forms of nocardiae can be induced and persist within the host for long periods $(59,61-63,65,66,89$, 129). It was shown in mice that L-forms of $N$. otitidiscaviarum can persist (especially within the brain) for the life of the animal. Furthermore, these L-forms play an important role in pulmonary and systemic disease, and L-forms of $N$. otitidiscaviarum could be isolated from and induce mycetomas within mice $(59,61-63,65,66,89)$. Although $\mathrm{L}$-forms can be isolated from humans including those with CNS infections, their role in human disease is not known (62).

It was shown in mice that some strains of $N$. asteroides can invade through endothelial cells in capillaries and arterioles in specific regions of the brain without necessarily inducing an inflammatory response or damaging the integrity of the bloodbrain barrier $(88,388)$. These bacteria then pass through the basal lamina and grow within neurons, axons, and glial cells (71). Following a sublethal infection, the nocardiae persist within the brain parenchyma for several days; this is followed by a decline in recoverability so that after 2 weeks the brain appears to be sterile $(388,498,499)$. At this time the mice begin to express a variety of movement and behavior disorders coincidental with neurodegeneration $(71,388,498,499)$.

Neither the clinical significance nor the long-term consequences of subclinical infection of humans by $N$. asteroides spp. is known. However, it should be noted that $10 \%$ of mice subclinically infected with $N$. asteroides GUH-2 develop a progressive neurodegeneration that results in an L-dopa-responsive movement disorder that shares many features with Parkinson's disease (388). In addition, other types of neurodegenerative responses are recognized in many other mice (70). Furthermore, after 1 to 2 years, the disease reactivated in some of these mice, and they developed clinical nocardiosis (53). On the basis of these observations, it is clear that much more research is necessary concerning the mechanisms of host- 

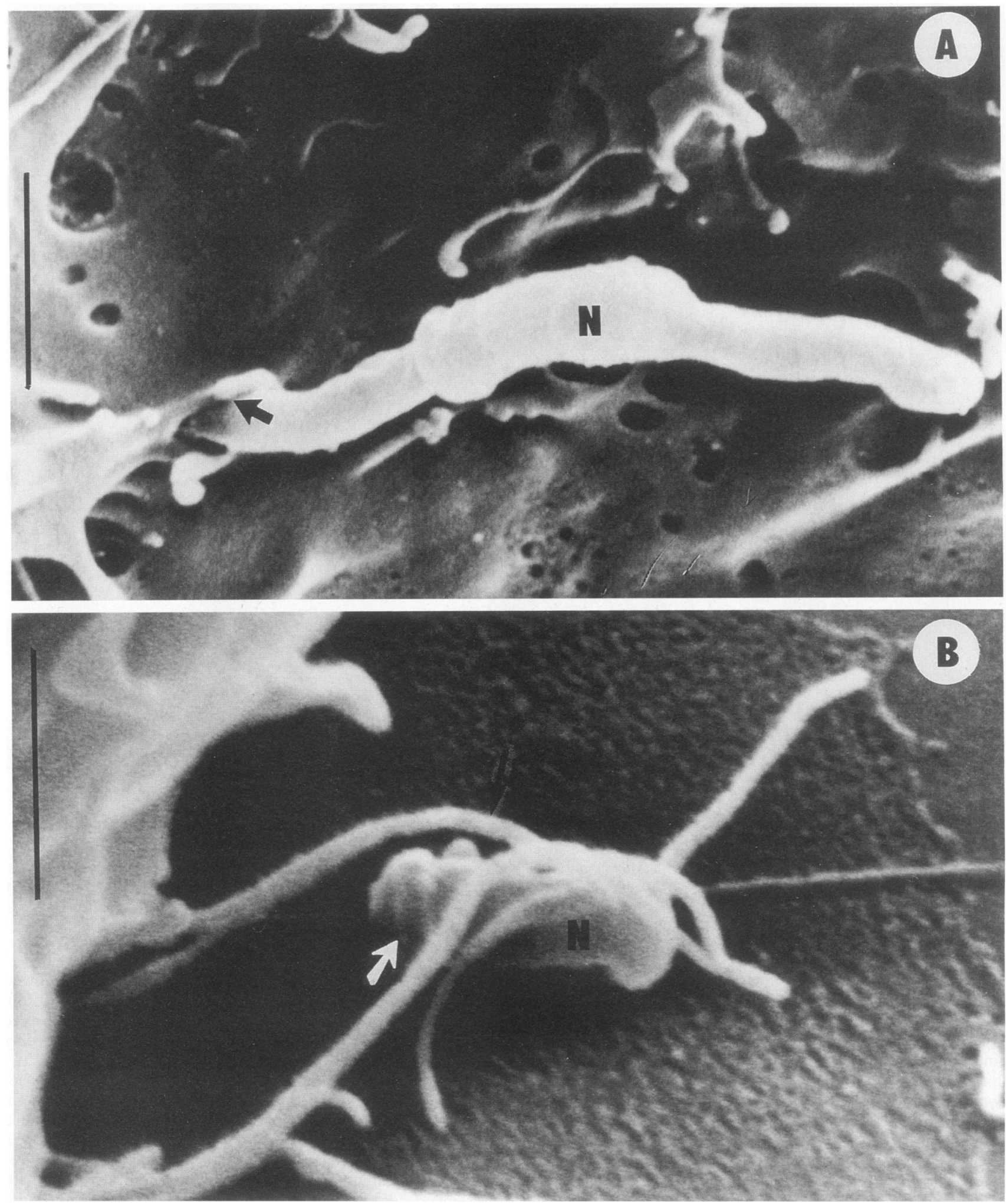

FIG. 18. Scanning electron micrographs of the interaction of in vitro grown astroglia with cells of $N$. asteroides GUH-2. (A) Nocardial filament (N) actively penetrating through the astroglial cell surface (arrow). Bar, $1 \mu \mathrm{m}$. Reprinted from reference 97 with permission. (B) Nocardial cell (N) that has become entwined by the pseudopodia of an astroglial cell (arrow). This process appears to be similar to the specialized coiling phagocytosis reported to occur during uptake of $L$. pneumophila by macrophages (325). Refer to Fig. 19. Bar, $1 \mu \mathrm{m}$. 

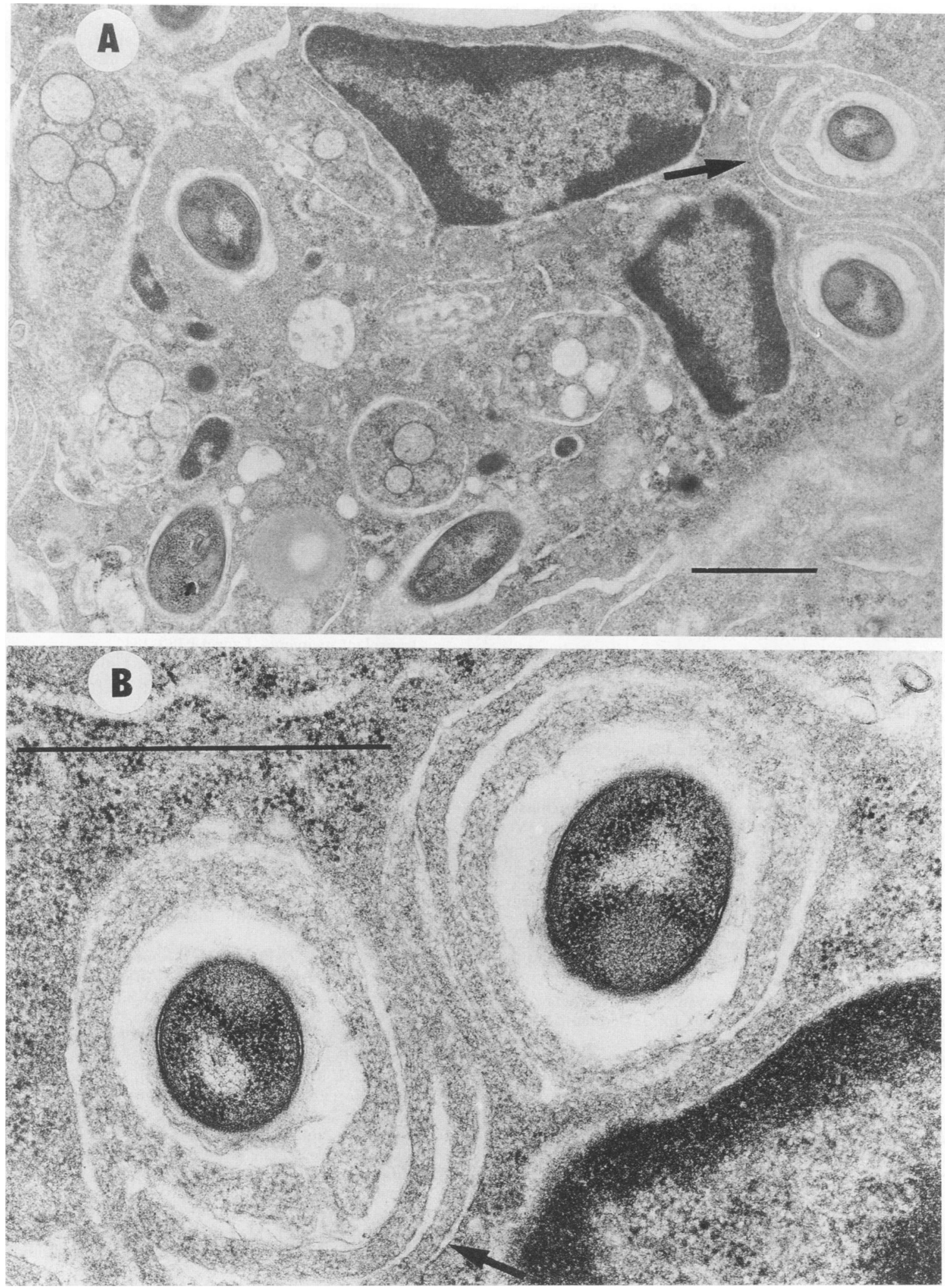

FIG. 19. Electron micrographs of $N$. otitidiscaviarum CDC 112 in a lesion induced at the base of the skull in an athymic nude BALB/c mouse 12 weeks after i.v. injection. The nocardiae are localized within a PMN, and two nocardial cells are being phagocytized by the PMN by a process that has been identified as pseudopod coiling (arrow) during phagocytosis of L. pneumophila by macrophages (325). Bar, $1 \mu \mathrm{m}$. (B) High-magnification insert showing pseudopod coiling around the nocardiae by a PMN. Bar, $1 \mu \mathrm{m}$. 
parasite interactions as well as the incidence and the neurologic consequences of subclinical infection of humans by Nocardia spp.

\section{ACKNOWLEDGMENTS}

Portions of this review were supported by Public Health Service grant RO1-AI20900 from the National Institute of Allergy and Infectious Diseases.

We thank Lynn Diaz for typing the manuscript.

\section{REFERENCES}

1. Abdi, E. A., J. C. Ding, and I. A. Cooper. 1987. Nocardia infection in splenectomized patients: case reports and a review of the literature. Postgrad. Med. J. 63:455-458.

2. Abraham, S., H. S. Randhawa, V. P. Kurup, V. N. Damodaran, B. Basu, and P. R. Mazumdar. 1967. Pulmonary nocardiosis. Indian J. Chest Dis. 9:165-169.

3. Adair, J. C., I. J. Amber, and J. M. Johnston. 1987. Peritonsillar abscess caused by Nocardia asteroides. J. Clin. Microbiol. 25: 2214-2215.

4. Adair, J. C., A. C. Beck, R. I. Apfelbaum, and J. R. Baringer. 1987. Nocardial cerebral abscess in the acquired immunodeficiency syndrome. Arch. Neurol. 44:548-550.

5. Adams, A. R., J. M. Jackson, J. Scopa, G. K. Lane, and R. Wilson. 1971. Nocardiosis: diagnosis and management, with a report of three cases. Med. J. Aust. 581:669-674.

6. Adams, H. G., B. A. Beeler, L. S. Wann, C. K. Chin, and G. F. Brooks. 1984. Synergistic action of trimethoprim and sulfamethoxazole for Nocardia asteroides: efficacious therapy in five patients. Am. J. Med. Sci. 287:8-12.

7. Aisu, T. O., P. P. Eriki, A. B. Morrissey, J. J. Ellner, and T. M. Daniel. 1991. Nocardiosis mimicking pulmonary tuberculosis in Ugandan AIDS patients. Chest 100:888.

8. Ajax, E. T. 1964. Acquired dyslexia: a comparative study of two cases. Arch. Neurol. 11:66-72.

9. Ajello, L., W. W. Walker, D. L. Dungworth, and G. L. Brumfield. 1961. Isolation of Nocardia brasiliensis from a cat. J. Am. Vet. Med. Assoc. 138:370-376.

10. Alderman, D. J., S. W. Feist, and J. L. Polgase. 1986. Possible nocardiosis of crayfish, Austropotamobius pallipes. J. Fish Dis. 9:345-347.

11. Al-Doory, Y., M. E. Pinkerton, T. E. Vice, and V. Hutchinson. 1969. Pulmonary nocardiosis in a vervet monkey. J. Am. Vet. Med. Assoc. 155:1179-1180.

12. Allen, V., M. Raff, C. Shumway, K. Lin, and R. Baker. 1984 Cutaneous nocardiosis in cancer patients receiving immunotherapy injections-Bahamas. Morbid. Mortal. Weekly Rep. 33:471477.

13. Alteras, I., and E. J. Feuerman. 1986. The second case of mycetoma due to Nocardia caviae in Israel. Mycopathologia 93:185-187.

14. Alteras, I., E. J. Feuerman, and I. Dayan. 1980. Mycetoma due to Nocardia caviae: the first Israeli patient. Int. J. Dermatol. 19:260262.

15. Andersen, B. R., R. E. Ecklund, and W. F. Kellow. 1960. Pulmonary alveolar proteinosis with systemic nocardiosis. A case report. JAMA 174:110-113.

16. Anderson, C. G., B. J. Berger, and S. Lavie. 1992. Nocardia brasiliensis soft tissue infection in an immunocompromised host N.Y. State J. Med. 92:275-276.

17. Anderson, K. L., and J. R. Wilcke. 1980 . Potential sulfonamides in the treatment of bovine pulmonary nocardiosis. J. Vet. Pharmacol. Ther. 3:217-220.

18. Anderson, R. D., L. A. Larson, and T. F. Smith. 1985. Mycoplasma pneumoniae and Nocardia asteroides in lung biopsy tissue of an immunodeficient infant. Diagn. Microbiol. Infect. Dis. 3:175-177.

19. Andriole, V. T., M. Ballas, and G. L. Wilson. 1964. The association of nocardiosis and pulmonary alveolar proteinosis. Ann. Intern. Med. 60:266-274.

20. Armstrong, P. J. 1980. Nocardial pleuritis in a cat. Can. Vet. J. 21:189-191.
21. Aron, R., and W. Gordon. 1972. Pulmonary nocardiosis. Case report and evaluation of current therapy. S. Afr. Med. J. 46:2931 .

22. Arroyo, J. C., S. Nichols, and G. F. Carrol. 1977. Disseminated Nocardia caviae infection. Am. J. Med. 62:409-412.

23. Asmar, B. I., and B. N. Bashour. 1991. Septic arthritis due to Nocardia asteroides. South. Med. J. 84:933-934.

24. Asselineau, J. 1981. Complex lipids of the cell envelope of Actinomycetales, p. 391-400. In K. P. Schaal and G. Pulverer (ed.), Actinomycetes. Gustav Fischer Verlag, Stuttgart, Germany.

25. Aswapokee, P., N. Aswapokee, P. Chirawong, and A. Leelarasamee. 1977. Pulmonary nocardiosis in a patient receiving immunosuppressive agent. Southeast Asian J. Trop. Med. Public Health 8:317-321.

26. Avram, M. M., S. R. Nain, H. I. Lipner, and C. E. Cherubin. 1978. Persistent nocardemia following renal transplantation. Association with pulmonary nocardiosis. JAMA 239:2779-2780.

27. Awad, I., J. W. Bay, and J. M. Petersen. 1984. Nocardial osteomyelitis of the spine with epidural spinal cord compression. Neurosurgery 15:254-256.

28. Ayers, K. M., F. M. Garner, and L. A. Griner. 1971. Disseminated nocardiosis in a north African antelope. J. Am. Vet. Med. Assoc. 159:611-613.

29. Azuma, I., F. Kanetsuna, Y. Tanaka, M. Mera, Y. Yanagihara, I. Mifuchi, and Y. Yamamura. 1973. Partial characterization of the cell wall of Nocardia asteroides strain 131. Jpn. J. Microbiol. 17:154-159.

30. Azuma, I., D. W. Thomas, A. Adam, J. M. Ghuysen, R. Bonaly, J. F. Petit, and E. Lederer. 1970. Occurrence of N-glycolylmuramic acid in bacterial cell walls. A preliminary survey. Biochim. Biophys. Acta 208:444-451.

31. Bach, M. C., J. L. Adler, J. Breman, F.-K. Peng, A. Sahyoun, R. M. Schlesinger, P. Madras, and A. P. Monaco. 1973. Influence of rejection therapy on fungal and nocardial infections in renaltransplant recipients. Lancet i: $180-184$.

32. Bach, M. C., A. P. Monaco, and M. Finland. 1973. Pulmonary nocardiosis: therapy with minocycline and with erythromycin plus ampicillin. JAMA 224:1378-1381.

33. Baddour, L. M., V. S. Baleski, M. J. Herr, G. D. Christensen, and A. L. Bisno. 1986. Nocardiosis in recipients of renal transplants: evidence for nosocomial acquisition. Am. J. Infect. Control 14:214-219.

34. Bagchi, A. K. 1983. Infections and infestations of the central nervous system in India. Neurosurg. Rev. 6:93-101.

35. Baghdadlian, H., S. Sorger, K. Knowles, M. McNeil, and J. Brown. 1989. Nocardia transvalensis pneumonia in a child. Pediatr. Infect. Dis. J. 8:470-471.

36. Baikie, A. G., C. B. MacDonald, and G. R. Mundy. 1970. Systemic nocardiosis treated with trimethoprim and sulfamethoxazole. Lancet ii:261.

37. Baily, G. G., P. Neill, and V. J. Robertson. 1988. Nocardiosis: a neglected chronic lung disease in Africa? Thorax 43:905-910.

38. Balikian, J. P., P. G. Herman, and S. Kopit. 1978. Pulmonary nocardiosis. Radiology 126:569-573.

39. Ballenger, C. N., and D. Goldring. 1957. Nocardiosis in childhood. J. Pediatr. 50:145-169.

40. Balloul, H., C. Perrone, R. El Rassi, I. Bouali, and F. Vachon. 1991. Un cas de nocardiose rélévant un syndrome d'immunodéficience acquise. Ann. Med. Interne 142:457-459.

41. Balozet, L., and P. Pernot. 1936. Meningite du chien causée par un Actinomyces. Bull. Acad. Vet. France 9:168-177.

42. Banerjee, M., and P. P. Gupta. 1979. A note on pulmonary actinomycosis and nocardiosis in goats of Punjab (Ludhiana area). Indian J. Anim. Sci. 49:972-975.

43. Barmeir, E., J. H. Mann, and R. H. Marcus. 1981. Cerebral nocardiosis in renal transplant patients. Br. J. Radiol. 54:11071109.

44. Barnicoat, M. J., A. S. Wierzbicki, and P. M. Norman. 1989 Cerebral nocardiosis in immunosuppressed patients: five cases. Q. J. Med. New Ser. 72:689-698.

45. Barot-Ciorbaru, R., T. J. Linna, M. R. Patel, J. Altman, and C. Carnaud. 1989. Enhancement of natural killer cell activity by Nocardia opaca fractions. Scand. J. Immunol. 29:133-141. 
46. Bartels, R. H., A. N. Van der Spek, and H. R. Oosten. 1992. Acute pancreatitis due to sulfamethoxazole-trimethoprim. South. Med. J. 85:1006-1007.

47. Bates, R. R., and D. Rifkind. 1971. Nocardia brasiliensis lymphocutaneous syndrome. Am. J. Dis. Child. 121:246-247.

48. Batshon, B. A., O. C. Brosius, and J. C. Snyder. 1971. A case report of Nocardia asteroides of the eye. Mycologia 63:459-461.

49. Battista, A. J., J. Huysman, and B. A. Cunha. 1990. Nocardia brasiliensis leg ulcer in a child. Pediatr. Infect. Dis. J. 9:370-371.

50. Bauman, J. M., R. Osenback, M. F. Hartshorne, L. Youngblood, L. Crooks, A. J. Landry, and M. A. Cawthon. 1986. Positive indium-111 leukocyte scan in Nocardia brain abscess. J. Nuclear Med. 27:60-72.

51. Bayley, S., P. S. Robinson, and S. J. Eykyn. 1981. Successful treatment of systemic nocardiosis with co-trimoxazole. J. Infect. 3:230-233.

52. Baylot, D., S. Berthier, F. Lucht, P. Gromolland, G. Jacquemond, J. Hypert, and J. Brunon. 1991. Cerebral nocardiosis cured by repeated stereotaxic punctures and antibiotic therapy. Presse Med. 20:744-746.

53. Beaman, B. L. Unpublished data.

54. Beaman, B. L. 1973. An ultrastructural analysis of Nocardia during experimental infections in mice. Infect. Immun. 8:828-840.

55. Beaman, B. L. 1975 . Structural and biochemical alterations of Nocardia asteroides cell walls during its growth cycle. J. Bacteriol. 123:1235-1253.

56. Beaman, B. L. 1976. Possible mechanisms of nocardial pathogenesis, p. 386-417. In M. Goodfellow, G. H. Brownell, and J. A. Serrano (ed.), Biology of the nocardiae. Academic Press Ltd., London.

57. Beaman, B. L. 1977. In vitro response of rabbit alveolar macrophages to infection with Nocardia asteroides. Infect. Immun. 15:925-937.

58. Beaman, B. L. 1979. Interaction of Nocardia asteroides at different phases of growth with in vitro maintained macrophages obtained from the lungs of normal and immunized rabbits. Infect. Immun. 26:355-361.

59. Beaman, B. L. 1980. Induction of L-phase variants of Nocardia caviae within intact murine lungs. Infect. Immun. 29:244-251.

60. Beaman, B. L. 1981. Mechanisms of pathogenesis and host resistance to the Actinomycetes. Zentralbl. Bakteriol. Mikrobiol. Hyg. Abt. 1 Suppl. 11:209-220.

61. Beaman, B. L. 1981. The possible role of L-phase variants of Nocardia in chronic infections. Zentralbl. Bakteriol. Mikrobiol. Hyg. Abt. 1 Suppl. 11:221-227.

62. Beaman, B. L. 1982. Nocardiosis: role of the cell wall deficient state of Nocardia, p. 231-255. In G. J. Domingue (ed.), Cell wall defective bacteria: basic principles and clinical significance. Addison-Wesley Publishing Co. Inc., Reading, Mass.

63. Beaman, B. L. 1984. The cell wall as a determinant of pathogenicity in Nocardia: the role of L-forms in pathogenesis, p. 89-105. In L. Ortiz-Ortiz, L. F. Bojalil, and V. Yakoleff (ed.), Biological, biochemical and biomedical aspects of actinomycetes. Academic Press, Inc., Orlando, Fla.

64. Beaman, B. L. 1984. Actinomycete pathogenesis, p. 457-479. In M. Goodfellow, M. Mordarski, and S. T. Williams (ed.), The biology of the actinomycetes. Academic Press Ltd., London.

65. Beaman, B. L. 1985. Ultrastructure of L-forms of Nocardia asteroides. Microsc. Electron. Biol. Cell. 8:173-185.

66. Beaman, B. L. 1986. The biology of cell wall defective forms of Nocardia, p. 203-227. In S. Madoff (ed.), The bacterial L-forms. Marcel Dekker, Inc., New York.

67. Beaman, B. L. 1986. Determinants of infection in nocardiosis, p. 635-645. In G. Szabo, S. Biro, and M. Goodfellow (ed.), Biological, biochemical and biomedical aspects of actinomycetes. Sixth Int. Symp. Actinomycete Biol. Akademiai Kiado, Budapest.

68. Beaman, B. L. 1988. The role of cellular morphology and structure in actinomycete pathogenesis, p. 501-506. In Y. Okami, T. Bepper, and H. Ogawana (ed.), Biology of actinomycetes 88 . Japan Scientific Societies Press, Tokyo.

69. Beaman, B. L. 1992. Nocardia as a pathogen of the brain: mechanisms of interactions in the murine brain-a review. Gene 115:213-217.
70. Beaman, B. L. 1992. Nocardia: an environmental bacterium possibly associated with neurodegenerative diseases in humans, p. 147-166. In R. L. Isaacson and K. F. Jensen (ed.), The vulnerable brain and environmental risks, vol. 2. Toxins in food. Plenum Press, New York.

71. Beaman, B. L. 1993. Ultrastructural analysis of the growth of Nocardia asteroides during invasion of the murine brain. Infect. Immun. 61:274-283.

72. Beaman, B. L., L. Beaman, J. A. Kjelstrom, and S. A. Ogata. 1994. Bacteria and neurodegeneration, p. 319-338. In D. Calne (ed.), Neurodegenerative diseases. The W. B. Saunders Co., Orlando, Fla.

73. Beaman, B. L., C. M. Black, F. Doughty, and L. Beaman. 1985. Role of superoxide dismutase and catalase as determinants of pathogenicity of Nocardia asteroides: importance in resistance to microbicidal activities of human polymorphonuclear neutrophils. Infect. Immun. 47:135-141.

74. Beaman, B. L., P. Boiron, L. Beaman, G. Brownell, K. Schaal, and M. Gomert. 1992. Nocardia and nocardiosis. J. Med. Vet. Mycol. 30(Suppl. I):317-331.

75. Beaman, B. L., and A. L. Bourgeois. 1981. Variations in properties of Nocardia asteroides resulting from growth in the cell wall-deficient state. J. Clin. Microbiol. 14:574-578.

76. Beaman, B. L., A. L. Bourgeois, and S. E. Moring. 1981. Cell wall modification resulting from in vitro induction of $\mathrm{L}$-phase variants of Nocardia asteroides. J. Bacteriol. 148:600-609.

77. Beaman, B. L., and J. Burnside. 1973. Pyridine extraction of nocardial acid fastness. Appl. Microbiol. 26:426-428.

78. Beaman, B. L., J. Burnside, B. Edwards, and W. Causey. 1976 Nocardial infections in the United States, 1972-1974. J. Infect. Dis. 134:286-289.

79. Beaman, B. L., M. E. Gershwin, A. Ahmed, S. M. Scates, and R. Deem. 1982. Response of CBA/N $\times \mathrm{DBA} 2 / \mathrm{F}_{1}$ mice to Nocardia asteroides. Infect. Immun. 35:111-116.

80. Beaman, B. L., M. E. Gershwin, and S. Maslan. 1978. Infectious agents in immunodeficient murine models: pathogenicity of Nocardia asteroides in congenitally athymic (nude) and hereditarily asplenic $(\mathrm{Dh} /+)$ mice. Infect. Immun. 20:381-387.

81. Beaman, B. L., M. E. Gershwin, S. S. Scates, and Y. Ohsugi. 1980. Immunobiology of germfree mice infected with Nocardia asteroides. Infect. Immun. 29:733-743.

82. Beaman, B. L., E. Goldstein, M. E. Gershwin, S. Maslan, and W. Lippert. 1978. Lung response of congenitally athymic (nude), heterozygous, and Swiss Webster mice to aerogenic and intranasal infection by Nocardia asteroides. Infect. Immun. 22:867-877.

83. Beaman, B. L., and S. Maslan. 1977. Effect of cyclophosphamide on experimental Nocardia asteroides infection in mice. Infect. Immun. 16:995-1004.

84. Beaman, B. L., and S. Maslan. 1978. Virulence of Nocardia asteroides during its growth cycle. Infect. Immun. 20:290-295.

85. Beaman, B. L., S. Maslan, S. Scates, and J. Rosen. 1980. Effect of route of inoculation on host resistance to Nocardia. Infect. Immun. 28:185-189.

86. Beaman, B. L., and S. E. Moring. 1988. Relationship among cell wall composition, stage of growth, and virulence of Nocardia asteroides GUH-2. Infect. Immun. 56:557-563.

87. Beaman, B. L., S. E. Moring, and T. Ioneda. 1988. Effect of growth stage on mycolic acid structure in cell walls of Nocardia asteroides GUH-2. J. Bacteriol. 170:1137-1142.

88. Beaman, B. L., and S. A. Ogata. 1993. Ultrastructural analysis of attachment to and penetration of capillaries in the murine pons, mid-brain, thalamus, and hypothalamus by Nocardia asteroides. Infect. Immun. 61:955-965.

89. Beaman, B. L., and S. M. Scates. 1981. Role of L-forms of Nocardia caviae in the development of chronic mycetomas in normal and immunodeficient murine models. Infect. Immun. 33:893-907.

90. Beaman, B. L., S. M. Scates, S. E. Moring, R. Deem, and H. P. Misra. 1983. Purification and properties of a unique superoxide dismutase from Nocardia asteroides. J. Biol. Chem. 258:91-96.

91. Beaman, B. L., J. A. Serrano, and A. A. Serrano. 1977. Comparative ultrastructure within the Nocardia. Zentralbl. Bakteriol. Mikrobiol. Hyg. Abt. 1 Suppl. 6:201-220. 
92. Beaman, B. L., and M. Smathers. 1976. Interaction of Nocardia asteroides with cultured rabbit alveolar macrophages. Infect. Immun. 13:1126-1131.

93. Beaman, B. L., and A. M. Sugar. 1983. Nocardia in naturally acquired and experimental infections in animals. J. Hyg. 91:393419 .

94. Beaman, L., and B. L. Beaman. 1984. The role of oxygen and its derivatives in microbial pathogenesis and host defense. Annu. Rev. Microbiol. 38:27-48.

95. Beaman, L., and B. L. Beaman. 1990. Monoclonal antibodies demonstrate that superoxide dismutase contributes to protection of Nocardia asteroides within the intact host. Infect. Immun. 58:3122-3128.

96. Beaman, L., and B. L. Beaman. 1992. The timing of exposure of mononuclear phagocytes to recombinant interferon $\gamma$ and recombinant tumor necrosis factor $\alpha$ alters interactions with Nocardia asteroides. J. Leukocyte Biol. 51:276-281.

97. Beaman, L., and B. L. Beaman. 1993. Interactions of Nocardia asteroides with murine glia cells in culture. Infect. Immun. 61:343-347.

98. Beaman, L., M. Paliescheskey, and B. L. Beaman. 1988. Acid phosphatase stimulation of the growth of Nocardia asteroides and its possible relationship to the modification of lysosomal enzymes in macrophages. Infect. Immun. 56:1652-1654.

99. Beckmeyer, W. J. 1959. Nocardiosis. Report of a successfully treated case of cutaneous granuloma. Pediatrics 23:33-39.

100. Becton, J. L., and J. J. Niebauer. 1970. Nocardia infection of the hand. J. Bone J. Surg. 52:1443-1444.

101. Belliveau, R. R., and F. Geiger. 1977. Lymphocutaneous Nocardia brasiliensis infection simulating sporotrichosis. West. J. Med. 127:245-246.

102. Benbow, E. P., D. T. Smith, and K. S. Grimson. 1944. Sulfonamide therapy in actinomycosis: two cases caused by aerobic partially acid-fast actinomyces. Am. Rev. Tuberc. 49:395-407.

103. Benedict, W. L., and H. A. Iverson. 1944. Chronic keratoconjunctivitis associated with Nocardia. Arch. Ophthalmol. 32:89-92.

104. Berd, D. 1973. Nocardia asteroides. A taxonomic study with clinical correlations. Am. Rev. Respir. Dis. 108:909-917.

105. Berd, D. 1973. Nocardia brasiliensis infection in the United States: a report of nine cases and a review of the literature. Am. J. Clin. Pathol. 60:254-258.

106. Bergstrom, R., L. Edebo, B. Fors, and K. B. Tegner. 1966. Systemic Nocardia infection. Scand. J. Respir. Dis. 47:75.

107. Berkey, P., and G. P. Bodey. 1989. Nocardial infection in patients with neoplastic disease. Rev. Infect. Dis. 11:407-412.

108. Bernstein, I. L., J. E. Cook, H. Plotnick, and F. J. Tenczar. 1952. Nocardiosis: three case reports. Ann. Intern. Med. 36:852-863.

109. Bertoldi, R. V., and M. R. Sperling. 1984. Nocardia brain stem abscess: diagnosis and response to medical therapy. Bull. Clin Neurosci. 49:99-104.

110. Bianco, A. J., E. W. Johnson, W. J. Martin, and D. R. Nicholas. 1957. Nocardiosis without involvement of the pulmonary or central nervous system. Proc. Mayo Clin. 32:119-123.

111. Biberstein, E. L., S. S. Jang, and D. C. Hirsh. 1985. Nocardia asteroides infection in horses: a review. J. Am. Vet. Med. Assoc. 186:273-277.

112. Binford, C. H., and J. D. Lane. 1945. Actinomycosis due to Nocardia asteroides: report of a case. Am. J. Clin. Pathol. 15: $17-23$.

113. Birdsell, D. C., D. R. Callihan, and J. T. Powell. 1984. Adherence of Actinomyces viscosus to teeth and its role in pathogenesis, p. 33-46. In L. Ortiz-Ortiz, L. F. Bojalil and V. Yakoleff (ed.), Biological, biochemical and biomedical aspects of actinomycetes. Academic Press, Inc., Orlando, Fla.

114. Bishburg, F., R. H. Fog, J. Slim, G. Perez, and F. Johnson. 1989 Brain lesions in patients with acquired immunodeficiency syndrome. Arch. Intern. Med. 149:941-943.

115. Black, C. M., B. L. Beaman, R. M. Donovan, and E. Goldstein. 1983. Effect of virulent and less virulent strains of Nocardia asteroides on acid-phosphatase activity in alveolar and peritoneal macrophages maintained in vitro. J. Infect. Dis. 148:117-124.

116. Black, C. M., B. L. Beaman, R. M. Donovan, and E. Goldstein 1985. Intracellular acid phosphatase content and ability of differ- ent macrophage populations to kill Nocardia asteroides. Infect. Immun. 47:375-383.

117. Black, C. M., M. Palieschesckey, B. L. Beaman, R. M. Donovan, and E. Goldstein. 1986. Acidification of phagosomes in murine macrophages: blockages by Nocardia asteroides. J. Infect. Dis. 154:952-958.

118. Black, C. M., M. Palieschesckey, B. L. Beaman, R. M. Donovan, and E. Goldstein. 1986. Modulation of lysosomal proteaseesterase and lysozyme in Kupffer cells and peritoneal macrophages infected with Nocardia asteroides. Infect. Immun. 54:917919.

119. Blanchard, R. 1896. Parasites végetaux a l'exclusion des bacteries. p. 811-932. In B. Bouchard (ed.), Traite de pathologie generale, vol. 2. G. Masson, Paris.

120. Bloch, H. 1950. Studies on the virulence tubercle bacilli. Isolation and biological properties of a constituent of virulent organisms. J. Exp. Med. 91:197-217.

121. Bobbitt, O. B., I. H. Friedman, and C. Lupton. 1955. Nocardiosis: report of three cases. N. Engl. J. Med. 252:893-897.

122. Boiron, P., F. Provost, G. Chevrier, and B. Dupont. 1992. Review of nocardial infections in France 1987 to 1990. Eur. J. Clin. Microbiol. Infect. Dis. 11:709-714.

123. Boiron, P., and D. Stynen. 1992. Immunodiagnosis of nocardiosis. Gene 115:219-222.

124. Boixeda, P., A. Espana, J. Suarez, L. Buzon, and A. Ledo. 1991. Cutaneous nocardiosis and human immunodeficiency virus infection. Int. J. Dermatol. 30:804-805.

125. Bonacini, M., and J. M. Walden. 1990. Nocardia brasiliensis peritonitis in a patient with AIDS. Am. J. Gastroenterol. 85: 1432-1433.

126. Boncyk, L. H., B. McCullough, D. D. Grotts, and S. S. Kalter. 1975. Localized nocardiosis due to Nocardia caviae in a baboon (Papio cynocephalus). Lab. Anim. Sci. 25:88-91.

127. Boniver, J., C. Focan, J. Bury, and R. Marcelle. 1973. Proteinose alveolaire et nocardiose. Etude anatomo-clinique d'un cas conceptions pathogéniques actuelles. Acta Clin. Belg. 28:162-175.

128. Bordet, C., and G. Michel. 1969. Structure et biogenese des lipides a haute poids moleculaire de Nocardia asteroides. Bull. Soc. Chim. Biol. 51:527-548.

129. Bourgeois, L., and B. L. Beaman. 1974. Probable L-forms of Nocardia asteroides induced in cultured mouse peritoneal macrophages. Infect. Immun. 9:576-590.

130. Bourgeois, L., and B. L. Beaman. 1976. In vitro spheroplast and L-form induction within the pathogenic nocardiae. J. Bacteriol 127:584-594.

131. Bradney, I. W. 1985 . Vertebral osteomyelitis due to Nocardia in a dog. Aust. Vet. J. 62:315-316.

132. Bradsher, R. W., T. P. Monson, and K. W. Steele. 1982. Brain abscess due to Nocardia caviae. Am. J. Clin. Pathol. 78:124-127.

133. Braun, T. I., L. A. Kerson, and F. P. Eisenberg. 1991. Nocardial brain abscesses in a pregnant woman. Rev. Infect. Dis. 13:630632.

134. Brechot, J. M., F. Capron, J. Prudent, and J. Rochemaure. 1987. Unexpected pulmonary nocardiosis in a non-immunocompromised patient. Thorax 42:479-480.

135. Brine, J. A. S. 1965. Human nocardiosis: a developing clinical picture. Med. J. Aust. 1:339-342.

136. Brochier, J., C. Bona, R. Ciorbaru, J. P. Revillard, and L. Chedid. 1976. A human T-independent B lymphocyte mitogen extracted from Nocardia opaca. J. Immunol. 117:1434-1439.

137. Brooks, J. G., R. A. D. Mills, and D. J. Coster. 1992. Nocardial scleritis. Am. J. Ophthalmol. 114:371-372.

138. Bross, J. E., and G. Gordon. 1991. Nocardial meningitis: case reports and review. Rev. Infect. Dis. 13:160-165.

139. Brown, R. B., M. Sands, and M. Ryczak. 1986. Communityacquired pneumonia caused by mixed aerobic bacteria. Chest 90:810-814.

140. Bruce, G. M., and D. Locatcher-Khorazo. 1942. Actinomyces. Recovery of the streptothrix in a case of superficial punctate keratitis. Arch. Ophthalmol. 27:294-298.

141. Buchanan, A. M., B. L. Beaman, N. C. Pedersen, M. Anderson, and J. L. Stott. 1983. Nocardia asteroides recovery from a dog with steroid- and antibiotic-unresponsive idiopathic polyarthritis. 
J. Clin. Microbiol. 18:702-708.

142. Buggy, B. P. 1987. Nocardia asteroides meningitis without brain abscess. Rev. Infect. Dis. 9:228-231.

143. Bujak, J. S., E. A. Ottesen, C. A. Dinarello, and V. J. Brenner. 1973. Nocardiosis in a child with chronic granulomatous disease. J. Pediatr. 83:98-100.

144. Bullock, J. D. 1983. Endogenous ocular nocardiosis: a clinical and experimental study. Trans. Am. Ophthalmol. Soc. 81:451-531.

145. Burbank, B., T. G. Morrione, and S. S. Cutler. 1960. Pulmonary alveolar proteinosis and nocardiosis. Am. J. Med. 28:1002-1007.

146. Burdon, D. W. 1971. Nocardiosis after appendicectomy. Br. Med. J. 1:538-539.

147. Burton, D. M., and L. P. A. Burgess. 1990. Nocardiosis of the upper aerodigestive tract. Ear Nose Throat J. 69:350-353.

148. Burton, F., M. L. Patete, and W. J. Goodwill. 1992. Indications for open cervical node biopsy in HIV-positive patients. Otolaryngol. Head Neck Surg. 107:367-369.

149. Burpee, J. C., and W. R. Starke. 1971. Bilateral metastatic intraocular nocardiosis. Arch. Ophthalmol. 86:666-669.

150. Bushnell, R. B., A. C. Pier, R. E. Fishtner, B. L. Beaman, H. A. Boos, and M. D. Salman. 1979. Clinical and diagnostic aspects of herd problems with nocardial and mycobacterial mastitis. Am. Assoc. Vet. Lab. Diagn. 22:1-12.

151. Butler, W. R., J. O. Kilburn, and G. P. Kubica. 1987. Highperformance liquid chromatography analysis of mycolic acids as an aid in laboratory identification of Rhodococcus and Nocardia species. J. Clin. Microbiol. 25:2126-2131.

152. Butterfield, E. E. 1905. A case of pulmonary infection with an acid fast actinomyces. J. Infect. Dis. 2:421-430.

153. Byrne, E., B. P. Brophy, and L. V. Perrett. 1979. Nocardial cerebral abscess: New concepts in diagnosis and prognosis. J. Neurol. Neurosurg. Psychiatry 42:1038-1045.

154. Cahen, R., A. Boibieux, M. Chomarat, P. Trolliet, B. Francois, and D. Peyramont. 1987. Nocardiose sous-cutanée primitive compliquant un syndrome néphrotique sous corticothérapie. Presse Med. 16:1242-1243.

155. Calero, C. 1946. Pulmonary actinomycosis. Report of the first case observed in the Isthmus of Panama. Dis. Chest. 12:402-408.

156. Callen, J. P., and J. Kingman. 1984. Disseminated cutaneous Nocardia brasiliensis infection. Pediatr. Dermatol. 2:49-51.

157. Camp, M., J. B. Mehta, and M. Whitson. 1987. Bronchiolitis obliterans and Nocardia asteroides infection in the lung. Chest 92:1107-1108.

158. Campbell, G., and R. M. MacKelvie. 1968. Infection of brook trout (Salvelinus fontinalis) by nocardiae. J. Fish. Res. Board Can. 25:423-425.

159. Carlile, W. K., K. E. Holley, and G. B. Logan. 1963. Fatal acute disseminated nocardiosis in a child. JAMA 184:477-480.

160. Carlisle, J. T., D. L. Greer, and N. E. Hyslop. 1988. Actinomycetoma of the hand caused by Nocardia asteroides. J. Infect. Dis. 158:244-246.

161. Carlsen, E. T., R. B. Hill, Jr., and D. T. Rowlands. 1964. Nocardiosis and pulmonary alveolar proteinosis. Ann. Intern. Med. 60:275-281.

162. Carter, J. M., W. R. Green, C. O. Callender, and B. Peters. 1990. Pulmonary cavitation with Nocardia and Aspergillus in a renal transplant patient. J. Natl. Med. Assoc. 82:527-531.

163. Casale, T. B., A. M. Macher, and A. S. Fauci. 1984. Concomitant pulmonary aspergillosis and nocardiosis in a patient with chronic granulomatous disease of childhood. South. Med. J. 77:274-275.

164. Causey, W. A. 1974. Nocardia caviae: a report of 13 new isolations with clinical correlation. Appl. Microbiol. 28:193-198.

165. Causey, W. A., P. Arnell, and J. Brinker. 1974. Systemic Nocardia caviae infection. Chest 65:360-362.

166. Causey, W. A., and B. Sieger. 1974. Systemic nocardiosis caused by Nocardia brasiliensis. Am. Rev. Respir. Dis. 109:134-137.

167. Chang, P., and H. Logeman. 1992. Mini-mycetoma due to Nocardia brasiliensis. Int. J. Dermatol. 31:180-181.

168. Chapman, S. W., and J. P. Wilson. 1990. Nocardiosis in transplant patients. Semin. Respir. Infect. 5:74-79.

169. Chavez, C. M., W. A. Causey, and J. H. Conn. 1972. Constrictive pericarditis due to infection with Nocardia asteroides. Chest 61:79-81.
170. Chechani, V. 1992. Invasive pulmonary aspergillosis complicated by nocardiosis in a patient with agnogenic myeloid metoplasia. Missouri Med. 89:98-101.

171. Chen, C. J. 1983. Nocardia asteroides endophthalmitis. Ophthalmic Surg. 14:502-505.

172. Chen, S. C. 1992. Study on the pathogenicity of Nocardia asteroides to the formosa snakehead, Channamaculata (lacepede), and largemouth bass, Micropterus salmoides (lacepede). J. Fish Dis. 15:47-53.

173. Chen, S. C. 1992 . The study on the pathogenicity of Nocardia asteroides to largemouth bass, Micropterus salmoides lacepede. Fish Pathol. 27:1-5.

174. Cherubin, C. E. 1992. Nocardiosis in patients with AIDS. Clin. Infect. Dis. 15:370.

175. Chick, E. W. 1962. Pulmonary fungal infections simulating and misdiagnosed as other diseases. Am. Rev. Respir. Dis. 85:702707.

176. Christoph, I. 1990. Pulmonary Cryptococcus neoformans and disseminated Nocardia brasiliensis in an immunocompromised host. N.C. Med. J. 51:219-220.

177. Clague, H. W., M. Harth, D. Hellyer, and W. K. C. Morgan. 1982. Septic arthritis due to Nocardia asteroides in association with pulmonary alveolar proteinosis. J. Rheumatol. 9:469-472.

178. Clapp, M. P., and M. J. Williams. 1955 . Nocardiosis: discussion of two cases with emphasis on diagnostic features. Tex. Rep. Biol. Med. 13:11.

179. Claveria, L. E., G. H. DuBoulay, and I. F. Moseley. 1976 Intracranial infections: investigations by computerized axial tomography. Neuroradiology 12:59-71.

180. Climenhaga, D. B., A. C. Tokarewicz, and N. R. Willis. 1984. Nocardia keratitis. Can. J. Ophthalmol. 19:284-286.

181. Clinicopathologic Conference. 1967. Pulmonary lesion, headache and neurologic deficit. Resume of a case. Mayo Clinic Proc. 42:565.

182. Cockerill, F. R., R. S. Edson, G. D. Roberts, and J. C. Waldorf. 1984. Trimethoprim/sulfamethoxazole-resistant Nocardia asteroides causing multiple hepatic abscesses. Am. J. Med. 77:558560.

183. Cohen, M. L., E. B. Weiss, and A. P. Monaco. 1971. Successful treatment of Pneumocystis carinii and Nocardia asteroides in a renal transplant patient. Am. J. Med. 50:269-276.

184. Coker, R. J., G. Bignardi, P. Horner, M. Savage, T. Cook, D. Tomlinson, and J. Weber. 1992. Nocardia infection in AIDS: a clinical and microbiological challenge. J. Clin. Pathol. 45:821822.

185. Collins, C. H., M. D. Yates, and A. H. C. Uttley. 1988. Presumptive identification of nocardias in a clinical laboratory. J. Appl. Bacteriol. 65:55-59.

186. Connar, R. G., T. B. Ferguson, W. C. Sealy, and N. F. Conant. 1951. Nocardiosis: report of a single case with recovery. J. Thorac. Cardiovasc. Surg. 22:424-433.

187. Cons, F., A. Trevino, and C. Lavalle. 1985. Septic arthritis due to Nocardia brasiliensis. J. Rheumatol. 12:1019-1021.

188. Cook, F. V., and W. E. Farrar, Jr. 1978. Treatment of Nocardia asteroides infection with trimethoprim-sulfamethoxazole. South Med. J. 71:512-515.

189. Cooper, J. E. 1973. Post-mortem findings in east african birds of prey. J. Wildl. Dis. 9:368-375.

190. Cornelissen, J. J., L. K. Bakker, M. J. Van der Veen, M. Rozenberg-Arska, and J. W. J. Bijlsma. 1991. Nocardia asteroides pneumonia complicating low dose methotrexate treatment of refractory rheumatoid arthritis. Ann. Rheum. Dis. 50:642-644.

191. Cosidow, O., P. Wolkenstein, M. Bagot, F. Girard-Pipau, C. Brun-Buisson, S. Fraitag, J. C. Roujeau, and J. Revuz. 1990. Nocardia asteroides septicemia in a pemphigus patient. Dermatologica 181:311-313.

192. Cosnett, J. E., M. Moodley, P. Bill, and R. Bullock. 1988. Operculum syndrome from brain abscess in a left hander. $\mathbf{J}$. Neurol. Neurosurg. Psychiatry 51:307-308.

193. Cotton, R. E., and H. E. D. Lloyd. 1960. Lipid pneumonia and infection with Nocardia asteroides complicating achalasia of the cardia. J. Pathol. Bacteriol. 79:251-256.

194. Cox, F., J. F. Hall, C. F. Ballenger, and R. T. Leshner. 1986. 
Nocardia asteroides brain abscess following mastoidectomy. Pediatr. Neurol. 7:183-184.

195. Cox, F., and W. T. Hughes. 1975. Contagious and other aspects of nocardiosis in the compromised host. Pediatrics 55:135-138.

196. Cross, R. M., and C. H. Binford. 1962. Infections by fungi that are commonly primary pathogens: is Nocardia asteroides an opportunist? Lab. Invest. 11:1103-1109.

197. Cruickshank, M. A., M. J. Riley, and R. M. Standish White. 1975 Nocardiosis and actinomycosis in the Mashonaland Province of Rhodesia. Cent. Afr. J. Med. 21:152-158.

198. Cruz, P. T., and C. F. Clancy. 1952. Nocardiosis: nocardial osteomyelitis and septicemia. Am. J. Pathol. 28:607-627.

199. Cummins, C. S. 1962. Chemical composition and antigenic structure of cell walls of Corynebacterium, Mycobacterium, Nocardia, Actinomyces and Arthrobacter. J. Gen. Microbiol. 28:35-50.

200. Cummins, C. S. 1965. Chemical and antigenic studies on cell walls of Mycobacterium, Corynebacterium and Nocardia. Am. Rev. Respir. Dis. 92:63-72.

201. Cupp, C. M., W. M. Edwards, M. E. Walton, and E. A. Cleve. 1960. Nocardiosis of the central nervous system: report of two fatal cases. Ann. Intern. Med. 52:223-226.

202. Curley, R. K., T. Hayward, and C. A. Holden. 1990. Cutaneous abscesses due to systemic nocardiosis-a case report. Clin. Exp. Dermatol. 15:459-461.

203. Curry, W. A. 1980. Human nocardiosis: a clinical review with selected case reports. Arch. Intern. Med. 140:818-826.

204. Das, B. C., R. McGowan, and J. Dawson. 1983. An unusual presentation of nocardiosis. J. Infect. 7:169-170.

205. Davenport, D. J., and G. C. Johnson. 1986. Cutaneous nocardiosis in a cat. J. Am. Vet. Med. Assoc. 188:728-729.

206. Davidson, S., and H. C. Foerster. 1967. Intraocular nocardial abscess, endogenous. Trans. Am. Acad. Ophthalmol. Otolaryngol. 71:847-850.

207. Davis, D. J. 1914. An acid-fast streptothrix (Nocardia). Arch. Intern. Med. 14:1-7.

208. Davis-Scibienski, C., and B. L. Beaman. 1980. Interaction of Nocardia asteroides with rabbit alveolar macrophages: association of virulence, viability, ultrastructural damage, and phagosomelysosome fusion. Infect. Immun. 28:610-619.

209. Davis-Scibienski, C., and B. L. Beaman. 1980. Interaction of Nocardia asteroides with rabbit alveolar macrophages: effect of growth phase and viability on phagosome-lysosome fusion. Infect. Immun. 29:24-29.

210. Davis-Scibienski, C., and B. L. Beaman. 1980. Interaction of alveolar macrophages with Nocardia asteroides: immunological enhancement of phagocytosis, phagosome-lysosome fusion, and microbicidal activity. Infect. Immun. 30:578-587.

211. Deem, R. L., B. L. Beaman, and M. E. Gershwin. 1982. Adoptive transfer of immunity to Nocardia asteroides in nude mice. Infect. Immun. 38:914-920.

212. Deem, R. L., F. A. Doughty, and B. L. Beaman. 1983. Immunologically specific direct T lymphocyte-mediated killing of Nocardia asteroides. J. Immunol. 130:2401-2406.

213. De Korte, W. E. 1917. Nocardia cylindracea: a South African otomycosis. Ann. Trop. Med. 11:265-278.

214. de la Hoz Caballer, B., M. Fernandez-Rivas, S. Q. Gancedo, I. D. Ruiz, J. P. Ruiz, J. C. Herranz, E. A. Cuesta, M. Cuevas, and M. J. P. Elias. 1991. Management of sulfadiazine allergy in patients with acquired immunodeficiency syndrome. J. Allergy Clin. Immunol. 88:137-138.

215. DeLouvois, J. 1984. Antimicrobial therapy in the treatment of brain abscess. J. Antimicrob. Chemother. 12:205-207.

216. De Luca, J., B. Walsh, W. Robbins, and E. B. Visconti. 1986 Nocardia asteroides osteomyelitis. Postgrad. Med. J. 62:673-674.

217. de Silva, R., P. M. Stoopack, and J. P. Raufman. 1990. Esophageal fistulas associated with mycobacterial infections at risk for AIDS. Radiology 175:449-453.

218. Diamond, R. D., and J. E. Bennett. 1973. Disseminated Nocardia brasiliensis infection. Arch. Intern. Med. 131:735-736.

219. Dietlein, F., R. Firsching, and G. Peters. 1988. Therapy of brain abscess caused by Nocardia farcinica. Med. Klin. 83:613-614.

220. DiVittorio, G., J. T. Carpenter, Jr., and J. C. Bennett. 1982 Arthritis in systemic nocardiosis. South. Med. J. 75:507-508.
221. Dohoo, I. R. 1991. Update on Nocardia sp. mastitis. Can. Vet. J. 32:116.

222. Dolan, T. F., Jr., N. B. McCullough, and L. E. Gibson. 1960. Nocardiosis: report of two cases in children. Am. Med. Assoc. J. Dis. Child. 99:234-237.

223. Dong, Z. P., Y. Z. Xiu, Z. P. Lu, M. Y. Huang, and P. S. Sun. 1982. Nocardiosis in deer: report of a case. Chin. J. Vet. Med. 8:26-27.

224. Donnenfeld, E. D., E. J. Cohen, M. Barza, and J. Baum. 1985. Treatment of Nocardia keratitis with topical trimethoprim-sulfamethoxazole. Am. J. Ophthalmol. 99:601-602.

225. Dufresne, R. G., Jr., D. L. Latour, and J. P. Fields. 1986. Sulfur granules in lymphocutaneous nocardiosis. J. Am. Acad. Dermatol. 14:847.

226. Ekizlerian, S. M., S. L. Brandão-Filho, and C. L. Silva. 1986. Mouse toxicity induced by lipids and cell walls isolated from actinomycetes. J. Gen. Microbiol. 132:2647-2651.

227. Ekizlerian, S. M., S. L. Brandão-Filho, I. Tincani, L. M. Carareto Alves, and C. L. Silva. 1987. Studies on the pathogenesis of actinomycotic mycetoma in animals injected with fractions isolated from Nocardia brasiliensis. Br. J. Exp. Pathol. 68:115-123.

228. Ellner, J. J., and J. E. Bennett. 1976. Chronic meningitis. Medicine 55:341-369.

229. Emerueva, A. C. 1986. Isolation and some properties of betahemolysis produced by Nocardia asteroides. Mycopathologia 95: 29-35.

230. Eppinger, H. 1890. Über eine neue, pathogene Cladothrix und eine durch sie hervorgerufene pseudotuberculosis. Wien. Klin. Wochenschr. 3:321-323.

231. Eppinger, H. 1891. Über eine neue, pathogene Cladothrix und eine durch sie hervorgerufene pseudotuberculosis (cladothrichica). Beitr. Pathol. Anat. Allg. Pathol. 9:287-328.

232. Epstein, S., M. Holden, J. Feldshuh, and J. M. Singer. 1963. Unusual cause of spinal cord compression: nocardiosis. N.Y. State J. Med. 63:3422-3427.

233. Erchul, J. W., and M. L. Koch. 1955. Cerebral nocardiosis with coexistent pulmonary tuberculosis. Am. J. Clin. Pathol. 25:775781

234. Ertl, G., K. P. Schaal, and K. Kochsiek. 1987. Nocardial endocarditis of an aortic valve prosthesis. Heart J. 57:384-386.

235. Evans, R. A., and R. E. Benson. 1971. Complicated nocardiosis successfully treated with trimethoprim and sulphamethoxazole. Med. J. Aust. 58:684-685.

236. Fairley, N. H., and F. P. Mackie. 1935. Case of streptothrical ulceration of the colon with portal and systemic pyaemia. Trans. R. Soc. Trop. Med. Hyg. 29:151-156.

237. Feigin, D. S. 1986. Nocardiosis of the lung: chest radiographic findings in 21 cases. Thorac. Radiol. 159:9-14.

238. Fernandez, P., M., L. Paredes P., M. Castillo G., y A. Donoso S. 1987. Nocardiosis: aspectos clinicos y bacteriologicos experiencia en 16 casos. Rev. Med. Chile 115:1053-1060.

239. Fernandez-Guerrero, M. L., A. Torres, M. Diaz Curiel, and F. Soriano. 1985. Successful treatment of Nocardial thigh abscess and possible brain abscess with Co-trimoxazole. Eur. J. Clin. Microbiol. 4:430-431.

240. Ferns, L., I. Dohoo, and A. Donald. 1991. A case control study of nocardia-mastitis in Nova-Scotia dairy herds. Can. Vet. J. 32:673677.

241. Ferry, A. P., R. L. Font, R. S. Weinberg, M. Boniuk, and C. L. Schaffer. 1988. Nocardial endophthalmitis: report of two cases studied histopathologically. Br. J. Ophthalmol. 72:55-61.

242. Filice, G. A. 1983. Resistance of Nocardia asteroides to oxygendependent killing by neutrophils. J. Infect. Dis. 148:861-867.

243. Filice, G. A. 1985 . Inhibition of Nocardia asteroides by neutrophils. J. Infect. Dis. 151:47-56.

244. Filice, G. A., B. L. Beaman, J. A. Krick, and J. S. Remington. 1980. Effects of human neutrophils and monocytes on Nocardia asteroides: failure of killing despite occurrence of the oxidative metabolic burst. J. Infect. Dis. 142:432-438.

245. Filice, G. A., B. L. Beaman, and J. S. Remington. 1980. Effects of activated macrophages on Nocardia asteroides. Infect. Immun. 27:643-649.

246. Filice, G. A., and D. E. Niewoehner. 1987. Contribution of neutrophils and cell-mediated immunity to control of Nocardia 
asteroides in murine lungs. J. Infect. Dis. 156:113-121.

247. Flexner, S. 1898. Pseudo-tuberculosis hominis streptothricha. J. Exp. Med. 3:435-450.

248. Folb, P. I., G. Altman, D. Merzbach, and E. Ipp. 1976. Nocardiosis in Israel. A report of five cases. Isr. J. Med. Sci. 12:150-153.

249. Fono, R., and A. Csillag. 1959. Case of pulmonary nocardiosis with recovery. Acta Pediatr. 48:273-277.

250. Fontaneda-Lopez, P., M. Corrales-Rodriguez de Temhlegise, F. Fernandez-Ortega, J. L. Sarasa Corral, J. Gomez-Garcas, and M. Fernandez-Guerrero. 1989. Nocardiosis: clinical observations apropos of 9 cases. Rev. Clin. Esp. 185:454-458.

251. Forbes, G. M., F. A. H. Harvey, J. N. Philpott-Howard, J. G. O'Grady, R. D. Jensen, M. Sahathevan, M. W. Casewell, and R. Williams. 1990. Nocardiosis in liver transplantation: variation in presentation, diagnosis and therapy. J. Infect. 20:11-19.

252. Forrett-Kaminsky, M. C., C. Scherer, M. Bemer, V. Robert, G. Steinbach, and J. F. Poussel. 1991. Nocardia asteroides otitis media in AIDS. Presse Med. 20:1512-1513.

253. Frazier, A., E. C. Rosenow, and G. D. Roberts. 1975. Nocardiosis: a review of 25 cases occurring during 24 months. Mayo Clin. Proc. 50:657-663.

254. Freese, J. W., W. G. Young, Jr., W. C. Sealy, and N. F. Conant. 1963. Pulmonary infection by Nocardia asteroides. Findings in eleven clinical cases. J. Thorac. Cardiovasc. Surg. 46:537-547.

255. Fried, J., D. Hinthorn, J. Ralstin, P. Gerjarusak, and C. Liu. 1988. Cure of brain abscess caused by Nocardia asteroides resistant to multiple antibiotics. South. Med. J. 81:412-413.

256. Friedman, C. S., and R. P. Hedrick. 1991. Pacific oyster nocardiosis: isolation of the bacterium and induction of laboratory infections. J. Invertebr. Pathol. 57:109-120.

257. Frumkin, A. 1989. Nocardial infections in Israel: a survey. Isr. J. Med. Sci. 25:324-327.

258. Garty, B. Z., H. Stark, I. Yaniv, I. Varsano, and Y. L. Danon. 1985. Pulmonary nocardiosis in a child with systemic lupus erythematosus. Pediatr. Infect. Dis. J. 4:66-68.

259. Geelhoed, G. W., and G. H. Myers, Jr. 1974. Nocardiosis of the testes. J. Urol. 111:791-793.

260. Geiseler, P. J., and B. R. Anderson. 1979. Results of therapy in systemic nocardiosis. Am. J. Med. Sci. 278:188-194.

261. Geiseler, P. J., F. Check, F. Lamothe, and B. R. Andersen. 1979. Failure of trimethoprim/sulfamethoxazole in invasive Nocardia asteroides infection. Arch. Intern. Med. 139:355-356.

262. George, R. B., R. L. Penn, and G. T. Kinaseivitz. 1985. Mycobacterial, fungal, actinomycotic and nocardial infections of the pleura. Clin. Chest Med. 6:63-75.

263. Georghiou, P. R., and Z. M. Blacklock. 1992. Infection with Nocardia species in Queensland: a review of 102 clinical isolates. Med. J. Aust. 156:692-697.

264. Germain, P., G. Remy, J. Deville, A. Strady, G. Dropsy, J. F. Guyot, and M. Puot. 1974. Nocardiosis, osseous and cerebral locations. Apropos of 2 cases. Ann. Med. Interne (Paris) 125: 201-206.

265. Gezuelle, E. 1972. Fatal infection by Nocardia brasiliensis in an armadillo. Sabouraudia 10:63-65.

266. Gibb, W., and A. Williams. 1986. Nocardiosis mimicking Wegener's granulomatosis. Scand. J. Infect. Dis. 18:583-585.

267. Gilligan, B. S., I. Williams, and A. K. Perceval. 1962. Nocardial meningitis: report of a case with bacteriological studies. Med. J. Aust. 49:747-752.

268. Gingrich, W. D. 1962. Keratomycosis. JAMA 179:602-608.

269. Girouard, Y., G. Albert, B. Thivierge, and M. Lorange-Rodrigues. 1987. Primary cutaneous nocardiosis due to Nocardia caviae. Can. Med. Assoc. J. 136:844-845.

270. Glover, R. P., W. E. Herrell, F. R. Heilman, and K. H. Pfuetze. 1948. Nocardiosis. Nocardia asteroides infection simulating pulmonary tuberculosis. JAMA 136:172-175.

271. Goldstein, F. W., B. Hautefort, and J. F. Acar. 1987. Amikacin containing regimens for treatment of nocardiosis in immunocompromised patients. Eur. J. Clin. Microbiol. 6:198-200.

272. Goldsworthy, N. E. 1937. Pulmonary actinomycosis caused by an acid-fast species of actinomyces. J. Pathol. Bacteriol. 45:17-27.

273. Gonzalez-Ochoa, A. 1962. Mycetomas caused by Nocardia brasiliensis; with a note on the isolation of the causative organism from soil. Lab. Invest. 11:1118-1123.

274. Gonzalez-Ochoa, A. 1973. Virulence of nocardiae. Can. J. Microbiol. 19:901-904.

275. Goodfellow, M. 1992. The family Nocardiaceae, p. 1188-1213. In A. Ballows, H. G. Truper, M. Dworkin, W. Harder, and K. H. Schleifer (ed.), The prokaryotes, vol. II, 2nd ed. Springer-Verlag, New York.

276. Goodman, J. S., and M. G. Koenig. 1970. Nocardia infections in a general hospital. Ann. N.Y. Acad. Sci. 174:552-567.

277. Gordon, M. A. 1964. Nocardia brasiliensis in New England. N. Engl. J. Med. 270:42-43.

278. Gordon, R. E. 1981. A proposed new status for Nocardia asteroides. Zentralbl. Bakteriol. Microbiol. Hygiene Abt. 1. Suppl. 11:3-6.

279. Goren, M. B. 1990. Mycobacterial fatty acid esters of sugars and sulfosugars, p. 363-461. In M. Kaitz (ed.), Glycolipids, phosphoglycolipids and sulfoglycolipids. Handbook of lipid research, vol. 6. Plenum Press, New York.

280. Gorevic, P. D., E. I. Katler, and B. Agus. 1980. Pulmonary nocardiosis. Occurrence in men with systemic Lupus erythematosus. Arch. Intern. Med. 140:361-363.

281. Grain, E., N. Ackerman, and W. Castleman. 1978. Disseminated nocardiosis in a dog. Calif. Vet. 32:9-11.

282. Green, W. O., and T. E. Adams. 1964. Mycetoma in the United States: a review and report of seven additional cases. Am. J. Clin. Pathol. 42:75-91.

283. Greer, K. E. 1974. Nocardia mycetoma. Virginia Med. Monthly 101:193-195.

284. Grossman, C. B., D. G. Bragg, and D. Armstrong. 1970. Roentgen manifestations of pulmonary nocardiosis. Radiology 96:325330 .

285. Gruberg, L., M. Thaler, J. Rozenman, I. Bank, and M. Pras. 1991. Nocardia asteroides infection complicating rheumatoid arthritis. J. Rheumatol. 18:459-461.

286. Gugnani, H. C., J. O. Ojukwu, and A. V. Suscelan. 1982. Mycetoma of thumb caused by Nocardia transvalensis. Mycopathologia 80:55-60.

287. Gugnani, H. C., I. C. Unaogu, and C. N. Emeruwa. 1991 Incidence of pulmonary infection due to Nocardia species in Nigeria. Mycoses 34:359-361.

288. Guidon-Attali, C., J. Bertrando, M. Sethian, R. Perez, J. F. Pellissier, and J. C. Peragut. 1988. Nocardiose cerebrale isolee une observation. Presse Med. 17:1649.

289. Guiral, J., C. Refolio, P. Carrero, and S. Carbajosa. 1991. Sacral osteomyelitis due to Nocardia asteroides. A case report. Acta Orthop. Scand. 62:389-390.

290. Gupta, M. L., P. Singh, B. K. Goyal, A. Goyal, and R. D. Sharma. 1982. Bilateral conjunctivitis associated with Nocardia asteroides. A case report. Indian J. Ophthalmol. 30:167-168.

291. Guy, W. H., and T. R. Helmbold. 1933. Nocardiosis cutis gangrenosa. Arch. Dermatol. Syphilol. 27:224-231.

292. Gydell, K., I. Juhlin, H. Ljunggren, J. G. Norden, and B. Fors. 1965. Nocardiosis during steroid treatment of auto-immune haemolytic anaemia. Report of a fatal case. Acta Med. Scand. 178:221-231.

293. Hachisuka, H., M. Ichiki, N. Yoshida, S. Nakano, and Y. Sasai. 1989. Primary subcutaneous abscess caused by Nocardia otitidiscaviarum. J. Am. Acad. Dermatol. 21:137-139.

294. Hadley, M. N., R. F. Spetzler, N. A. Martin, and P. C. Johnson. 1988. Middle cerebral artery aneurysm due to Nocardia asteroides: case report of aneurysm excision and extracranial-intracranial bypass. Neurosurgery 22:923-928.

295. Hager, H. F., A. V. Migliaccio, and R. M. Young. 1949. Nocardiosis. Pneumonia and empyema due to Nocardia asteroides. N. Engl. J. Med. 241:226-231.

296. Haim, S., and D. Merzbach. 1979. Primary chancriform syndrome caused by Nocardia asteroides. Mykosen 22:360-363.

297. Hall, E. R., and D. A. Cooley. 1957. Pulmonary nocardiosis: report of a case complicated by tuberculosis. Dis. Chest 31:453456.

298. Hall, W. A., A. J. Martinez, J. S. Dummer, B. P. Griffith, R. I. Hardesty, H. T. Babrson, and L. D. Lunsford. 1989. Central nervous system infections in heart-lung transplant recipients. 
Arch. Neurol. 46:173-177.

299. Hall, W. A., A. J. Martinez, J. S. Dummer, and L. D. Lunsford. 1987. Nocardial brain abscess: diagnostic and therapeutic use of sterotactic aspiration. Surg. Neurol. 28:114-118.

300. Hamal, P. B. 1974. Primary pulmonary nocardiosis: case report. Thorax 29:382-386.

301. Hargrove, M. D., W. R. Mathews, and P. A. McIntyre. 1967. Intestinal lymphangiectasia with response to corticosteroids. Arch. Intern. Med. 119:206-220.

302. Harris, J. O., J. R. Castle, E. W. Swenson, and A. J. Block. 1974. Lobar lavage: therapeutic benefit in pulmonary alveolar filling disorders. Chest 65:655-659.

303. Harth, Y., R. Friedman-Birnbaum, E. Lefler, and R. Bergman. 1992. Two patients with simultaneous, unusually located primary cutaneous nocardiosis. J. Am. Acad. Dermatol. 26:132-133.

304. Hathaway, B. M., and K. N. Mason. 1962. Nocardiosis. Study of fourteen cases. Am. J. Med. 32:903-909.

305. Hay, R. J., and D. W. R. Mackenzie. 1983. Mycetoma (madura foot) in the United Kingdom-a survey of forty-four cases. Clin. Exp. Dermatol. 8:553-562.

306. Hayashi, S., T. Masuno, S. Hosoe, I. Kawase, M. Sakatani, T. Ogura, S. Kishimoto, and Y. Yamamura. 1986. Augmented production of colony-stimulating factor in $\mathrm{C} 3 \mathrm{H} / \mathrm{HeN}$ mice immunized with Nocardia rubra cell wall skeleton. Infect. Immun. 52:128-133.

307. Henderson, J. W., W. E. Wellman, and L. A. Weed. 1960. Nocardiosis of the eye: report of case. Proc. Staff Mayo Clin. 35:614-618.

308. Henrici, A. T., and E. L. Gardner. 1921. The acid fast actinomycetes: with a report of a case from which a new species was isolated. J. Infect. Dis. 28:232-248.

309. Herkes, G. K., J. Fryer, R. Rushworth, R. Pritchard, R. M. Wilson, and R. Joffe. 1989. Cerebral nocardiosis-clinical and pathological findings in three patients. Aust. N.Z. J. Med. 19:475-478.

310. Hershewe, G. L., L. E. Davis, and J. M. Bicknell. 1988. Primary cerebellar brain abscess from nocardiosis in a heroin addict. Neurology 38:1655-1656.

311. Hessen, M. T., and J. Santoro. 1988. Lymphocutaneous nocardiosis in Pennsylvania. Pa. Med. 91:54-56.

312. Heuschmann-Brunner, G. 1966. Nocardia-infektion bei Rogenbogenforellen (Salvelinus fontinalis). Berl. Munch. Tierarztl. Wochenschr. 79:96-97.

313. Hickey, R. C., and E. M. Berglund. 1953. Nocardiosis: aerobic actinomycosis with emphasis on the alimentary tract as a portal of entry. Arch. Surg. 67:381-391.

314. Hinokuma, K., I. Shimoyama, T. Ninchoji, and K. Uemura. 1984. Nocardia asteroides brain abscess. Case report. Neurol. Med. Chir. (Tokyo) 24:135-138.

315. Hironaga, M., T. Mochizuki, and S. Watanabe. 1990. Acute primary cutaneous nocardiosis. J. Am. Acad. Dermatol. 23:399 400.

316. Hirst, L. W., G. K. Harrison, W. G. Merz, and W. Stark. 1979. Nocardia asteroides keratitis. Br. J. Ophthalmol. 63:449-454.

317. Hirst, L. W., W. G. Merz, and W. R. Green. 1982. Nocardia asteroides corneal ulcer. Am. J. Ophthalmol. 94:123-124.

318. Hocken, A. G., E. R. Smith, and I. Aarons. 1978. Goodpasture's syndrome complicated by Nocardia asteroides infection. N.Z. Med. J. 87:38-41.

319. Hoepelman, I. M., L. J. Bakker, R. F. M. Jessurun, M. Rozenberg-Arska, and J. Verhoef. 1987. Disseminated Nocardia asteroides infection complicating renal transplantation. Neth. J. Med. 31:175-182.

320. Hoeprich, P. P., D. Brandt, and R. H. Parker. 1968. Nocardial brain abscess cured with cycloserine and sulfonamides. Am. J. Med. Sci. 255:208-216.

321. Hogshead, H. P., and G. H. Stein. 1970. Mycetoma due to Nocardia brasiliensis. J. Bone J. Surg. 52:1229-1234.

322. Holdaway, M. D., J. Kennedy, T. Ashcroft, and J. J. Kay-Butler. 1967. Pulmonary nocardiosis in a 3-year-old child. Thorax 22: 375-381.

323. Holm, P. 1975. Seven cases of human nocardiosis caused by Nocardia farcinica. Sabouraudia 13:161-169.
324. Holtz, H. A., D. P. Lavery, and R. Kapila. 1985. Actinomycetes infection in the acquired immunodeficiency syndrome. Ann Intern. Med. 102:203-205.

325. Horwitz, M. A. 1984. Phagocytosis of the Legionnaires' disease bacterium (Legionella pneumophila) occurs by a novel mechanism: engulfment within a pseudopod coil. Cell 36:27-33.

326. Hosty, T. S., C. McDurmont, L. Ajello, L. K. Georg, G. L. Brumfield, and A. A. Calix. 1961. Prevalence of Nocardia asteroides in sputa examined by a tuberculosis diagnostic laboratory. $\mathbf{J}$. Lab. Clin. Med. 58:107-114.

327. Huang, C. C., C. C. Lee, and N. S. Chu. 1991. A case of cerebral nocardiosis successfully treated with trimethoprim-sulfamethoxazole. J. Formosan Med. Assoc. 90:407-410.

328. Hunter, L. R., A. K. Krinsky, and C. H. Fleener. 1992. Preseptal cellulitis caused by Nocardia brasiliensis. Am. J. Ophthalmol. 114:373-374.

329. Hutter, R. V. P., and H. S. Collins. 1962. The occurrence of opportunistic fungus infection in a cancer hospital. Lab. Invest. 11:1035-1045.

330. Idemyor, V., and C. E. Cherubin. 1992. Pleurocerebral Nocardio in a patient with human immunodeficiency virus. Ann. Pharmacother. 26:188-189.

331. Idriss, Z. H., R. J. Cunningham, and C. M. Wilfert. 1975. Nocardiosis in children: report of three cases and review of the literature. Pediatrics 55:479-484.

332. Inamura, N., K. Nakahara, Y. Kuroda, I. Yamaguchi, H. Aoki, and M. Kohsaka. 1988. Effect of Nocardia rubra cell wall skeleton on interleukin 1 production from mouse peritoneal macrophages. Int. J. Immunopharmacol. 10:547-554.

333. Ioneda, T. 1984. Lipids of the Actinomycetes: their structures and biosyntheses, p. 239-249. In L. Ortiz-Ortiz, L. F. Bojalil, and V. Yakoleff (ed.), Biological, biochemical and biomedical aspects of actinomycetes. Academic Press, Inc., Orlando, Fla.

334. Ioneda, T., and B. L. Beaman. 1992. Molecular weight determination of methyl esters of mycolic acids using thermospray mass spectrometry. Chem. Phys. Lipids 63:41-46.

335. Ioneda, T., E. Lederer, and J. Rozanis. 1970. Sur la structure des diesters de trehalose (cord factors) produits par Nocardia asteroides et Nocardia rhodochrous. Chem. Phys. Lipids 4:375-392.

336. Ioneda, T., N. T. Niigaki, E. T. Dealmeida, and C. E. Levy. 1989 Occurrence of trehalose mycolate as the major lipidic component carrying toxic property in clinical Nocardia isolates. Rev. Microbiol. 20:345-348.

337. Ishibashi, Y., R. Watamabe, S. Hommura, A. Koyama, T. Ishikawa, and Y. Mikami. 1990. Endogenous Nocardia asteroides endophthalmitis in a patient with systemic lupus erythematosus Br. J. Ophthalmol. 74:433-436.

338. Iyer, P. K. R., and P. P. Rao. 1971. Suspected pulmonary nocardiosos in a duck. Sabouraudia 9:79-80.

339. Iyer, P. K. R., P. P. Rao, L. N. Acharjyo, S. Sahu, and S. K. Mishra. 1972. Systemic nocardiosis in a hill mynah (Gracula religiosa) -a pathological study. Mycopathol. Mycol. Appl. 48 223-229.

340. Jacob, E. T., Z. Ziskind, O. Nativ, and M. Shabtai. 1985. Severe pulmonary nocardiosis in a kidney allograft recipient with a low immunological response. Isr. J. Med. Sci. 21:613-616.

341. Jacobs, S. I., and R. M. Gibson. 1963. A fatal case of cerebral abscess due to Nocardia asteroides. J. Neurol. Neurosurg. Psychiatry 26:363-367.

342. Jacobson, J. R., and R. B. Cloward. 1948. Actinomycosis of the central nervous system. JAMA 137:769-771.

343. Jampol, L. M., B. S. Strauch, and D. M. Albert. 1973. Intraocular nocardiosis. Am. J. Ophthalmol. 76:568-573.

344. Jansen, C., H. M. E. Frenay, W. P. Vandertop, and M. R. Visser. 1991. Intracerebral Nocardia asteroides abscess treated by neurosurgical aspiration and combined therapy with sulfadiazine and cefotaxime. Clin. Neurol. Neurosurg. 93:253-255.

345. Jasmin, A. M., C. P. Powell, and J. N. Baucom. 1972. Actinomycotic mycetoma in the bottlenose dolphin (Tursiops truncatus) due to Nocardia paraguayenesis. Vet. Med. Small Anim. Clin. 67:542-543.

346. Javaly, K., H. W. Horowitz, and G. P. Wormser. 1992. Nocardiosis in patients with human immunodeficiency virus infection: 
report of 2 cases and review of the literature. Medicine 71:128138.

347. Jesiotr, M., and A. M. Beemer. 1969. Vaccine and antimicrobial therapy in pulmonary nocardiosis. Scand. J. Respir. Dis. 50:54 60.

348. Johnston, H. C., A. O. Shigeoka, D. C. Hurley, and T. J. Pysher. 1989. Nocardia pneumonia in a neonate with chronic granulomatous disease. Pediatr. Infect. Dis. J. 8:526-529.

349. Jonas, A. M., and D. S. Wyand. 1966. Pulmonary nocardiosis in the rhesus monkey. Pathol. Vet. 3:588-600.

350. Jonsson, S., R. J. Wallace, Jr., S. I. Hull, and D. M. Musher. 1986. Recurrent Nocardia pneumonia in an adult with chronic granulomatous disease. Am. Rev. Respir. Dis. 133:932-934.

351. Joshi, N., and B. H. Hamory. 1991. Drug-resistant Nocardia asteroides infection in a patient with acquired immunodeficiency syndrome. South. Med. J. 84:1155-1156.

352. Kahn, F. W., C. C. Gornick, and R. W. Tofte. 1981. Primary cutaneous Nocardia asteroides infection with dissemination. Am. J. Med. 70:859-863.

353. Kalb, R. E., M. H. Kaplan, and M. E. Grossman. 1985. Cutaneous nocardiosis. case reports and review. J. Am. Acad. Dermatol. 13:125-133.

354. Kamat, B. R., and A. M. Dvorak. 1984. The electron microscopic appearance of Nocardia asteroides in human lung tissue. Arch. Pathol. Lab. Med. 108:862-864.

355. Kaneda, K., Y. Sumi, F. Kurano, Y. Kato, and I. Yano. 1986 Granuloma formation and hemopoiesis induced by $\mathrm{C}_{36-48}-\mathrm{my}-$ colic acid containing glycolipids from Nocardia rubra. Infect. Immun. 54:869-875.

356. Karalus, N. C., R. T. Cursons, R. A. Leng, C. B. Mahood, R. P. Rothwell, B. Hancock, S. Cepulis, M. Wawatai, and L. Coleman. 1991. Community acquired pneumonia: aetiology and prognostic index evaluation. Thorax 46:413-418.

357. Karassik, S. L., L. Subramanyam, R. E. Green, and J. Brook. 1976. Disseminated Nocardia brasiliensis infection. Arch. Dermatol. 112:370-372.

358. Karunasagar, I., G. Krohne, and W. Goebel. 1993. Listeria ivanovii is capable of cell-to-cell spread involving actin polymerization. Infect. Immun. 61:162-169.

359. Kattan, H. M., and S. C. Pflugfelder. 1990. Nocardia scleritis. Am. J. Ophthalmol. 110:446-447.

360. Katz, P., and A. S. Fauci. 1977. Nocardia asteroides sinusitis. Presentation as a trimethoprim-sulfamethoxazole responsive fever of unknown origin. JAMA 238:2397-2398.

361. Kaufman, N., and L. C. Prieto. 1952. Cerebral nocardiosis. Arch. Pathol. 53:379-384.

362. Keall, D. D., and A. Zorbas. 1966. Nocardiosis: a fatal case with pulmonary and systemic involvement. Med. J. Aust. 2:651-652.

363. Keegan, J. M., and J. M. Byrd. 1988. Nocardiosis associated with low dose methotrexate for rheumatoid arthritis. J. Rheumatol. 15:1585-1586.

364. Kelly, S. J., D. Waghorn, and A. Ademokun. 1991. Nocardiosis in an immunocompromised patient-an unusual presentation. Case report. J. Infect. 22:269-271.

365. Kepes, J. J., and A. Schoolman. 1965. Post-traumatic abscess of the medulla oblongata containing Nocardia asteroides. J. Neurosurg. 22:511-514.

366. Kerbel, N. C. 1962. Long-term steroid therapy of the nephrotic syndrome in an adult complicated by fatal nocardiosis. Can. Med. Assoc. J. 87:129-132.

367. Kessel, J. F., and E. B. Goolden. 1938. A comparison of strains of actinomyces recovered from human lesions. Am. J. Trop. Med. 18:689-699.

368. Kessler, M. J., and R. J. Brown. 1981. Mycetomas in a squirrel monkey (Saimiri sciureus). J. Zoo Anim. Med. 12:91-93.

369. Kessler, R., F. Follis, D. Daube, and J. Wernly. 1991. Constrictive pericarditis from Nocardia asteroides infection. Ann. Thorac. Surg. 52:861-862.

370. Khalili, A. H. 1982. Nocardial brain abscess: a case report. J. Neurol. 227:115-120.

371. Khuller, G. K. 1976. The mannophosphoinositides of Nocardia asteroides. Experientia 32:1371-1372.

372. Kilgore, T. L., and D. L. Myers. 1983. Lung culture by fiberoptic bronchoscopy. South. Med. J. 76:820.

373. Kim, J., G. Y. Minamoto, and M. H. Grieco. 1991. Nocardial infection as a complication of AIDS: report of six cases and review. Rev. Infect. Dis. 13:624-629.

374. Kim, J., G. Y. Minamoto, C. D. Hoy, and M. H. Grieco. 1991. Presumptive cerebral Nocardia asteroides infection in AIDS: treatment with ceftriaxone and minocycline. Am. J. Med. 90:656658.

375. Kim, O. H., H. R. Yang, and Y. W. Bahk. 1992. Pulmonary nocardiosis manifested as miliary nodules in a neonate: a case report. Pediatr. Radiol. 22:229-230.

376. Kinde, H., R. L. Walker, V. A. Skinner, B. M. Daft, and R. L. Hughes. 1992. Actinomycetales infections in slender-horned gazelles: six cases (1987-1989). J. Am. Vet. Med. Assoc. 200:17191722

377. King, L. P., W. B. Furlong, W. S. Gilbert, and C. Levy. 1991. Nocardia asteroides infection following scleral buckling. Ophthalmic Surg. 22:150-152.

378. King, R. B., W. C. Stoops, J. Fitzgibbons, and P. Bunn. 1966 Nocardia asteroides meningitis: a case successfully treated with large doses of sulfadiazine and urea. J. Neurosurg. 24:749-751.

379. Kirby, W. M. M., and J. B. McNaught. 1946. Actinomycosis due to Nocardia asteroides: report of two cases. Arch. Intern. Med. 78:578-591.

380. Kirmani, N., C. U. Tuazon, J. A. Ocuin, A. M. Thompson, N. C. Kramer, and G. W. Geelhoed. 1978. Extensive cerebral nocardiosis cured with antibiotic therapy alone. J. Neurosurg. 49:924 928.

381. Kirpensteijn, J., and R. B. Finegold. 1992. Cutaneous actinomycosis and nocardiosis in dogs: 48 cases (1980-1990). J. Am. Vet. Med. Assoc. 201:917-920.

382. Kitao, T., L. Ruangpan, and M. Fukudome. 1989. Isolation and classification of a Nocardia species from diseased giant gourami, Osphronemus goramy. J. Aquat. Anim. Health 1:154-162.

383. Kjelstrom, J. A. 1992. Ph.D. thesis. University of California, Davis.

384. Kjelstrom, J. A., and B. L. Beaman. 1993. Development of a serologic panel for the recognition of nocardial infections in a murine model. Diagn. Microbiol. Infect. Dis. 16:291-301.

385. Klein-Gitelman, M. S., and I. S. Szer. 1991. Disseminated Nocardia brasiliensis infection: an unusual complication of immunosuppressive treatment for childhood dermatomyositis. J. Rheumatol. 18:1243-1246.

386. Knouse, M. C., and B. Lorber. 1990. Early diagnosis of Nocardia asteroides endophthalmitis by retinal biopsy: case report and review. Rev. Infect. Dis. 12:393-398.

387. Koehne, G., and R. C. Giles. 1981. Nocardia asteroides abortion in swine. J. Am. Vet. Med. Assoc. 179:478-479.

388. Kohbata, S., and B. L. Beaman. 1991. L-Dopa responsive movement disorder caused by Nocardia asteroides localized in the brains of mice. Infect. Immun. 59:181-191.

389. Kohn, P. M., M. Tager, M. L. Siegel, and R. Ashe. 1951. Aerobic actinomyces septicemia. Report of a case. N. Engl. J. Med. 245:640-644.

390. Koike, M., Y. Maeda, N. Funata, T. Takizawa, M. Fukayama, and Y. Iwasaki. 1992. Pulmonary lesions of acquired immunodeficiency syndrome-analysis of 24 Japanese autopsy cases with AIDS. Jpn. J. Thorac. Dis. 30:746-755.

391. Koll, B. S., A. E. Brown, T. E. Kiehn, and D. Armstrong. 1992 Disseminated Nocardia brasiliensis infection with septic arthritis. Clin. Infect. Dis. 15:469-472.

392. Kong, N. C., Z. Morad, A. B. Suleiman, I. K. Cheong, and I. Lajin. 1990. Spectrum of nocardiosis in renal patients. Ann. Acad. Med. (Singapore) 19:375-379.

393. Kramer, M. R., and R. B. Uttamchandani. 1990. The radiographic appearance of pulmonary nocardiosis associated with AIDS. Chest 98:382-385.

394. Kremer, E. P. 1972. Pulmonary and cerebral nocardial abscess. Med. J. Aust. 59:538-540.

395. Krick, J. A., E. B. Stinson, and J. S. Remington. 1975. Nocardia infection in heart transplant patients. Ann. Intern. Med. 82:1826.

396. Krone, A., K. P. Schaal, A. Brawanski, and B. Schuknecht. 1989. 
Nocardial cerebral abscess cured with imipenem/amikacin and enucleation. Neurosurg. Rev. 12:333-340.

397. Krueger, E. G., L. Norsa, M. Kenney, and P. A. Price. 1954. Nocardiosis of the central nervous system. J. Neurosurg. 11:226233.

398. Kubota, S. S., T. Kariya, Y. Nakamura, and K. Kira. 1968. Nocardial infection in cultured yellowtails (Serida quinquerodiata and S. purpurescens). II. Histological study. Fish Pathol. 3:24-33.

399. Kudo, T., K. Hatai, and A. Seino. 1988. Nocardia seriolae sp. nov. causing nocardiosis of cultured fish. Int. J. Syst. Bacteriol. 38:173-178.

400. Kuhlman, J. E., E. K. Fishman, R. H. Hruban, M. Knowles, E. A. Zerhouni, and S. S. Siegelman. 1989. Diseases of the chest in AIDS: CT diagnosis. RadioGraphics 9:827-857.

401. Kurup, V. P., H. S. Randhawa, and S. K. Mishra. 1967. Use of paraffin bait technique in the isolation of Nocardia asteroides from sputum. Mycopathol. Mycol. Appl. 40:113-130.

402. Kurup, V. P., V. N. Sharma, R. Viswanathan, R. S. Sandhu, H. S. Randhawa, and V. N. Damodaran. 1968. Pulmonary fungal ball due to a Nocardia species. Scand. J. Respir. Dis. 49:9-14.

403. Kurup, V. P., J. E. Piechura, E. Y. Ting, and J. A. Orlowski. 1983. Immunochemical characterization of Nocardia asteroides antigens: support for a single species concept. Can. J. Microbiol. 29:425-432.

404. Kurup, V. P., and G. H. Schribner. 1981. Antigenic relationship among Nocardia asteroides immunotypes. Microbios 31:25-30.

405. Kusuda, R., and H. Taki. 1973. Studies on a nocardial infection of cultured yellowtail. I. Morphological and biochemical characteristics of Nocardia isolated from diseases in fish. Bull. Jpn. Soc. Sci. Fish. 40:369-373.

406. Kusunose, E., K. Ichihara, Y. Noda, and M. Kusunose. 1976. Superoxide dismutase from Mycobacterium tuberculosis. J. Biochem. 80:1343-1352.

407. Kutlin, E. S., M. Feldman, S. Perl, U. Klopper, A. Nyska, and T. A. Nobel. 1980. Canine nocardiosis in Israel. Refu. Vet. 37:15-23.

408. Lajos, T. Z., and S. V. Jarzylo. 1970. Pulmonary Nocardiosis and empyema. N.Y. State J. Med. 70:2829-2832.

409. Lampe, R. M., C. J. Baker, E. J. Septimus, and R. J. Wallace. 1981. Cervicofacial nocardiosis in children. J. Pediatr. 99:593595.

410. Landau, Z., S. Feld, A. Frumkin, and P. Resnitzky. 1986. Nocardia brasiliensis skin infections. Isr. J. Med. Sci. 22:397-399.

411. Landreneau, R. J., S. R. Hazelrigg, P. F. Ferson, J. A. Johnson, W. Nawarawong, T. M. Boley, J. J. Curtis, C. M. Bowers, D. B. Herlan, and R. D. Dowling. 1992. Thorascopic resection of 85 pulmonary lesions. Ann. Thorac. Surg. 54:415-420.

412. Laneelle, M. A., J. Asselineau, and G. Castelnuovo. 1965. Etudes sur les mycobacteries et les nocardiae. Ann. Inst. Pasteur (Paris) 108:69-82.

413. Langevin, R. W., and S. Katz. 1964. Fulminating pulmonary nocardiosis. Dis. Chest 46:310-316.

414. Larsen, M. C., H. D. Diamond, and H. S. Collins. 1959. Nocardia asteroides infection. Arch. Intern. Med. 103:712-725.

415. Larson, R. K., and R. Gordinier. 1965. Pulmonary alveolar proteinosis. Report of six cases, review of the literature, and formulation of a new theory. Ann. Intern. Med. 62:292-312.

416. Lass, J. H., R. A. Thoft, A. R. Bellows, and H. H. Slansky. 1981. Exogenous Nocardia asteroides endophthalmitis associated with malignant glaucoma. Ann. Ophthalmol. 13:317-321.

417. Laurin, J. M., C. S. Resnik, D. Wheeler, and B. W. Needleman. 1991. Vertebral osteomyelitis caused by Nocardia asteroides: report and review of the literature. J. Rheumatol. 18:455-458.

418. Law, B. J., and M. I. Marks. 1982. Pediatric nocardiosis. Pediatrics 70:560-565.

419. Leaker, B., A. Hellyar, G. H. Neild, C. Rudge, M. Mansell, and F. D. Thompson. 1989. Nocardia infection in a renal transplant unit. Transplant. Proc. 21:2103-2104.

420. Lechevalier, H. A. 1989. Nocardioform actinomycetes, p. 23482404. In S. T. Williams, M. E. Sharpe, and J. G. Holt (ed.), Bergey's manual of systematic bacteriology, vol. 4. The Williams \& Wilkins Co., Baltimore.

421. Lee, B. Y., F. Tolete, and R. Douglass. 1970. Pulmonary nocar- diosis successfully treated with chemotherapy and resection. Chest 58:388-391.

422. Lee, C., D. C. Dorman, and P. G. Bradhurst. 1963. Disseminated nocardiosis: an acute fatal episode in a young girl. Med. J. Aust. 50:536-543.

423. Leggiardo, R. J., and R. B. Miller. 1987. Cutaneous nocardiosis presenting as a tick-borne infection. Pediatr. Infect. Dis. J. 6:421-422.

424. Lerner, G., G. C. Tarasidis, and F. S. Jenney. 1967. Nocardiosis the importance of early diagnosis and treatment. Am. Rev. Respir. Dis. 96:494-500.

425. Leung, W.-H., K.-L. W, C.-P. Lau, and C.-K. Wong. 1990. Purulent pericarditis and cardiac tamponade caused by Nocardia asteroides in mixed connective tissue disease. J. Rheumatol. 17:1237-1239.

426. Liebenberg, S. P., and W. E. Giddens. 1985. Disseminated nocardiosis in three macaque monkeys. Lab. Anim. Sci. 35:162166.

427. Lissner, G. S., R. O'Grady, and E. Choromokos. 1978. Endogenous intraocular Nocardia asteroides in Hodgkin's disease. Am. J. Ophthalmol. 86:388-394.

428. List, C. F., J. F. Williams, C. B. Beeman, and C. A. Payne. 1954 Nocardiosis with multiocular cerebellar abscess: report of a cured case. J. Neurosurg. 11:394-398.

429. Long, P., and H. A. Campana. 1966. An unusual mycetoma. Arch. Dermatol. 93:341-345.

430. Lope, E. S., and D. C. Gutierrez. 1977. Nocardia asteroides primary cerebral abscess and secondary meningitis. Acta Neurochir. 37:139-145.

431. Loupal, V. G., M. Schonbauer, and A. Schonbauer-Langle. 1982. Nocardiose bei einem Rotfrichs (Vulpes vulpes) und einem kleinen mungo (Herpestes javanica). Berl. Muench. Tierarztl. Wochenschr. 95:312-315.

432. Louria, D. B. 1984. Symposium on infectious complications of neoplastic disease. I. Introduction and epidemiology. Am. J. Med. 76:414-420.

433. Lovett, I. S., E. Houang, S. Burge, M. Turner-Warwick, F. D. Thompson, A. R. Harrison, A. M. Joekes, and M. C. Parkinson. 1981. An outbreak of Nocardia asteroides infection in a renal transplant unit. Q. J. Med. New Ser. 198:123-135.

434. Lundmerer, K. M., and J. M. Kissane. 1989. Headache, mental status changes, and death in a 36 year-old woman with lupus. Am. J. Med. 86:94-102.

435. Lynn, W., M. Whyte, and J. Weber. 1989. Nocardia, mycobacteria and AIDS. AIDS 3:766-767.

436. MacCallum, W. G. 1902. On the life history of Actinomyces asteroides. Zentralbl. Bakteriol. Parasitenkd. Infektionskr. Hyg. Abt. 1 Orig. 31:528-547.

437. Macfarlane, D. E., B. Bain, G. Char, L. LaGrande, and E. Williams. 1985. Nocardiosis in patients treated with corticosteroids. A report on three cases. West Indian Med. J. 34:134-138.

438. Macher, A. M., M. L. De Vinatea, M. J. Daly, and J. T. Stocker. 1986. AIDS: case for diagnosis. Military Med. 151:74-80.

439. Macotela-Ruiz, E., and A. Gonzalez-Angulo. 1966. Electron microscopic studies on granules of Nocardia brasiliensis in man. Sabouraudia 5:92-98.

440. Maderazo, E., and R. Quintiliani. 1974. Treatment of nocardial infections with trimethoprim and sulfamethoxazole. Am. J. Med. 57:671-675.

441. Madoff, S. 1986. Introduction to the bacterial L-forms, p. 1-20. In S. Madoff (ed.), The bacterial L-forms. Marcel Dekker, Inc., New York.

442. Mahajan, V. M., S. C. Padhy, Y. Dayal, I. M. Bhatia, and K. S. Ratnakar. 1977. Experimental pulmonary nocardiosis in monkeys. Sabouraudia 15:47-50.

443. Mahvi, T. A. 1964. Disseminated nocardiosis caused by Nocardia brasiliensis. Arch. Dermatol. 89:426-431.

444. Mamalis, N., M. J. Daily, and D. Ross. 1988. Presumed intraocular nocardiosis in a cardiac-transplant patient. Ann. Ophthalmol. 20:271-276.

445. Mammana, R. B., E. A. Petersen, J. K. Fuller, K. Siroky, and J. G. Copeland. 1983. Pulmonary infections in cardiac transplant patients: modes of diagnosis, complications, and effectiveness of 
therapy. Ann. Thorac. Surg. 36:700-705.

446. Manchanda, K. S., L. Kumar, and P. Talwar. 1978. Pulmonary nocardiosis in a child (a case report). Indian Pediatr. 15:857-860.

447. Maniar, S. H., and P. C. Anderson. 1966. Mycetoma caused by Nocardia brasiliensis in Missouri. Missouri Med. 63:273-275.

448. Manz, H. J. 1983. Pathobiology of neurosarcoidosis and clinicopathologic correlation. Can. J. Neurol. Sci. 10:50-55.

449. Marin Casanova, P., P. Garcia Martos, C. Fernandez Gutierrez del Alamo, J. Garcia Herrazo, J. C. Escribano, Moriana, and A. Aznar Martin. 1991. Nocardiosis in a patient with AIDS. Rev. Clin. Esp. 188:83-84.

450. Martinelli, B., and E. A. Tagliapietra. 1970. Actinomycosis of the arm. Bull. Hosp. Jt. Dis. 31:31-42.

451. Martínez-Maldonado, M., and G. Ramírez de Arellano. 1966. Pulmonary alveolar proteinosis, nocardiosis and chronic granulocytic leukemia. South. Med. J. 59:901-904.

452. Mason, K. N., and B. M. Hathaway. 1969. A study of Nocardia asteroides: white mice used as test animals. Arch. Pathol. 87:389392.

453. Masters, D. L., and J. R. Lentino. 1984. Cervical osteomyelitis related to Nocardia asteroides. J. Infect. Dis. 149:824-825.

454. May, J. 1979. Disseminated nocardiosis in an immunosuppressed host. Rocky Mt. Med. J. 76:133-134.

455. Mazzoni, A., and T. Franco. 1971. Considerazioni su un caso de nocardiosi polmonare. G. Mal. Infett. Parassit. 23:239-241.

456. McAndrew, G. M. 1965. Cerebral nocardiosis. Postgrad. Med. J. 41:639-642.

457. McClure, H. M., J. Chang, W. Kaplan, and J. M. Brown. 1976. Pulmonary nocardiosis in an Orangutan. J. Am. Vet. Med. Assoc. 169:943-945.

458. McLaughlin, S. A., A. H. Brightman, L. C. Helper, J. P. Manning, and J. E. Tomes. 1983. Pathogenic bacteria and fungi associated with extraocular disease in the horse. J. Am. Vet. Med. Assoc. 182:241-242

459. McNeil, M. M., J. M. Brown, C. H. Magruder, K. T. Shearlock, R. A. Saul, D. P. Allred, and L. Ajello. 1992. Disseminated Nocardia transvalensis infection: an unusual opportunistic pathogen in severely immunocompromised patients. J. Infect. Dis. 165:175-178.

460. Meier, B., U. Metzger, F. Müller, W. Siegenthaler, and R. Lüthy. 1986. Successful treatment of a pancreatic Nocardia asteroides abscess with amikacin and surgical drainage. Antimicrob. Agents Chemother. 29:150-151.

461. Mestre, C., E. Nares, G. M. Fernandez, and J. R. Boixados. 1983. Multiple cerebral abscesses caused by Nocardia asteroides. Rev. Clin. Esp. 171:185-190.

462. Meurs, P. J., and O. P. VanBijsterveld. 1984. Nocardia gypsoides corneal ulcer. Br. J. Ophthalmol. 68:179-181.

463. Meyer, S. L., R. L. Font, and R. P. Shaver. 1970. Intraocular nocardiosis. Report of three cases. Arch. Ophthalmol. 83:536541.

464. Michel, G., and C. Bordet. 1976. Cell walls of nocardiae, p. 141-159. In M. Goodfellow, G. H. Brownell, and J. A. Serrano (ed.), The biology of the nocardiae. Academic Press Ltd., London.

465. Mikami, Y., S. F. Yu, K. Yazawa, K. Fukushima, A. Maeda, J. Uno, K. Terao, N. Saito, A. Kubo, and K. Suzuki. 1990. A toxic substance produced by Nocardia otitidiscaviarum isolated from cutaneous nocardiosis. Mycopathologia 112:113-118.

466. Miksits, K., G. Stoltenburg, H.-H. Neumayer, H. Spiegel, K. P. Schaal, J. Cervos-Navarro, A. Distler, H. Stein, and H. Hahn. 1991. Disseminated infection of the central nervous system caused by Nocardia farcinica. A case report. Nephrol. Dial. Transplant 6:209-214.

467. Miller, R. C., and Y. M. Felman. 1967. Pemphigus vulgaris and pulmonary nocardiosis. Arch. Dermatol. 96:548-551.

468. Mills, V. A., T. G. Cleary, L. Frankel, M. E. Miner, R. J. Wallace, and M. Silva-Sosa. 1982. Central nervous system Nocardia infection. Clin. Pediatr. 21:248-250.

469. Minnikin, D. E., and A. G. O'Donnell. 1984. Actinomycete envelope lipid and peptidoglycan composition, p. 335-388. In $\mathrm{M}$. Goodfellow, M. Mordarski, and S. T. Williams (ed.), The biology of the actinomycetes. Academic Press Ltd., London.
470. Mital, O. P., and M. C. Agarwala. 1967. Pulmonary nocardiosis Indian J. Chest Dis. 9:170-172.

471. Mitchell, G., G. M. Wells, and J. S. Goodman. 1975. Sporotrichoid Nocardia brasiliensis infection. Response to potassium iodide. Am. Rev. Respir. Dis. 112:721-723.

472. Moeller, C. A., and C. S. Burton III. 1986. Primary lymphocutaneous Nocardia brasiliensis infection. Arch. Dermatol. 122:11801182.

473. Moore, M., and A. H. Conrad. 1967. Sporotrichoid nocardiosis caused by Nocardia brasiliensis. Arch. Dermatol. 95:390-393.

474. Moore, M., C. W. Lane, and L. E. Gaul. 1954. Nocardiosis of the knee caused by Nocardia brasiliensis. Report of first case in a native of the United States. Am. Med. Assoc. Arch. Dermatol. Syphilol. 70:302-310.

475. Morey, L. W., Jr. 1974. Infection by Nocardia asteroides: report of a case. J. Am. Osteopath. Assoc. 74:156-161.

476. Mounier, J., A. Ryter, M. Coquis-Rondon, and P. J. Sansonetti. 1990. Intracellular and cell-to-cell spread of Listeria monocytogenes involves interaction with $\mathrm{F}$-actin in the enterocytelike cell line Caco-2. Infect. Immun. 58:1048-1058.

477. Munslow, R. A. 1954. Actinomycotic (Nocardia asteroides) brain abscess with recovery: case report. J. Neurosurg. 11:399-402.

478. Murray, J. F., S. M. Finegold, S. Froman, and D. W. Will. 1961 The changing spectrum of nocardiosis. Am. Rev. Respir. Dis. 83:315-330.

479. Murray, J. F., H. F. Haegelin, W. L. Hewitt, H. Latta, D. McVickar, A. F. Rasmussen, Jr., and L. G. Rigler. 1966. Opportunistic pulmonary infections. Ann. Intern. Med. 65:566-587.

480. Murray, K. J., S. K. Ackerman, S. N. Chow, and S. D. Douglas 1977. Hypogammaglobulinemia and Nocardia brain abscess Neurosurgery 1:297-299.

481. Nahas, L. F., and J. E. Bennett. 1981. Nocardiosis of the upper limb. Plast. Reconstr. Surg. 68:593-595.

482. Natarajan, M., A. K. Muthu, and K. Arumugham. 1974. Nocardial extradural granuloma causing spinal cord compression. Neurol. India 22:97-99.

483. Natas, O. B., and Y. Willassen. 1983. Lung infection caused by Nocardia asteroides in a renal-transplant patient. Scand. J. Infect. Dis. 15:317-320.

484. Nauta, H. J. W., F. L. Contreras, R. L. Weiner, and M. J. Crofford. 1987. Brain stem abscess managed with computed tomography-guided sterotactic aspiration. Neurosurgery 20:476480.

485. Neimeister, R. P., N. T. Patterson, J. H. Cocklin, and G. F. Harada. 1971. The isolation of pathogenic fungi from sodium hydroxide-processed sputum specimens from patients suspected to have tuberculosis. Am. J. Clin. Pathol. 54:201-203.

486. Neu, H. C., M. Silva, E. Hazen, and S. H. Rosenheim. 1967. Necrotizing nocardial pneumonitis. Ann. Intern. Med. 66:274284.

487. Neu, T. R., and K. Poralla. 1988. An amphiphilic polysaccharide from an adhesive Rhodococcus strain. FEMS Microbiol. Lett. 49:389-392.

488. Neumark, E., F. M. Polack, and A. C. Ellison. 1971. Report of a case of Nocardia asteroides keratitis. Am. J. Ophthalmol. 72:813815.

489. Nitidandhaprabhas, P., and D. Sittapairochana. 1975. Treatment of nocardial mycetoma with trimethoprim and sulfamethoxazole. Arch. Dermatol. 111:1345-1348.

490. Nocard, E. 1888. Note sur la maladie des boeufs de la Gouadeloupe connue sous le nom de farcin. Ann. Inst. Pasteur (Paris) 2:293-302.

491. Noll, H., H. Block, J. Asselineau, and E. Lederer. 1956. The chemical structure of the cord factor of Mycobacterium tuberculosis. Biochim. Biophys. Acta 20:299-309.

492. Norden, C. W., F. L. Ruben, and R. Selker. 1983. Nonsurgical treatment of cerebral nocardiosis. Arch. Neurol. 40:594-595.

493. Nyamathi, A. 1989. AIDS-related heart disease: a review of the literature. J. Cardiovasc. Nursing 3:65-66.

494. Oarada, M., E. Ito, Y. Mikami, K. Yazawa, and K. Terao. 1990. Fatty degeneration of the liver induced by HS-6 toxin produced by Nocardia otitidiscaviarum from human cutaneous nocardiosis. Agric. Biol. Chem. 54:2737-2739. 
495. Oda, Y., Y. Kamijyo, and Y. Kang. 1986. Nocardia brain abscess and ventriculitis. No Shinkei Geka Neurol. Surg. 14:1155-1159.

496. Oddó, D., and S. González. 1986. Actinomycosis and nocardiosis: a morphologic study of 17 cases. Pathol. Res. Pract. 181:320-326.

497. Odell, E. W., and A. W. Segal. 1991. Killing of pathogens associated with chronic granulomatous disease by the nonoxidative microbicidal mechanisms of human neutrophils. J. Med. Microbiol. 34:129-135.

498. Ogata, S. A., and B. L. Beaman. 1992. Adherence of Nocardia asteroides within the murine brain. Infect. Immun. 60:1800-1805.

499. Ogata, S. A., and B. L. Beaman. 1992. Site-specific growth of $N$. asteroides in the murine brain. Infect. Immun. 60:3262-3267.

500. Ohara, K., Y. Hirano, H. Ishida, T. Mitamura, and H. Noguchi. 1990. Possible involvement of lymphocyte activating factor (LAF) as an endogenous pyrogen in fever induced by the cell wall skeleton of Nocardia rubra (N-CWS). Chem. Pharm. Bull. 38: 804-806.

501. Ohara, K., Y. Hirano, H. Ishida, J. Mori, and A. Tensho. 1989. Possible involvement of a tumor necrosis factor (TNF)-like mediator as an endogenous pyrogen in fever induction by Nocardia rubra cell wall skeleton (N-CWS). Chem. Pharm. Bull. 37:2795-2798.

502. Okoye, J. O. A., H. C. Gugnani, and C. N. Okeke. 1991. Experimental infection of chickens with Nocardia asteroides and Nocardia transvalensis. Avian Pathol. 20:17-24.

503. Opsahl, M. S., and W. F. O'Brien. 1983. Systemic nocardiosis in pregnancy. J. Reprod. Med. 28:621-623.

504. Orchard, V. A. 1979. Nocardial infections of animals in New Zealand, 1976-1978. N.Z. Vet. J. 27:159-165.

505. O'Reilly, M. J. J., and R. E. Powell. 1953. Report of a case of nocardial infection in Australia. Med. J. Aust. 40:703-705.

506. Orfanakis, M. G., H. G. Wilcox, and C. B. Smith. 1972. In vitro studies of the combined effect of ampicillin and sulfonamides on Nocardia asteroides and results of therapy in four patients. Antimicrob. Agents Chemother. 1:215-220.

507. Ortiz-Ortiz, L., E. I. Melendro, and C. Conde. 1984. Hostparasite relationship in infections due to Nocardia brasiliensis, $\mathrm{p}$. 119-133. In L. Ortiz-Ortiz, L. F. Bojalil, and V. Yakoleff (ed.), Biochemical and biomedical aspects of actinomycetes. Academic Press, Inc., Orlando, Fla.

508. Ortiz-Ortiz, L., D. E. Parks, J. S. Lopez, and W. O. Weigle. 1979. B-lymphocyte activation with an extract of Nocardia brasiliensis. Infect. Immun. 25:627-634.

509. Otcenasek, M., and J. Vitovek. 1982. Multiple mycetoma in goat lungs. Mykosen 25:90-98.

510. Palmer, D. L., R. L. Harvey, and J. K. Wheeler. 1974. Diagnostic and therapeutic considerations in Nocardia asteroides infection. Medicine 53:391-401.

511. Panijayanond, P., C. A. Ollson, M. L. Spivack, G. W. Schmitt, B. A. Idelson, B. J. Sachs, and D. C. Nabseth. 1972. Intraocular nocardiosis in a renal transplant patient. Arch. Surg. 104:845847.

512. Parmentier, J. C., H. W. Vanlanduyt, J. J. Prignot, and W. Tanghe. 1968. A case of disseminated nocardiosis. Br. J. Dis. Chest 62:46-51.

513. Parmentier, L., D. Salmon-Ceron, P. Boiron, G. Paul, T. Guez, B. Dupont, and D. Sicard. 1992. Pneumopathy and kidney abscess due to Nocardia farcinica in an HIV-infected patient. AIDS 6:891-893.

514. Pascual, J., M. A. Gomez Aguinaga, R. Vidal, A. Maudes, A. Sureda, E. Gomez Mampaso, and L. Fogue. 1989. Alveolar proteinosis and nocardiosis: a patient treated by bronchopulmonary lavage. Postgrad. Med. J. 65:674-677.

515. Pavillard, E. R. 1973. Treatment of nocardial infection with trimethoprim-sulfamethoxazole. Med. J. Aust. 60(Suppl.):65-69.

516. Peabody, J. W., Jr., and J. H. Seabury. 1960. Actinomycosis and nocardiosis. Am. J. Med. 28:99-115.

517. Peacock, J. E., M. R. McGinnis, and M. S. Cohen. 1984. Persistent neutrophilic meningitis. Medicine 63:379-395.

518. Pellegrino, E. D., and R. R. Henderson. 1961. Response of pulmonary nocardiosis to treatment with massive doses of penicillin intravenously. Am. Rev. Respir. Dis. 84:242-255.

519. Penikette, E. J., and D. L. Rees. 1962. Nocardia asteroides infection of the nasal lacrimal system. Am. J. Ophthalmol. 53:1006-1008.

520. Peral-Prieto, V., M. Alonso Suarez, C. Rodriguez Suarez, M. de la Torre Fernandez, V. Cuesto Fernandez, and J. Herrera Perez de Villar. 1991. Systemic nocardiosis with cerebral abscess in a kidney transplant patient. An. Med. Interna 8:188-189.

521. Perschak, H., J. Gubler, R. Speich, and E. Russi. 1991. Pulmonary nocardiosis concurrent with Pneumocystis carinii pneumonia in two patients undergoing immunosuppressive therapy. Case reports. J. Infect. 23:183-185.

522. Pesce, C. M., and A. C. Quaglia. 1984. Nocardia lung infection with hematogenous spread in a woman with adrenal cortical hyperfunction. Eur. J. Respir. Dis. 65:613-615.

523. Petersen, E. A., M. L. Nash, R. B. Mammana, and J. G. Copeland. 1983. Minocycline treatment of pulmonary nocardiosis. JAMA 250:930-932.

524. Petersen, J. M., M. Awad, I. Ahmad, J. W. Bay, and M. C. McHenry. 1983. Nocardia osteomyelitis and epidural abscess in the nonimmunosuppressed host. Cleveland Clin. Q. 50:453-459.

525. Peterson, D. L., L. D. Hudson, and K. Sullivan. 1978. Disseminated Nocardia caviae with positive blood cultures. Arch. Intern. Med. 138:1164-1165.

526. Petri, M., P. Katzenstein, and D. Hellmann. 1988. Laryngeal infection in lupus: report of nocardiosis and review of laryngeal involvement in lupus. J. Rheumatol. 15:1014-1015.

527. Petrillo, V. F., L. C. Severo, A. T. Londero, and N. S. Porto. 1978 Pulmonary nocardiosis report of the first two Brazilian cases. Mycopathologia 66:17-20.

528. Phillips, W. B., C. L. Shields, J. A. Shields, R. C. Eagle, L. Masciulli, and D. L. Yarian. 1992. Nocardial choroidal abscess. Br. J. Ophthalmol. 76:694-696.

529. Pier, A. C., and R. E. Fitchner. 1981. Distribution of serotypes of Nocardia asteroides from animal, human and environmental sources. J. Clin. Microbiol. 13:548-553.

530. Pier, A. C., A. K. Takayama, and A. Y. Miyahara. 1970. Cetacean nocardiosis. J. Wildl. Dis. 6:112-118.

531. Pijper, A., and B. D. Pullinger. 1927. South African nocardiases J. Trop. Med. Hyg. 30:153-156.

532. Pinkhas, J., I. Oliver, A. de Vries, S. A. Spitzer, and E. Henig. 1973. Pulmonary nocardiosis complicating malignant lymphoma successfully treated with chemotherapy. Chest 63:367-370.

533. Pitchenik, A. E., and F. Zaunbrecher. 1978. Superior vena cava syndrome caused by Nocardia asteroides. Am. Rev. Respir. Dis. 117:795-798.

534. Pizzolato, P., J. Ziskind, H. Derman, and E. E. Buff. 1961. Nocardiosis of the brain. Report of three cases. Am. J. Clin. Pathol. 36:151-156.

535. Poland, G. A., C. R. Jorgensen, and G. A. Sarosi. 1990. Nocardia asteroides pericarditis: report of a case and review of the literature. Mayo Clin. Proc. 65:819-824.

536. Pomeroy, C., and G. A. Filice. 1988. Effect of intravenous silica on the course of Nocardia asteroides pneumonia. Infect. Immun. 56:2507-2511.

537. Poretz, D. M., M. N. Smith, and C. H. Park. 1979. Intracranial suppuration secondary to trauma infection with Nocardia aster oides. JAMA 232:730-731.

538. Presant, C. A., P. H. Wiernik, and A. A. Serpick. 1970. Disseminated extrapulmonary nocardiosis presenting as a renal abscess. Arch. Pathol. 89:560-564.

539. Price, N. C., P. A. Frith, and P. N. Awdry. 1989. Intraocular nocardiosis: a further case and review. Int. Ophthalmol. 13:177180.

540. Raby, N., G. Forbes, and R. Williams. 1990. Nocardia infection in patients with liver transplants on chronic liver disease: radiologic findings. Radiology 174:713-716.

541. Raghavan, R., A. Date, and A. Bhaktaviziam. 1987. Fungal and nocardial infections of the kidney. Histopathology 11:9-20.

542. Raich, R. A., F. Casey, and W. H. Hall. 1961. Pulmonary and cutaneous nocardiosis. The significance of the laboratory isolation of Nocardia. Am. Rev. Respir. Dis. 83:505-509.

543. Ralph, R. A., M. A. Lemp, and G. Liss. 1976. Nocardia asteroides keratitis. A case report. Br. J. Ophthalmol. 60:104-106.

544. Randhawa, H. S., S. K. Mishra, R. S. Shanhu, P. R. Mazumdar, 
R. C. Jain, P. U. Rao, D. Prakash, R. Viswanathan, S. Subramanian, V. N. Sharma, and V. N. Damodaran. 1973. Prevalence of nocardiosis in bronchopulmonary diseases. Indian J. Med. Res. 61:689-699.

545. Rankin, P., and M. Javid. 1955. Nocardiosis of the central nervous system. Neurology 5:815-820.

546. Rao, K. V., T. J. O'Brien, and R. C. Andersen. 1981. Septic arthritis due to Nocardia asteroides after successful kidney transplantation. Arthritis Rheum. 24:99-101.

547. Rapaport, J. 1966. Primary chancriform syndrome caused by Nocardia brasiliensis. Arch. Dermatol. 93:62-64.

548. Ratlidge, C., and G. A. Snow. 1974. Isolation and structure of Nocobactin NA, a lipid-soluble iron-binding compound from Nocardia asteroides. Biochem. J. 139:407-413.

549. Reinhold, L., E. Haltrich, and R. Thierbach. 1969. Nocardiose im kindesalter. Helv. Paediatr. Acta 24:600-608.

550. Retzinger, G. S. 1987. Dissemination of beads coated with trehalose-6,6'-dimycolate: a possible role for coagulation in the dissemination process. Exp. Mol. Pathol. 46:190-198.

551. Richter, R. W., M. Silva, H. C. Neu, and P. M. Silverstein. 1968. The neurological aspects of Nocardia asteroides infection. Assoc. Res. Nerv. Ment. Dis. Infect. Nerv. Syst. 44:424-444.

552. Rico, G., R. Ochoa, A. Oliva, A. Gonzalez-Mendoza, S. M. Walker, and L. Ortiz-Ortiz. 1982. Enhanced resistance to Nocardia brasiliensis infection in mice depleted of antigen-specific B-cells. J. Immunol. 129:1688-1693.

553. Rifkind, P., T. L. Marchioso, S. A. Schneck, and R. B. Hall. 1967. Systemic fungal infections complicating renal transplantation and immunosuppressive therapy. Am. J. Med. 43:28-38.

554. Rivera, J. V., and J. B. Perez. 1957. Pulmonary nocardiosis treated with chloramphenicol. Arch. Intern. Med. 100:152-156.

555. Roberts, G. D., N. S. Brewer, and P. E. Hermans. 1974. Diagnosis of nocardiosis by blood culture. Mayo Clin. Proc. 49:293-296.

556. Roberts, W. C., C. W. Berard, and N. S. Braunwald. 1967. Roentgenogram of the month. Dis. Chest 51:439-440.

557. Robinson, D., and N. Halperin. 1989. Nocardia asteroides infection of an Austin-Moore hemiarthroplasty in a nonimmunocompromised host: a case report. Bull. Hosp. J. Dis. Orthop. Inst. 49:107-110.

558. Robinson, P. J. 1983. Computed tomographic appearance of Nocardia abscesses. Br. J. Radiol. 56:578-580.

559. Rodriguez, J. L., J. L. Barrio, and A. E. Pitchenik. 1986. Pulmonary nocardiosis in the acquired immune deficiency syndrome. Chest 90:912-914.

560. Rogers, S. J., and B. L. Johnson. 1977. Endogenous Nocardia endophthalmitis: report of a case in a patient treated for lymphocytic lymphoma. Ann. Ophthalmol. 9:1123-1131.

561. Roman, M., and E. Reiss-Levy. 1984. Nocardia asteroides infection. Med. J. Aust. 140:447-448.

562. Roquer, J., A. Pou, J. Herraiz, I. Campodarve, T. Sequeira, J. Vilato, F. Alameda, and R. Serrano. 1990. Primary cerebral abscess due to Nocardia presented as "ghost tumor." Eur. Neurol. 30:254-257.

563. Rosen, S. H., B. Castleman, A. A. Liebow, F. M. Enzinger, and R. T. N. Hunt. 1958. Pulmonary alveolar proteinosis. N. Engl. J. Med. 258:1123-1142.

564. Rosenblum, M. L., and H. Rosegay. 1979. Resection of multiple nocardial brain abscesses: diagnostic role of computerized tomography. Neurosurgery 4:315-318.

565. Rosendale, D. E., C. Myers, E. J. Boyko, and B. Jafek. 1988. Nocardia asteroides cervical osteomyelitis in an immunocompetent host. Otolaryngol. Head Neck Surg. 99:334-337.

566. Rosett, W., and G. R. Hodges. 1978. Recent experience with nocardial infections. Am. J. Med. Sci. 276:279-285.

567. Rubin, E., and M. S. Shin. 1984. Pleural and extrapleural disease in nocardia infections. J. Can. Assoc. Radiol. 35:189-191.

568. Rubin, E., G. Weisbrod, and D. E. Sanders. 1980. Pulmonary alveolar proteinosis. Radiology 135:35-41.

569. Ruebush, T. K., and J. S. Goodman. 1975. Nocardia asteroides bacteremia in an immunosuppressed renal-transplant patient. Am. J. Clin. Pathol. 64:537-539.

570. Sachs, M. K. 1992. Lymphocutaneous Nocardia brasiliensis infection acquired from a cat scratch: case report and review. Clin.
Infect. Dis. 15:710-711.

571. Sahathevan, M., F. A. H. Harvey, G. Forbes, J. O'Grady, A. Gimson, S. Bragman, R. Jensen, J. Philpott-Howard, R. Williams, and M. W. Casewell. 1991. Epidemiology, bacteriology and control of an outbreak of Nocardia asteroides infection on a liver unit. J. Hosp. Infect. 18:473-480.

572. Sakakibara, I., Y. Sugimoto, H. Minato, M. Takasaka, and S. Honjo. 1984. Spontaneous nocardiosis with brain abscess caused by Nocardia asteroides in a Cynomolgus monkey. J. Med. Primatol. 13:89-95.

573. Salfield, S. A. W., B. I. Duerden, J. A. S. Dickson, and R. D. G. Milner. 1983. Abdominal nocardiosis in a Sudanese girl. Eur. J. Pediatr. 140:135-137.

574. Salh, B., C. Fegan, A. Hussain, A. Jaulim, K. Whale, and A. Webb. 1988. Pulmonary infection with Nocardia caviae in a patient with diabetes mellitus and liver cirrhosis. Thorax 43:933934.

575. Salman, M. D., R. B. Bushnell, and A. C. Pier. 1982. Determination of sensitivity and specificity of the Nocardia asteroides skin test for detection of bovine mammary infections caused by Nocardia asteroides and Nocardia caviae. Am. J. Vet. Res. 43:332-335.

576. Saltzman, H. A., E. W. Chick, and N. F. Conant. 1962. Nocardiosis as a complication of other diseases. Lab. Invest. 11:1110 1117.

577. Sandhu, D. K., S. K. Mishra, V. N. Damodaran, R. S. Sandhu, and H. S. Randhawa. 1975. Mycetoma of the knee due to Nocardia caviae. Sabouraudia 13:170-171.

578. Santen, R. J., and I. S. Wright. 1967. Systemic Lupus erythematosus associated with pulmonary nocardiosis. Arch. Intern. Med. 119:202-205.

579. Sanyal, M., A. Thammayya, and N. Basu. 1978. Actinomycetoma caused by organisms of the Nocardia asteroides complex and closely related strains. Mykosen 21:109-121.

580. Satterwhite, T. K., and R. J. Wallace, Jr. 1979. Primary cutaneous nocardiosis. JAMA 242:333-336.

581. Saul, A., A. Bonifaz, M. Messina, and R. Andrade. 1987. Mycetoma due to Nocardia caviae. Int. J. Dermatol. 26:174-177.

582. Savage, M. W., C. E. Clarke, and G. M. Yuill. 1990. Silent Nocardia cerebral abscesses in treated dermatomyositis. Postgrad. Med. J. 66:582-583.

583. Schaal, K. P., and B. L. Beaman. 1984. Clinical significance of actinomycetes, p. 389-424. In M. Goodfellow, M. Mordarski, and S. T. Williams (ed.), The biology of the actinomycetes. Academic Press Ltd., London.

584. Schaal, K. P., and H. Bickenbach. 1978. Soil occurrence of pathogenic nocardiae. Zentralbl. Bakteriol. Mikrobiol. Hyg. Abt. 1 Suppl. 6:429-434.

585. Schaal, K. P., and H. J. Lee. 1992. Actinomycete infections in humans-a review. Gene 115:201-211.

586. Schardt, W. M., A. C. Unsworth, and C. V. Hayes. 1956. Corneal ulcer due to Nocardia asteroides. Am. J. Ophthalmol. 42:303-305.

587. Schlossberg, D., D. Bronstein, R. Jeffries, and M. Sams. 1980. Pulmonary nocardiosis. JAMA 243:1897.

588. Schmid, A., H. Traupe, H. C. Todt, and S. Trittmacher. 1987. Intracerebral Nocardia brasiliensis infection. Neurosurg. Rev. 10:315-319.

589. Schreiner, D. T., P. deCastro, J. L. Jorizzo, A. R. Solomon, and W. R. Holder. 1986. Disseminated Nocardia brasiliensis infection following cryptococcal disease. Arch. Dermatol. 122:1186-1190.

590. Schulman, L. L. 1987. Case report: Nocardia pneumonitis and the adult respiratory distress syndrome. Am. J. Med. Sci. 293:315319.

591. Schwartz, J. G., D. A. McGough, R. E. Thorner, R. J. Fetchick, F. O. Tio, and M. G. Rinaldi. 1988. Primary lymphocutaneous Nocardia brasiliensis infection: three case reports and a review of literature. Diagn. Microbiol. Infect. Dis. 10:113-120.

592. Schwartz, J. G., and F. O. Tio. 1987. Nocardial osteomyelitis: a case report and review of the literature. Diagn. Microbiol. Infect. Dis. 8:37-46.

593. Scott, W. W., and J. E. Kuhlman. 1991. Focal pulmonary lesions in patients with AIDS: percutaneous transthoracic needle biopsy. Radiology 180:419-421. 
594. Scully, R. E., J. J. Galdabini, and B. U. McNeely. 1981. Case records of the Massachusetts General Hospital. Case 26-1981. N. Engl. J. Med. 304:1592-1599.

595. Scully, R. E., E. J. Mark, and B. U. McNeely. 1983. Case records of the Massachusetts General Hospital. Case 19-1983. N. Engl. J. Med. 308:1147-1156.

596. Scully, R. E., E. J. Mark, W. F. McNeely, and B. U. McNeely. 1988. Case records of the Massachusetts General Hospital. Case 18-1988. N. Engl. J. Med. 318:1186-1194.

597. Scully, R. E., E. J. Mark, W. F. McNeely, and B. U. McNeely. 1991. Case records of the Massachusetts General Hospital. Case 42-1991. N. Engl. J. Med. 325:1155-1165.

598. Sengupta, A. N., and P. Chaudhuri. 1964. Thoracic nocardiosis. J. Indian Med. Assoc. 42:76-80.

599. Serrano, J. A., B. Beaman, M. A. Mejia, J. E. Viloria, and R. Zamora. 1988. Histological and microbiological aspects of actinomycetoma cases in Venezuela. Rev. Inst. Med. Trop. São Paulo 30:297-304.

600. Serrano, J. A., B. L. Beaman, J. E. Viloria, M. A. Mejia, and R. Zamora. 1986. Histological and ultrastructural studies of human actinomycetomas, p. 647-662. In G. Szabo, S. Biro, and M. Goodfellow (ed.), Biological, biochemical and biomedical aspects of actinomycetes. Akademiai Kiado, Budapest.

601. Shapiro, P. E., and M. E. Grossman. 1989. Disseminated Nocardia asteroides with pustules. J. Am. Acad. Dermatol. 20:889-892.

602. Sharer, L. R., and R. Kapila. 1985. Neuropathologic observations in acquired immunodeficiency syndrome (AIDS). Acta Neuropathol. 66:188-198.

603. Sharma, D. N., and J. N. Dwivedi. 1977. Pulmonary mycosis of sheep and goats in India. Indian J. Anim. Sci. 47:808-813.

604. Sharma, J. C., K. R. Joshi, M. C. R. Vyas, S. S. Sankhla, and S. P. Gupta. 1988. A clinicopathological and mycological study of mycetoma involving upper extremity at Jodhpur, India. Indian J. Med. Sci. 42:103-108.

605. Shashikala, C. A., P. S. Ramani, V. A. Ambekar, and K. P. Deodhar. 1985. Cerebral nocardiosis. J. Assoc. Phys. India 33: 182-183.

606. Shelkovitz-Shilo, I., and A. Feinstein. 1992. Lymphocutaneous nocardiosis due to Nocardia asteroides in a patient with intestinal lymphoma. Int. J. Dermatol. 31:178-179.

607. Sher, N. A., C. W. Hill, and D. E. Eifrig. 1977. Bilateral intraocular Nocardia asteroides infection. Arch. Ophthalmol. 95:1415-1418.

608. Shuster, M., M. M. Klein, H. C. Pribor, and W. Kozub. 1967. Brain abscess due to Nocardia. Arch. Intern. Med. 120:610-614.

609. Siao, P., P. McCabe, and P. Yagnik. 1989. Nocardial spinal epidural abscess. Neurology 39:996.

610. Sieratzki, H. J. 1992. Nocardia brasiliensis infection in patients with AIDS. Clin. Infect. Dis. 14:977-978.

611. Sierra, F., A. Restrepo, and L. H. Concada. 1974. Nocardiosis pulmonar. Antioquia Med. 24:65-69.

612. Sileo, L., P. R. Sievert, and M. D. Samuel. 1990. Cases of mortality of albatross chicks at Midway Atole. J. Wildl. Dis. 26:329-338.

613. Silva, C. L., and L. H. Faccioli. 1992. Tumor necrosis factor and macrophage activation are important in clearance of Nocardia brasiliensis from the livers and spleens of mice. Infect. Immun. 60:3566-3570.

614. Silva, C. L., J. L. Gesztesi, and T. Ioneda. 1979. Trehalose mycolates from Nocardia asteroides, $N$. farcinica, Gordona lentrifragmenta, and G. bronchialis. Chem. Phys. Lipids. 24:17-25.

615. Silva, C. L., I. Tincani, S. L. Brandão-Filho, and L. H. Faccioli. 1988. Mouse cachexia induced by trehalose dimycolate from Nocardia asteroides. J. Gen. Microbiol. 134:1629-1633.

616. Simmons, B. P., M. S. Gelfand, and G. D. Roberts. 1992. Nocardia otitidiscaviarum (caviae) infection in a heart transplant patient presented as having a thigh abscess (madura thigh). J. Heart Lung Transplant. 11:824-826.

617. Simpson, G. L., T. A. Raffin, and J. S. Remington. 1982. Association of prior nocardiosis and subsequent occurrence of nontuberculous mycobacteriosis in a defined, immunosuppressed population. J. Infect. Dis. 146:211-219.

618. Simpson, G. L., E. B. Stinson, M. J. Egger, and J. S. Remington.
1981. Nocardial infections in the immunocompromised host: a detailed study in a defined population. Rev. Infect. Dis. 3:492507.

619. Singer, J. J., and H. C. Ballon. 1930. Streptothricosis. Am. Rev. Tuberc. 22:233-266.

620. Smeal, W. E., and L. A. Schenfeld. 1986. Nocardiosis in the community hospital. Report of three cases. Postgrad. Med. 79:77-82.

621. Smego, R. A., and H. A. Gallis. 1984. The clinical spectrum of Nocardia brasiliensis infection in the United States. Rev. Infect. Dis. 6:164-180.

622. Smego, R. A., M. B. Moeller, and H. A. Gallis. 1983. Trimethoprim sulfamethoxazole therapy for Nocardia infections. Arch. Intern. Med. 143:711-718.

623. Smith, D. E., and J. Benecke. 1960. Pulmonary nocardiosis: report of a fatal case. Med. J. Aust. 47:254-258.

624. Smith, I. M., and A. H. S. Hayward. 1971. Nocardia caviae and Nocardia asteroides: comparative bacteriological and mouse pathogenicity studies. J. Comp. Pathol. 81:79-87.

625. Smith, R. W., G. E. Steinkraus, and B. W. Hendricks. 1980. CNS nocardiosis: response to sulfamethoxazole-trimethoprim. Arch. Neurol. 37:729-730.

626. Smith, W. G., R. McAleer, and W. Laurie. 1963. Nocardiosis in Australia. Med. J. Aust. 50:534-536.

627. Snieszko, S. F., G. L. Bullock, C. E. Dunbar, and L. L. Pettijohn. 1964. Nocardial infection in hatchery-reared fingerling rainbow trout (Salmo gairdneri). J. Bacteriol. 88:1809-1810.

628. Sodhi, H. S., and C. A. Salles. 1966. Nocardiosis in Ghana. Br. J. Dis. Chest 60:36-39.

629. Spargo, B. 1991. Ph.D. thesis. University of California, Davis.

630. Spargo, B. J., L. M. Crowe, T. Ioneda, B. L. Beaman, and J. H. Crowe. 1991. Cord factor $(\alpha, \alpha$-trehalose 6,6'-dimycolate) inhibits fusion between phospholipid vesicles. Proc. Natl. Acad. Sci. USA 88:737-740.

631. Spehn, J., S. Grosser, A. Jessel, J. V. Essen, and G. Klose. 1986 Hochdosierte cotrimoxazol-therapie einer disseminierten Nocar dia brasiliensis infektion. Dtsch. Med. Wochenschr. 111:215-218.

632. Splino, M., V. Merka, and F. Kyntera. 1975. Phagocytosis and intracellular proliferation of Nocardia asteroides (strain Weipheld) in cell structures in vitro. 1. Alveolar macrophages of Guinea-pigs. Zentralbl. Bakteriol. Mikrobiol. Hyg., 1 Abt. Orig. A 232:334-340.

633. Splino, M., V. Merka, and F. Kyntera. 1976. Phagocytosis and intracellular proliferation of Nocardia asteroides (strain Weipheld) in cell structures in vitro. 2. Peritoneal macrophages of Guinea-pigs. Zentralbl. Bakteriol. Mikrobiol. Hyg. 1 Abt. Orig. A 235:512-520.

634. Srinivasan, M., and S. Sharma. 1987. Nocardia asteroides as a cause of corneal ulcer. Arch. Ophthalmol. 105:464.

635. Stadler, H. E. 1964. Chronic pulmonary disease due to Nocardia. Am. J. Dis. Child. 88:485-491.

636. Stallworth, J. R., D. Perira, D. Boykin, F. H. Young, and R. C. Porter. 1985. Central nervous system nocardiosis associated with traumatic, polymicrobial brain abscess. Pediatr. Infect. Dis. J. 4:411-413.

637. Stamm, A. M., D. W. McFall, and W. E. Dismukes. 1983. Failure of sulfonamides and trimethoprim in the treatment of nocardiosis: report of a patient with pneumonia and empyema due to Nocardia brasiliensis and disseminated disease due to Nocardia asteroides. Arch. Intern. Med. 143:383-385.

638. Stein, L., R. E. Estrellado, and J. M. Judd. 1962. Nocardiosis and tuberculosis. J. Thorac. Cardiovasc. Surg. 43:314-319.

639. Steinberg, I. 1958. Fatal fungus infection in sarcoidosis: report of two cases treated with antibiotics and cortisone. Ann. Intern. Med. 48:1359-1372.

640. Stevens, D. A., A. C. Pier, B. L. Beaman, P. A. Morozumis, I. S Lovett, and E. T. Houang. 1981. Laboratory evaluation of an outbreak of nocardiosis in immunocompromised hosts. Am. J. Med. 71:928-934.

641. Stevens, H. 1953. Actinomycosis of the central nervous system. Neurology 3:761-772.

642. Stites, D. P., and W. P. Glezen. 1967. Pulmonary nocardiosis in childhood. A case report. Am. J. Dis. Child. 114:101-105. 
643. Strong, D. W., and C. V. Hodges. 1976. Disseminated nocardiosis presenting as testicular abscess. Urology 7:57-59.

644. Stropes, L., M. Bartlett, and A. White. 1980. Case report: multiple recurrences of nocardial pneumonia. Am. J. Med. Sci. 280:119-122.

645. St. Rupert, H., M. Reinhold, P. Jipp, G. Schröter, E. Egner, and K. P. Schaal. 1988. Erfolgreiche antibiotische behandlung einer pulmonalen infektion mit Nocardia asteroides (Biovarietät $\mathbf{A}_{3}$ ). Dtsch. Med. Wochenschr. 113:1801-1805.

646. Stuart, M. 1979. Peritoneal nocardiosis: report of a case. Dis. Colon Rectum 22:183-184.

647. Sugar, A. M., G. K. Schoolnik, and D. A. Stevens. 1985. Antibody response in human nocardiosis: identification of two immunodominant culture filtrate antigens derived from Nocardia asteroides. J. Infect. Dis. 151:895-901.

648. Sullivan, M. J., and M. E. Drake, Jr. 1984. Unilateral pruritis and Nocardia brain abscess. Neurology 34:828-829.

649. Summers, J. E. 1966. Pulmonary alveolar proteinosis. Review of the literature with follow-up studies and report of two new cases. Calif. Med. 104:428-436.

650. Sundararaj, T., and S. C. Agarwal. 1977. Cell-mediated immunity in experimental Nocardia asteroides infection. Infect. Immun. 15:370-375

651. Sundararaj, T., and S. C. Agarwal. 1977. Cell-mediated immunity to Nocardia asteroides induced by its ribonucleic acid protein fraction. Infect. Immun. 18:253-256.

652. Sundararaj, T., and S. C. Agarwal. 1978. Relationship of macrophages to cell-mediated immunity in experimental Nocardia asteroides infection. Infect. Immun. 20:685-691.

653. Supena, R., D. Karlin, R. Strate, and P. G. Cramer. 1974 Pulmonary alveolar proteinosis and nocardial brain abscess. Arch. Neurol. 30:266-268.

654. Susens, G. P., A. Al-Shamma, J. C. Rowe, C. C. Herbert, M. L. Bassis, and G. C. Coggs. 1967. Purulent constrictive pericarditis caused by Nocardia asteroides. Ann. Intern. Med. 67:1021-1032.

655. Suter, L. S. 1951. A new species of Nocardia, $N$. fastidiosa, $n$. $s p$., isolated from a penile ulcer. Mycologia 43:658-676.

656. Sweeney, J. C., G. Miyaki, P. M. Vainik, and R. H. Conklin. 1976. Systemic mycoses in marine mammals. J. Am. Vet. Med. Assoc. 169:946-948.

657. Taleghani-far, M., J. B. Barber, C. Sampson, and K. A. Harden. 1964. Cerebral nocardiosis and alveolar proteinosis. Am. Rev. Respir. Dis. 89:561-565.

658. Talwar, P., A. Chakrabarti, A. Ayyagari, N. Nayak, V. K. Khosla, M. Minz, and R. V. S. Yadav. 1989. Brain abscess due to Nocardia. Mycopathologia 108:21-23.

659. Talwar, P., and S. C. Sehgal. 1979. Mycetomas in North India. Sabouraudia 17:287-291.

660. Talwar, P., and S. C. Sehgal. 1980. Pulmonary nocardiosis: a report of 8 cases. Eur. J. Respir. Dis. 61:103-107.

661. Tamplin, M. L., and N. M. McClung. 1984. Quantitative studies of the relationship between trehalose lipids and virulence of Nocardia asteroides isolates, p. 251-258. In L. Ortiz-Ortiz, L. F. Bojalil, and V. Yakoleff (ed.), Biological, biochemical and biomedical aspects of actinomycetes. Academic Press, Inc., Orlando, Fla.

662. Tang, L. M., and M. S. Hsi. 1989. Nocardial cerebral abscess: report of a case. J. Formosan Med. Assoc. 88:186-188.

663. Taylor, C. E., R. Schwartz, and I. M. Madoff. 1967. Nocardiosis associated with a giant pleurolith secondary to a long-standing oleothorax. Ann. Intern. Med. 66:960-965.

664. Telzak, E. E., J. Hii, B. Polsky, T. E. Kiehn, and D. Armstrong. 1989. Nocardia infection in the acquired immunodeficiency syndrome. Diagn. Microbiol. Infect. Dis. 12:517-519.

665. Terao, K., E. Ito, M. Oarada, M. Ohkusu, K. Yazawa, Y. Mikami, and K. Igarashi. 1992. Light and electron microscopic studies on experimental nocardia-toxicosis in mice. Mycopathologia 119: $115-125$.

666. Terezhalmy, G. T., and W. K. Bottomley. 1978. Pulmonary nocardiosis associated with primary nocardial infection of the oral cavity. Oral Surg. 45:200-206.

667. Thaler, F., B. Gotainer, G. Teodori, C. Dubois, and P. Loirat. 1992. Mediastinitis due to Nocardia asteroides after cardiac transplantation. Intensive Care Med. 18:127-128.

668. Thammayya, A., N. Basu, D. Sur-Roy-Chowdburg, A. K. Banerjee, and M. Sanyal. 1972. Actinomycetoma pedis caused by Nocardia caviae in India. Sabouraudia 10:19-23.

669. Tight, R. R., and M. S. Bartlett. 1981. Actinomycetoma in the United States. Rev. Infect. Dis. 3:1139-1149.

670. Tilney, L. G., and D. A. Portnoy. 1989. Actin filaments and the growth, movement, and spread of the intracellular bacterial parasite, Listeria monocytogenes. J. Cell Biol. 109:1597-1608.

671. Tomiyasu, I. 1982. Mycolic acid composition and thermally adoptive changes in Nocardia asteroides. J. Bacteriol. 151:828837.

672. Torre, N. P., and B. K. Kim. 1991. Septic arthritis due to Nocardia caviae. Ann. Rheum. Dis. 50:968-969.

673. Trevisan, V. 1889. I generi le specie delle Batteriacee. Zanaboni and Gabussi, Milan.

674. Tsuboi, R., K. Takamori, H. Ogawa, Y. Mikami, and T. Arai. 1986. Lymphocutaneous nocardiosis caused by Nocardia asteroides. Arch. Dermatol. 122:1183-1185.

675. Tsukamura, M. 1982 . Nocardiae that recently caused lung infection in Japan-Nocardia asteroides and Nocardia farcinica. Microbiol. Immunol. 26:341-345.

676. Tsukamura, M. 1982. Numerical analysis of the taxonomy of nocardiae and rhodococci. Division of Nocardia asteroides sensu stricto into two species and descriptions of Nocardia paratuberculosis sp. nov. Tsukamura, Rhodococcus aichiensis sp. nov. Tsukamura, Rhodococcus chubuensis sp. nov. Tsukamura, and Rhodococcus obuensis sp. nov. Tsukamura. Microbiol. Immunol. 26:1101-1119.

677. Tsukamura, M., and M. Ohta. 1980. Nocardia farcinica as a pathogen of lung infection. Microbiol. Immunol. 24:237-241.

678. Tsukamura, M., H. Shimoide, K. Kaneda, R. Sakai, and A. Seino. 1988. A case of lung infection caused by an unusual strain of Nocardia farcinica. Microbiol. Immunol. 32:541-546.

679. Tucker, F. C., and E. F. Hirsch. 1949. Nocardiosis, with a report of three cases of actinomycosis due to Nocardia asteroides. J. Infect. Dis. 85:72-86.

680. Tunkel, A. R., J. K. Crane, and F. G. Hayden. 1991. Pulmonary nocardiosis in AIDS. Chest 100:295-296.

681. Turner, E., and J. L. Whitby. 1969. Nocardial cerebral abscess with systemic involvement successfully treated with aspiration and sulphonamides. J. Neurosurg. 31:227-229.

682. Turner, O. A. 1954. Brain abscess caused by Nocardia asteroides. J. Neurosurg. 11:312-318.

683. Tveten, L. 1965. Cerebral mycosis. Acta Neurol. Scand. 41:19-33.

684. Tyson, G. W., J. E. Welsh, A. B. Butler, J. A. Jane, and H. R. Winn. 1979. Primary cerebellar nocardiosis. J. Neurosurg. 51: 408-414.

685. Uesaka, I., K. Oiwa, K. Yasuhira, Y. Kobara, and N. M. McClung. 1971. Studies on the pathogenicity of Nocardia isolates for mice. Jpn. J. Exp. Med. 41:443-457.

686. Unaogic, I. C., H. C. Gugnani, and S. E. Ikerionwu. 1990. Experimental actinomycetoma due to Nocardia transvalensis in laboratory mice. Mycoses 33:99-102.

687. Utz, J. P. 1962. The spectrum of opportunistic fungus infections. Lab. Invest. 11:1018-1025.

688. Vacheron, M. J., M. Guinard, G. Michel, and J. M. Ghuysen. 1972. Structural investigations on the cell walls of Nocardia sp: the wall lipid and peptidoglycan moieties of Nocardia kirovani. Eur. J. Biochem. 29:156-166.

689. Valdez, I. E., and D. A. Conroy. 1963. The study of a tuberculosislike condition in neon tetras (Hyphessobrycon innesii). II. Characteristics of the bacterium isolated. Microbiol. Esp. 16:249-253.

690. Vanderstigel, M., R. Leclercq, C. Brun-Buisson, A. Schaeffer, and J. Duval. 1986. Blood-borne pulmonary infection with Nocardia asteroides in a heroin addict. J. Clin. Microbiol. 23:175-176.

691. Venugopal, P. V., T. V. Venugopal, S. Subramanian, and S. Arumugam. 1980. Nocardia species from bronchopulmonary infections and mycetomas. Sabouraudia 18:11-18.

692. Vickers, R. M., J. D. Rihs, and V. L. Yu. 1992. Clinical demonstration of isolation of Nocardia asteroides on buffered charcoalyeast extract media. J. Clin. Microbiol. 30:227-228.

693. Viroslav, J., and T. W. Williams. 1971. Nocardial infection of the 
pulmonary and central nervous system: successful treatment with medical therapy. South. Med. J. 64:1382-1385.

694. Virtanen, S., and E. Lundell. 1961. Nocardiosis. Report of a successful recovery. Ann. Chir. Gynaecol. Fenn. 50:472-475.

695. Vistica, C. A., and B. L. Beaman. 1983. Pathogenic and virulence characterization of colonial mutants of Nocardia asteroides GUH-2. Can. J. Microbiol. 29:1126-1135.

696. Walker, D. A., and S. M. McMahon. 1986. Pulmonary alveolar proteinosis complicated by cerebral abscess: report of a case. $\mathbf{J}$. Am. Osteopath. Assoc. 86:497-450.

697. Walker, R. M., L. R. Ashdown, and E. J. Maguire. 1991. Beneficial effects of hyperbaric oxygen therapy in Nocardia brasiliensis soft-tissue infection. Med. J. Aust. 155:122-123.

698. Wallace, R. J., B. A. Brown, M. Tsukamura, and J. M. Brown. 1991. Clinical and laboratory features of Nocardia nova. J. Clin. Microbiol. 29:2407-2411.

699. Wallace, R. J., M. Tsukamura, B. A. Brown, J. Brown, V. A. Steingrube, Y. Zhang, and D. R. Nash. 1990. Cefotaximeresistant Nocardia asteroides strains are isolates of the controversial species Nocardia farcinica. J. Clin. Microbiol. 28:2726-2732.

700. Wallace, R. J., Jr., E. J. Septimus, R. W. Williams, Jr., R. H. Conklin, T. K. Satterwhite, M. B. Bushby, and D. C. Hollowell. 1982. Use of trimethoprim-sulfamethoxazole for treatment of infections due to Nocardia. Rev. Infect. Dis. 4:315-325.

701. Wayl, P., J. Rakower, and A. Hochman. 1958. Pulmonary ray fungus disease: clinical aspects and pathogenesis. Dis. Chest 34:506-513.

702. Webster, B. H. 1956. Pulmonary nocardiosis. Am. Rev. Tuberc. 73:485-500

703. Webster, B. H. 1962. Bronchopulmonary nocardiosis. Am. J. Med. Sci. 244:40-43.

704. Webster, B. H. 1962. Pulmonary nocardiosis simulating pulmonary tuberculosis in the aged. J. Am. Geriatr. Soc. 10:192-196.

705. Weed, L. A., H. A. Anderson, C. A. Good, and A. H. Baggenstoss. 1955. Nocardiosis: clinical, bacteriologic and pathological aspects. N. Engl. J. Med. 253:1137-1143.

706. Weed, L. A., and A. H. Baggenstoss. 1949. Actinomycosis. A pathologic and bacteriologic study of twenty-one fatal cases. Am. J. Clin. Pathol. 19:201-216.

707. Weintraub, M. I., and G. H. Glaser. 1970. Nocardial brain abscess and pure motor hemiplegia. N.Y. State J. Med. 70:2717-2721.

708. Weiss, D., T. Bodmer, R. Mathiew, and R. Malinuerni. 1992 Systemic nocardia infection in an AIDS patient. J. Suisse Med. 122:1057-1059.

709. Weiss, M. H., and J. A. Jane. 1969. Nocardia brain abscess successfully treated by enucleation: case report. J. Neurosurg. 30:83-86.

710. Welsh, J. D., E. R. Rhoades, and W. Jaques. 1961. Disseminated nocardiosis involving spinal cord. Arch. Intern. Med. 108:141147.

711. Wheeler, J. S., D. J. Culkin, J. O'Connell, and G. Winters. 1986. Nocardia epididymo-orchitis in an immunosuppressed patient. $\mathrm{J}$. Urol. 136:1314-1315.

712. Whelan, M. A., J. Stern, and R. A. deNapoli. 1981. The computed tomographic spectrum of intracranial mycosis: correlation with histopathology. Radiology 141:703-707.

713. Whitmore, D. N., G. A. Gresham, and M. J. Grayson. 1961 Nocardiosis in anemic patients given steroids. J. Clin. Pathol. 14:259-263.

714. Whyte, H. J., and W. Kaplan. 1969. Nocardial mycetoma resembling granuloma faciale. Arch. Dermatol. 100:720-723.

715. Wichelhausen, R. H., A. B. Robinson, J. R. Mazzara, and C. J.
Everding. 1954. Nocardiosis. Am. J. Med. 16:295-303.

716. Wilhite, J. L., and F. H. Cole. 1966. Invasion of pulmonary cavities by Nocardia asteroides. Report of 5 cases. Am. Surg. 32:107-111.

717. Wilkerson, R. D., D. C. Taylor, S. M. Opal, and W. W. Curl. 1985. Nocardia asteroides sepsis of the knee. Clin. Orthop. Relat. Res. 197:206-208.

718. Williams, S. T., S. Lanning, and E. M. H. Wellington. 1983. Ecology of actinomycetes, p. 481-528. In M. Goodfellow, M. Mordarski, and S. T. Williams (ed.), The biology of the actinomycetes. Academic Press Ltd., London.

719. Wilson, J. P., H. R. Turner, K. A. Kirchner, and S. W. Chapman. 1989. Nocardial infections in renal transplant recipients. Medicine 68:38-53.

720. Winston, M. E. 1951. Actinomycosis of the spine. Lancet 260:945.

721. Wishnitzer, R., A. Berrebi, J. von der Walde, A. Miskin, and A. Frumkin. 1984. Nocardia brasiliensis lymphocutaneous syndrome in a patient with lymphosarcoma. Dermatologica 169:215-216.

722. Wlodaver, C. G., T. Tolomeo, and J. B. Benear. 1988. Primary cutaneous nocardiosis mimicking sporotrichosis. Arch. Dermatol. 124:659-660.

723. Wolinetz, E., and J. LeBeau. 1969. Abces cerebral a Nocardia asteroides. Rev. Neurol. 121:464-467.

724. Wolke, R. E., and T. L. Meade. 1974. Nocardiosis in chinook salmon. J. Wildl. Dis. 10:149-154.

725. Wren, M. V., A. M. Savage, and R. H. Alford. 1979. Apparent cure of intracranial Nocardia asteroides infection by minocycline. Arch. Intern. Med. 139:249-250.

726. Yamaguchi, Y., H. Miyake, N. Nakahara, and T. Masuzawa. 1989. Nocardial brain abscess: case report. Neurol. Surg. 17:285-289.

727. Yano, I., T. Imaeda, and M. Tsukamura. 1990. Characterization of Nocardia nova. Int. J. Syst. Bacteriol. 40:170-174.

728. Yano, I., K. Kageyama, Y. Ohno, M. Masai, E. Kusunose, M. Kusunose, and N. Akimori. 1978. Separation and analysis of molecular species of mycolic acids in Nocardia and related taxa by gas chromatography-mass spectrometry. Biomed. Mass Spectrom. 5:14-24.

729. Yano, I., I. Tomiyasu, K. Kaneda, Y. Kato, Y. Sumi, S. Kurano, N. Sugimoto, and H. Sawai. 1987. Isolation of mycolic acid-containing glycolipids in Nocardia rubra and their granuloma forming activity in mice. J. Pharmacobio-Dyn. 10:113-123.

730. Yanoff, D. B., and M. L. Church. 1983. Nocardial vertebral osteomyelitis. Clin. Orthop. Relat. Res. 175:223-226.

731. Yenrudi, S., S. Suangshoti, and K. Pupaibul. 1991. Nocardiosis: report of 2 cases with review of literature in Thailand. J. Med. Assoc. (Thailand) 74:47-54.

732. Yew, W. W., P. C. Wong, S. Y. L. Kwan, C. Y. Chan, and M. S. K. Li. 1991. Two cases of Nocardia asteroides sternotomy infection treated with ofloxacin and a review of other active antimicrobial agents. J. Infect. 23:297-302.

733. Yogev, R., T. Greenslade, C. F. Firlit, and P. Lewy. 1980. Successful treatment of Nocardia asteroides infection with amikacin. J. Pediatr. 96:771-773.

734. Young, L. S., D. Armstrong, A. Blevins, and P. Lieberman. 1971. Nocardia asteroides infection complicating neoplastic disease. Am. J. Med. 50:356-367.

735. Zahradka, W., H. Vieritz, and E. Sommer. 1988. Nokardiose der lunge. Z. Gesamte Inn. Med. Grenzgeb. 43:471-472.

736. Zecler, E., Y. Globoa, L. Elkina, G. Atlan, and D. Sompolinsky. 1977. Lymphocutaneous nocardiosis due to Nocardia brasiliensis. Arch. Dermatol. 113:642-643. 